\title{
DOE/OR/00033-- 7688
}

\section{An Investigation of Factors Affecting the Performance of Laboratory Fume Hoods}

\author{
by \\ Brent A. Altemose \\ A report submitted to the faculty of: \\ The University of North Carolina at Chapel Hill \\ In partial fulfillment of the requirements for the degree of: \\ Master of Science, Environmental Engineering \\ Department of Environmental Sciences and Engineering \\ School of Public Health \\ Chapel Hill, 1995
}

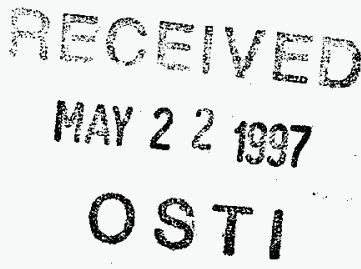

\section{DISCLAIMER}

This report was prepared as an account of work sponsored by an agency of the United States Government. Neither the United States Government nor any agency thereof, nor any of their employees, makes any warranty, express or implied, or assumes any legal liability or responsibility for the accuracy, completeness, or usefulness of any information, apparatus, product, or process disclosed, or represents that its use would not infringe privately owned rights. Reference herein to any specific commercial product; process, or service by trade name, trademark, manufacturer, or otherwise does not necessarily constitute or imply its endorsement, recommendation, or favoring by the United States Government or any agency thereof. The views and opinions of authors expressed herein do not necessarily state or reflect those of the United States Government or any agency thereof.

\author{
Michael R. Flynn, Advisor \\ David H. Leith, Reader \\ $\overline{\text { Michael J. Symons, Reader }}$
}




\section{DISCLAMMER}

Portions of this document may be illegible in electronic image products. Images are produced from the best available original document. 


\begin{abstract}
BRENT A. ALTEMOSE. An Investigation of Factors Affecting the Performance of Laboratory Fume Hoods. (Under the direction of Dr. MICHAEL R. FLYNN)

A "user tracer gas test" was performed on laboratory hoods, with a human subject standing in front of the hood, to assess hood containment ability. The relationship of face velocity and cross draft variables to hood containment ability is investigated. The ability of these variables and other tests, such as smoke challenges or tracer gas tests performed with a manikin at the hood, to predict the results of the user tracer gas test is evaluated.
\end{abstract}

All of the laboratory hoods tested in this study were identical bench top bypass hoods with horizontally sliding sashes. A face velocity traverse, cross draft measurements, a pitot traverse to measure exhaust flow, a smoke test, a manikin tracer gas test, and a user tracer gas test were performed on each hood in several different sash positions.

Based on the data collected, face velocity, its distribution and variability, and the magnitude of cross drafts relative to face velocity are important variables in determining hood leakage. "Unblocked" vortices, formed such that no physical barrier exists between the vortex and room air or a person in front of the hood, are identified as important sites of leakage. For the hoods evaluated in this study, unblocked vortices were observed along the beveled side edges. The data support the hypothesis that in the presence of a person standing in front of the hood, leakage is more likely to occur if unblocked vortices are formed than if all vortices are blocked. Evidence suggests that cross drafts are more likely to cause leakage when flowing in a direction that may cause separated flow along a beveled edge of the hood and thereby augment the unblocked vortices along the edge.

Results indicate that smoke tests, manikin tracer gas tests, and average face velocity all serve as useful monitoring techniques. Face velocity measurements and smoke tests, which are easy and inexpensive, may provide information which is as valuable as traditional manikin tracer gas tests. However, the agreement between the results of these tests and the results of the user tracer gas test are inconsistent and suggest that more research is needed to determine how to evaluate whether a hood protects its users. 


\section{TABLE OF CONTENTS}

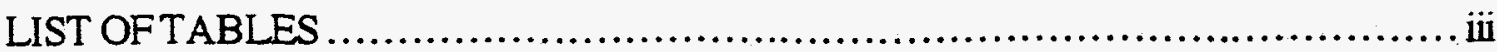

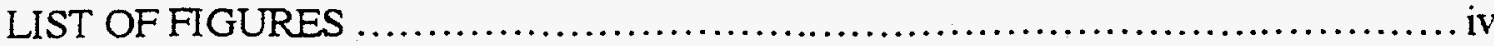

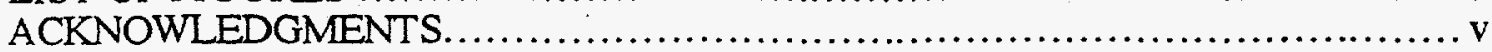

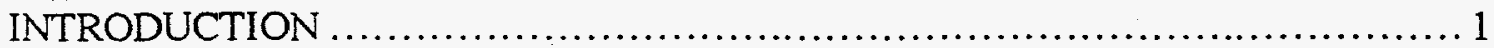

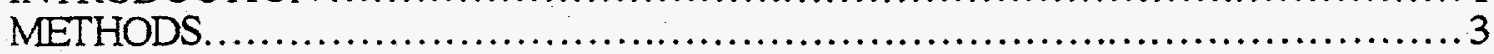

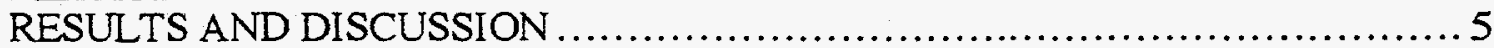

Comparison of High and Low Leakage Hoods............................ 5

Boundary Layer Separation Theory Applied to Explain Leakage................. 7

Prediction of Hood Containment Ability ..................................... 10

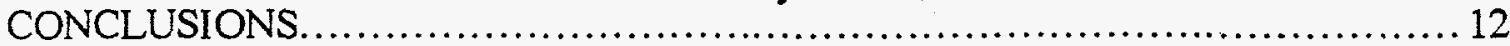

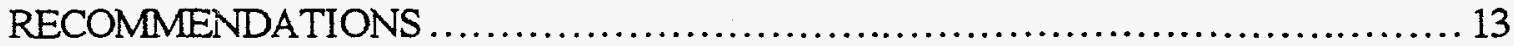

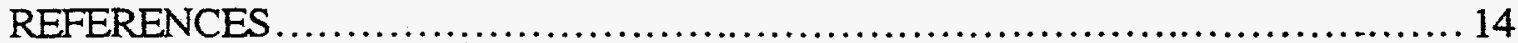

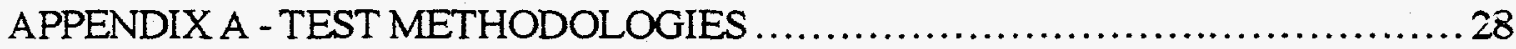

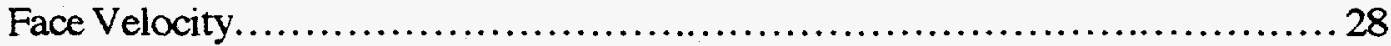

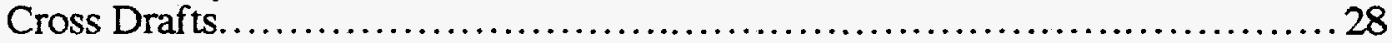

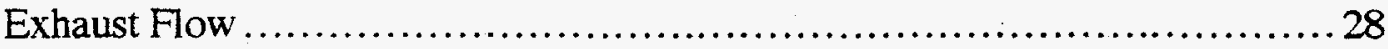

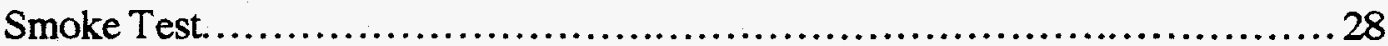

Manikin Tracer Gas Test ............................................ 29

User Tracer Gas Test ..................................................... 29

APPENDIX B - INSTRUMENT CALIBRATIONS ..................................... 34

Thermoanemometer Calibration ................................................. 34

Leakmeter Calibration.................................................... 34

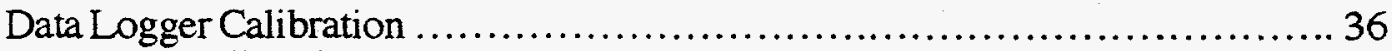

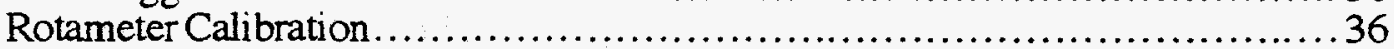

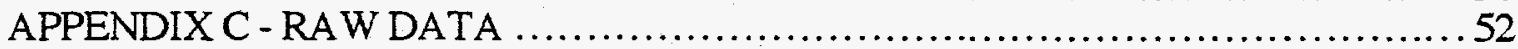

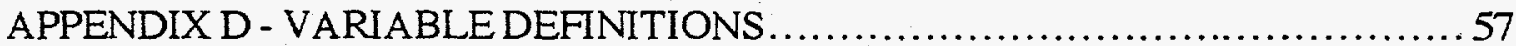

APPENDIX E - STATISTICAL TEST RESULTS $\ldots \ldots \ldots \ldots \ldots \ldots \ldots \ldots \ldots \ldots \ldots \ldots . .60$ 


\section{LIST OF TABLES}

Table 1. Comparison of Mean Values of Face Velocity and Cross Draft Variables for Low and High Leakage Hoods, Classified by a User Tracer Gas Test.

Table 2. Comparison of Mean Values of Face Velocity Variables, from Historical Data, for Low and High Leakage Hoods, Classified by a Manikin Tracer Gas Test.

Table 3. Comparison of Left and Right Sash Positions for a Given Hood to Evaluate the Effect of Cross Draft Direction on Leakage.

Table 4. Number of Hoods Passing or Failing Hood Tests, Stratified by User Tracer Gas

Test Result. . .

Table 5. Sensitivity and Specificity of Hood Tests for Predicting the User Tracer Gas Test

Results.

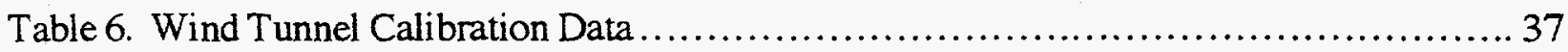

Table 7. Thermoanemometer Calibration Data ........................................ 38

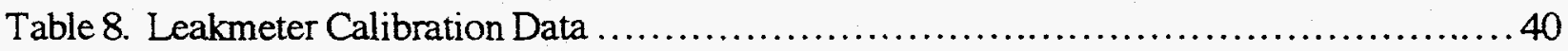

Table 9. Leakmeter Calibration Check Data ............................................ 41

Table 10. Data Logger Calibration Data............................................... 42

Table 11. Least Squares Regression Equations to Calculate Leakmeter Response Given

Data Logger Voltage Output........................................................ 44

Table 12. Test Data Collected June through October 1994. ............................. 52

Table 13. Historical Data Collected May 13, 1992 through July 17, 1992 ................... 55

Table 14. Test Data T-test Results for the Comparison of Mean Values of All Considered Variables for High and Low Leakage Groups as Determined by a User Tracer Gas Test....

Table 15. Historical Data T-test Results for the Comparison of Mean Values of All

Considered Variables for High and Low Leakage Groups as Determined by a Manikin

Tracer Gas Test. 


\section{LIST OF FIGURES}

Figure 1. Dimensions of Laboratory Hoods Tested................................. 21

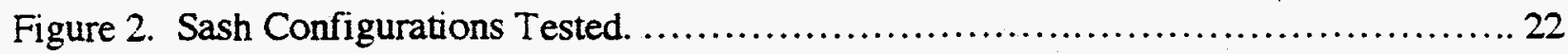

Figure 3. Typical Positions of Tested Hoods in Laboratories.............................23

Figure 4. Top View of Vortex Formation for Air Flow into a Hood with Horizontally Sliding Sashes. ......................................................................... 24

Figure 5. Side View of Vortex Formation for Air Flow into a Hood. ...................... 25

Figure 6. Lacation of Vortices Relative to the Wake Zone Formed Around a Person or Manikin in Front of a Hood with Horizontally Sliding Sashes. ............................ 26

Figure 7. Expected Cross Draft Flow Patterns at a Hood Face in the Absence of Air Flow into the Hood. ....................................................................... 27

Figure 8. Position and Numbering Convention for Face Velocity Traverses ..................30

Figure 9. Position and Numbering Convention for Cross Draft Measurements................31

Figure 10. Setup for Manikin Tracer Gas Test....................................... 32

Figure 11. Setup for User Tracer Gas Test......................................... 33

Figure 12. Thermoanemometer Calibration Set Up $\ldots \ldots \ldots \ldots \ldots \ldots \ldots \ldots \ldots \ldots \ldots \ldots \ldots \ldots$

Figure 13. Calibration of Wind Tunnel Velocity to Hood Static Pressure.....................46

Figure 14. Thermoanemometer Reading as a Function of Wind Tunnel Velocity ............ 47

Figure 15. Set Up to Fill Calibration Bag for Leakmeter Calibration ......................48

Figure 16. Leakmeter Response as a Function of Sulfur Hexafluoride Concentration.......... 49

Figure 17. Leakmeter Response During Calibration Checks Prior to Tracer Gas Tests ......... 50

Figure 18. Output Voltage to Data Logger as a Function of Leakmeter Display ............... 51 


\section{ACKNOWLEDGMENTS}

I would like to thank Mike Flynn, Jay Sprankle, and Tom Smith for their invaluable assistance in arranging and completing this project. Funding for this project came from Rhone Poulene $\mathrm{Ag}$ Company.

Research for this project was performed under appointment to the Industrial Hygiene Graduate Fellowship Program of the U.S. Department of Energy, Office of the Assistant Secretary for Environment, Safety and Health, Office of Health, Office of Worker Safety and Health, administered by the Oak Ridge Institute for Science and Education. 


\section{INTRODUCTION}

Many factors affect the containment ability of laboratory hoods. Some are dependent on work practices, such as arm movements of the user, the source characteristics and location, and the positioning of the hood sash.(1-6) Physical characteristics such as the shape of the hood opening and baffle locations and settings in the hood can also affect containment ability. $(3,6-8)$

Furthermore, the location of a hood can lead to disruptive cross drafts across the face, generated perhaps due to the location of air supply diffusers, doorways, windows, or aisle ways relative to the hood. $(9,10)$ Finally, operating parameters, such as the exhaust flow rate, which determine the face velocity, are also very important. $(2,7,11,12)$

Historically, the parameter recommended for assessing hood performance is face velocity. (11-13) However, this practice has been called into question, so new methods for hood testing have been developed. Visualization of air flow into the hoods with smoke or other visible plumes is one recommended test. $(14,15)$ Tracer tests which involve releasing a test gas in the hood and measuring its concentration in the breathing zone of a manikin, positioned at the hood face, are also commonly used. $(1,14,16)$ To more closely approximate the conditions of actual use for the hood, a tracer gas test performed while a human user is working at the hood has also been developed and tested. $(3,17)$

Information obtained when testing a hood should predict its ability to minimize exposure. Ideally, to determine the predictive ability of a test, its results could be compared to user chemical or biological exposure data. However, the low concentrations and variability in the types of contaminants and the conditions of their generation, under typical laboratory conditions, prohibit meaningful correlations with hood test data. Administering a tracer gas at a known release rate with a human user at the hood, under actual use conditions, as in I vany et al. and DiBerardinis et al., $(3,17)$ is an excellent method of determining how well a specific hood protects that user, under those use conditions. However, under more or less rigorous use conditions, the amount of tracer 
gas reaching the breathing zone will undoubtedly change. So, correlation of the test results to other parameters would be confounded by the hood use conditions.

For this study, tracer gas tests were performed on each hood with a human subject standing at the hood. The subject made prescribed movements during the test. This "user tracer gas test" was assumed to be the best indicator of the actual protective ability of a hood in the sash position tested.

This study investigates the relationship of face velocity and cross draft variables to hood containment ability, as indicated by the user tracer gas test. The ability of these variables and other tests, such as smoke challenges or tracer gas tests performed with a manikin at the hood, to predict the results of the user tracer gas test are evaluated. 


\section{METHODS}

All of the laboratory hoods tested in this study were identical Laboratory Furniture bench top bypass hoods with horizontally sliding sashes. The sashes were altered so that four doors, two on each track at the hood face, were present. On each track, one small door and one large door were present. Top, front, and side views, as well as the dimensions, of this type hood are shown in Figure 1.

The configuration of the four sash doors could be classified as either "stacked" or "staggered", as illustrated in Figure 2, which also shows the various possible sash configurations and the naming conventions used. The sash configurations shown are not an exhaustive list, only . those configurations which were tested in this study are shown.

The rooms in which the hoods were placed were similar in all cases. Figure 3 depicts a typical room geometry and the convention used to designate the hood location. Four hoods, two on each side, were present in each room. In some rooms, all four hoods were bench top enclosures. In other rooms, the two hoods closest to the air supply (one on each side of the room) were walk-in hoods. Only bench top hoods were evaluated in this study.

Fifteen bench top hoods were studied. For fourteen of these, three sash configurations were tested. The full left and full right openings were tested on all fourteen hoods, and the third set of tests was done in one of the possible center opening positions. For one hood, only two sash positions were tested, the full left opening and one center opening. Therefore, forty four sets of measurements were completed. For each hood opening, the following were performed: a face velocity traverse, cross draft measurements, a pitot traverse to measure exhaust flow, a smoke test, a manikin tracer gas test, and a user tracer gas test.

Face velocity traverses were completed with a thermoanemometer at six points across the hood face in each sash position. For each sash position, the hood doors were closed and cross draft measurements were made at two different heights with the thermoanemometer 18 inches from the hood face. Smoke tests were performed on each sash position, which was assigned a rating of 
good, fair, or poor. Good indicates the smoke was cleared quickly and no leakage occurred, fair indicates slow clearance or slight leakage, and poor indicates slow clearance and obvious leakage.

Both the manikin and user tracer gas tests were performed by releasing pure sulfur hexafluoride at 4 liters per minute inside of the hood from a 18 inch by 6 inch rectangular diffuser. The concentration of sulfur hexafluoride in the breathing zone of the manikin or human subject was monitored for five minutes with an Ion Track Instruments Model 120 Leakmeter, which contained an electron capture detector. The peak concentration of sulfur hexafluoride during the five minute tests was recorded and used to indicate hood leakage.

The conditions of the two tracer tests were identical with two exceptions. During the user test, a sampling line connected the breathing zone of the human subject to the detector. In the manikin test, the detector probe was placed directly in the manikin breathing zone. The human subject, during the user test, placed both arms into the hood, above the tracer gas diffuser, once every 30 seconds. The manikin's arms remained static at its side throughout the manikin test.

The methodology for the measurements and tests performed on these hoods is described in more detail in Appendix A. Calibration data for the instrumentation used to make the measurements are contained in Appendix B.

In addition to the measurements obtained for this study, a set of historical data were evaluated for 88 bench top hoods. These hoods were of the same type used in this study, Laboratory Furniture bench top bypass hoods with horizontally sliding sashes. The historical data provide information on a face velocity traverse, a smoke challenge, and a manikin tracer gas test for each hood in only one sash position. The face velocity traverses consisted of either six or nine points. The manikin tracer gas test was performed on each hood by releasing sulfur hexafluoride at 4 $\mathrm{L} / \mathrm{min}$, for five minutes, from an ejector which met the specifications of ASHRAE 110.(14) The concentration of sulfur hexafluoride in the manikin breathing zone was monitored with an electron capture detector. The peak concentration of sulfur hexafluoride measured during the test was recorded and used to indicate hood leakage. 


\section{RESULTS AND DISCUSSION}

The raw data used in these analyses are contained in Appendix C. The forty-four sets of measurements obtained for this study and the eighty-eight sets of measurements available from historical data are both included in the appendix. In the analysis of the first set of data, the user tracer gas tests are assumed to be the best indicator of the ability of a hood to protect its users. In analyzing the historical data, since a user test is unavailable, the manikin tracer gas tests are assumed to be the best indicator of this ability.

\section{Comparison of High and Low Leakage Hoods}

Definitions for the face velocity and cross draft variables evaluated are listed in Appendix D. A number of these variables are highly correlated with one another. So, four groups of variables were identified and one variable chosen from each group. The four variables chosen are the average face velocity, the average tempnral coefficient of variation of the face velocity, the spatial coefficient of variation of the face velocity, and the ratio of the maximum cross draft measured to the minimum average face velocity at any of the six traverse points. The average temporal coefficient of variation is calculated from the average of the standard deviations for the ten measurements taken at each face velocity traverse point. The spatial coefficient of variation is calculated from the standard deviation of the average velocity at the six traverse points.

Building a regression equation for hood containment with the four chosen variables is inappropriate with this data set, given the limited number of peak concentrations which exceeded the limit of detection for the Leakmeter, $0.1 \mathrm{ppm}$. Instead, the data are stratified into a "high leakage" group and a "low leakage" group. The level chosen as the cutoff between the high and low leakage groups is $0.25 \mathrm{ppm}$, the level at which the Leakmeter reliably differentiated between concentrations of the tracer gas.

The relationship of the four variables to hood containment ability is assessed by testing for the significance of the difference in their mean values in the two leakage groups. Table 1 shows 
the mean value for each of the four chosen variables for the high and low leakage groups. The ttest for comparing the means in each of these groups yields three variables for which $p<0.05$. These variables are the average face velocity, the average temporal coefficient of variation of the face velocity, and the ratio of the maximum cross draft to the minimum face velocity. The direction in which the means increase or decrease for the four variables are all in the a priori expected direction. On average, for the high leakage hoods, the face velocities are lower, the variations of the face velocity are higher, and the ratios of the maximum cross drafts to the minimum face velocities are higher.

The historical data are analyzed in the same manner, using the same cutoff value for tracer gas concentration to stratify the hoods as high or low leakage. In this case, however, a manikin tracer gas test is used to characterize hood containment ability since a user test is unavailable. Table 2 shows the mean values of the average face velocity and the spatial coefficient of variation of the face velocity for the high and low leakage groups. The differences between the mean values in the high and low leakage groups is statistically significant for both variables, with $\mathrm{p}<0.01$. The direction of increase or decrease for the two variables is in the a priori expected direction; the average face velocity is lower and its variation is greater for the high leakage hoods.

These findings suggest that, as practitioners have long observed, face velocity, its distribution and variability, and the magnitude of cross drafts relative to face velocity are important variables in determining hood leakage. Unfortunately, the complex interaction of these variables, the sensitivity of the tracer gas detector, and the inherent variability of the peak measures used as an outcome variable inhibit building a parametric model to predict leakage. It is encouraging, however, that despite these limitations, several of these face velocity and cross draft variables are related, in the expected directions, to the amount of leakage from the hood.

Appendix E contains the mean values and t-test information for other variables which were assessed from either data set but are not presented in this section. The equations used to perform the statistical analyses presented are also included in Appendix E. 


\section{Boundary Layer Separation Theory Applied to Explain Leakage}

Although a parametric model to predict leakage could not be formulated, a theoretical explanation for one mechanism by which face velocity and cross drafts can interact to allow tracer gas to escape from hoods with horizontally sliding sashes is developed.

Air flowing into a hood past any of its edges may result in boundary layer separation. This separation causes vortices and a region of low pressure to be formed. (18) The effect of the vortices is to inhibit the exhaust of contaminants in the hood and to allow for their accumulation over time. The decreased pressure in these regions may draw contaminants from elsewhere in the hood into the vortices. Figure 4 depicts a top view of the location of these vortices for the one-half full left opening and for a center opening. In the absence of cross drafts, the flow pattern for the one-half . full right opening is typically the mirror image of the one-half left opening. Figure 5 depicts a side view of vortices formed behind the top and bottom edges of the hood.

Vortices are formed behind the top edge, behind the sash doors, and behind the bottom edge. However, in these thee cases, the vortices are formed inside the hood with a phvsical barrier between it and room air or a person in front of the hood.

Vortices are also formed along the beveled side edge of the hood face. These vortices and low pressure regions are formed along the hood perimeter, where no barrier exists between the region and rom air. Because the vortices are not blocked, they are may be more prone to leakage.

Air flowing into a hood around a manikin or person will generate a wake zone. $(7,19)$ Vortices and negative pressure in this wake zone will tend to draw contaminants out of the hood. If this wake zone overlaps vortices formed by the physical shape of the hood, leakage is even more likely to occur. The wake zone may be more likely to overlap with a vortex and draw contaminants from it if the vortex is unblocked, as is the case for vortices formed along the beveled edge of the hoods in this study. Figure 6 shows the location of a hypothetical wake zone relative to a vortex formed along the beveled edge.

As shown in Figure 5, the center openings are not expected to produce unblocked vortices. The wake zone around a person standing in front of a center opening will be less likely to overlap 
with and draw contaminants from these blocked vortices. Therefore, a hood is expected to perform better in a center sash position than in a left or right opening position.

When tested in a center sash position, only 2 of 15 hoods had peak breathing zone concentrations during the user test greater than $0.25 \mathrm{ppm}$, with $0.3 \mathrm{ppm}$ being the highest concentration in both cases. When tested in the left or right sash position, the peak breathing zone concentration exceeded $0.25 \mathrm{ppm}$ in 12 of 29 cases, with one concentration reaching $5.5 \mathrm{ppm}$. Furthermore, for the smoke tests, none of the center positions tested received a fair or poor rating, while 14 of the 29 left or right positions received a fair or poor rating. Notably, the center positions typically had a higher face velocity than the left or right openings, which might explain their superior performance. However, five of the center positions tested had face velocities below 100 fpm. Among these five, only one hood had a peak breathing zone concentration above $0.25 \mathrm{ppm}$ and none received a fair or poor rating during the smoke tests. So, the data in this study support the hypothesis that unblocked vortices along the beveled edge of the hood, perhaps disrupted by the wake zone of a manikin or person at the hood face, are more likely to cause leakage than vortices which are blocked.

A second, less intuitive reason for leakage to occur along a particular edge of a hood is hypothesized. The placement of hoods in this study relative to the room air supply of ten resulted in observable, consistent cross drafts parallel to the hood face. The flow of cross drafts past the beveled edge of the hood is expected to favor the generation of a vortex and a region of low pressure, separated flow. (18) Figure 7 shows locations where these hypothetical vortices might form due to cross draft flow separation. The hypothetical vortices which correspond in location and direction of rotation to vortices already being formed by air flow into the hood are expected to augment these vortices. So, as indicated in Figure 7, the vortex formed along the first beveled edge the cross draft flows past is expected to augment vortices already being formed alcing the edgi in the presence of air flow into the hood. Cross drafts may disrupt but are not expected to augment vortices along other edges of the hood. 
As shown in Figure 7, for hoods with horizontally sliding sashes, the vortex formed along the first edge a cross draft flows past can either be in front of the hood opening or in front of the sash doors. Sash positions for which cross drafts form a vortex in front of the hood opening, and thereby augment the vortices formed by air flowing into the hood, are expected to have greater leakage. When the same hood's sash doors are pushed to the opposite side, the cross draft is no longer expected to augment vortex formation for the hood, and less leakage is expected to occur.

This hypothesis, that cross drafts generating a vortex in front of a hood opening will be more likely to cause leakage, can be evaluated by comparing the left and right openings of each hood tested in this study. For the two openings of a given hood, all of the operating parameters remain constant and the only significant change is the relative direction of the cross drafts. For instance, again consider Figure 7. In the top picture, for the left opening of the hood, the vortex generated by the cross draft is in front of the hood face and could augment the vortices along the beveled edge. When the doors are moved to the opposite side to provide a right opening, as in the bottom picture, the vortex is generated in front of the sash doors and will not augment vortices formed by air flowing into the hood.

Test information was available on the full left and full right openings for fourteen hoods. Because of the sensitivity limitations of the detector used in the tracer gas tests, the sash positions were considered different with respect to containment ability only if the peak breathing zone concentrations during the user test were greater than $0.2 \mathrm{ppm}$ apart. Under this criterion, only four of the hoods demonstrated significant differences between the two sash positions in their peak breathing zone concentration measurements.

As shown in Table 3, three of the four hoods leaked more in the sash position for which the cross draft is expected to augment the vortex along the beveled entrance of the hood. One hood leaked more in its left sash position, for which the cross draft was not expected to augment the vortex along the beveled edge. Notably, for this hood, the magnitude of the cross draft was significantly higher in front of the left opening, where it was $43 \mathrm{fpm}$, than in front of the right opening, where it was $26 \mathrm{fpm}$. So, although the cross draft is not expected to augment the vortex 
for the left opening of the hood, it may have caused greater leakage because of its greater magnitude.

The hypothesis that cross drafts flowing past a beveled edge may augment vortices formed along that edge, and thereby cause leakage, is supported. So, these findings suggest that the interplay of cross drafts with face velocities along an opening's beveled edge is an important factor in determining whether a hood will leak.

\section{Prediction of Hood Containment Ability}

In order to asses their utility for predicting hood containment ability, the manikin tracer gas test, the smoke test, and average face velocity results are compared to the user tracer gas test results. For each test, a cutoff for passing or failing a hood is chosen. For the user and manikin tracer gas tests, hoods with a peak breathing zone concentration below 0.25 ppm are given a passing rating and all others a failing rating. For the smoke tests, a good rating is considered passing and a fair or poor rating is considered failing. An average face velocity above $90 \mathrm{fpm}$ is given a pass rating, and below $90 \mathrm{fpm}$, a fail rating. Table 4 lists the number of hoods passing or failing the user test when passing or failing each candidate monitoring test.

The usefulness of each test may be evaluated by determining its sensitivity and specificity for predicting the results of the user test. $(20)$ The sensitivity of a test is the percentage of times it correctly fails the hoods which fail the user test. The specificity of a test is the percentage of times it correctly passes the hoods which pass the user test. Table 5 shows the sensitivity and specificity for the smoke test, the manikin tracer gas test, and the average face velocity.

Average face velocity is the most sensitive and least specific test. The smoke test is the most specific and least sensitive test. The manikin test was moderately sensitive and specific. Face velocity measurements and smoke tests, which are easy and inexpensive, may provide information which is as valuable as traditional manikin tracer gas tests.

The repercussions of basing decisions on the results of a particular test must be considered. For instance, based on the results of this study, using average face velocity to classify hoods 
identifies most hoods which are performing poorly. The consequence, however, is many hoods which are performing well are classified as failing. Increasing the air flow for these misclassified hoods may result in operating cost increases which are unnecessary.

These results indicate that smoke tests, manikin tracer gas tests, and average face velocity all serve as useful monitoring techniques. No test, including the manikin test, agrees with the user test for all of the hoods. The lack of consistent agreement between the user and manikin tests, in particular, suggests more research is needed to determine how to evaluate whether a hood protects its users. Perhaps peak concentrations during a five minute tracer gas test are not accurate indicators of hood containment ability. Or, perhaps the use of a static manikin during tracer gas tests is not an appropriate model for actual dynamic use conditions. However, the user and manikin tests may agree more often if average concentrations are recorded or the tracer gas is detected with greater sensitivity and precision. 


\section{CONCLUSIONS}

The findings of this study suggest that face velocity, its distribution and variability, and the magnitude of cross drafts relative to face velocity are important variables in determining whether a hood will leak. However, the complex interaction of cross drafts with face velocity and their relationship to hood performance are not well understood and warrant further study.

When air is being drawn into a hood, vortices form along its edges. If no barrier exists between a vortex and the hood's user, that vortex is expected to be a primary site of leakage for contaminants. Vortices and negative pressure in the wake zone formed around a user standing in front of a hood will also tend to cause leakage. If this wake zone overlaps vortices formed by the physical shape of the hood, as was the case for vortices formed along the beveled edge of the horizontally sliding sash hoods in this study, leakage is even more likely to occur. Because the vortices formed in center sash positions are blocked and therefore are less likely to leak, these positions perform better than left or right openings.

The hypothesis that cross drafts flowing in a direction so as to augment vortices along a hood's opening are more likely to cause leakage is supported. The findings in this study suggest that the interplay of cross drafts and face velocities along an opening's beveled edge is an important factor in determining whether a hood will leak.

Results indicate that smoke tests, manikin tracer gas tests, and average face velocity all serve as useful monitoring techniques. Face velocity measurements and smoke tests, which are easy and inexpensive, may provide information which is as valuable as traditional manikin tracer gas tests. However, the lack of consistent agreement between these tests and the results of a user tracer gas test suggests more research is needed to determine how to best evaluate whether a hood will protect its users. 


\section{RECOMMENDATIONS}

A laboratory hood should provide a barrier between its user and the vortices formed along its entrance edges. Horizontally sliding sashes should be arranged, if possible, to provide a center opening with doors flush against both side edges of the hood face. These measures should help to reduce leakage.

Laboratory hood users should avoid standing in front of regions where unblocked vortices may be formed. Arm movements in any regions where vortices are formed, and particularly in regions where unblocked vortices are formed, should be minimized.

Cross drafts across laboratory hood faces should be minimized. Cross drafts which may cause separated flow in front of the hood face are particularly problematic and should be redirected.

Face velocity measurements and smoke tests can be used as easy and inexpensive hood testing procedures. The utility of tracer gas tests should be investigated further. 


\section{REFERENCES}

1. Caplan, K.J.; Knutson, G.W.: A Performance Test for Laboratory Fume Hoods. Am. Ind. Hyg. Assoc. J. 43(10):722-737 (1982).

2. Macher, J.M.; First, M.W.: Effects of Air Flow Rate and Operator Activity on Containment of Bacterial Aerosols in an Class II Safety Cabinet. Appl. Environ. Microbiol. 48:481-485 (1984).

3. Ivany, R.E.; First, M.W.; DiBerardinis, L.J.: A New Method for Quantitative, In Use Testing of Laboratory Fume Hoods. Am. Ind. Hyg. Assoc. J. 50(5):275-280 (1989).

4. Fuller, F.H.; Etchells, A.W.: The Rating of Laboratory Hood Performance. ASHRAE J. 21(10):49-53 (1979).

5. Mikell, W.G.; Hobbs L.R.: Laboratory Hood Studies. J. Chem. Educ. 58(5):A 165-169 (1991).

6. Robertson, P.; Bailey P.V.: Suggested Improvements to Prevent the Escape of Fume From Beneath the Sash of a Fume Cupboard. Ann. Occup. Hyg. 23:305-308 (1980).

7. Guffey, S.E., Barnea N.: Effects of Face Velocity, Flanges, and Manikin Position on the Effectiveness of a Benchtop Enclosing Hood in the Absence of Cross Drafts. Am. Ind. Hyg. Assoc. J. 55(2):132-139 (1994).

8. Smith,T.C.; Flynn, M.R.; Dement, J.M.: A Design and Performance Analysis of Laboratory Fume Hoods. Appl. Occup. Environ. Hyg. 9(2):117-124 (1994).

9. Rake, B.W.: Influence of Cross Drafts on the Performance of a Biological Safety Cabinet. App. and Env. Microbiology. 36(2):278-283 (1978).

10. Caplan, K.J.; Knutson, G.W.: Influence of Room Air Supply on Laboratory Hoods. Am. Ind. Hyg. Assoc. J. 43(10):738-746 (1982).

11. Schulte, H.F.; Hyatt, E.C.; Jordan, H.S.; et al.: Evaluation of Laboratory Fume Hoods. Am. Ind. Hyg. Assoc. Quarterly. 15(3): 195-202 (1954).

12. Peterson, J.E.: An Approach to a Rational Method for Recommending Face Velocities for Laboratory Hoods. Am. Ind. Hyg. Assoc. J. 43(8):596-601 (1982).

13. American Conference of Governmental Industrial Hygienists: Industrial Ventilation: A Manual of Recommended Practice. 21st ed. ACGIH, Cincinnati, OH (1992).

14. American Society of Heating, Refrigerating, and Air-Conditioning Engineers, Inc.: American National Standard: Method of Testing Performance of Laboratory Fume Hoods. ANSI/ASHRAE 110. ASHRAE, Atlanta, GA (1985).

15. Kennedy, D.A.: Water as a Medium For Visualization of Air Flows: Evaluation of Protective Cabinetry. In: Ventilation '88, pp. 121-125. J.H. Vincent, ed. Pergammon Press, New York (1988). 
16. United States Environmental Protection Agency: Development of Quantitative Performance Tests for Laboratory Fume Hoods. EPA Contract No. 68-01-6197. EPA, Washington, DC (1982).

17. DiBerardinis, L.J.; First, M.W.; Ivany, R.E.: Field Results of an in Place, Quantitative Test for Laboratory Fume Hoods. Appl. Occup. Environ. Hyg. 23:305-308 (1991).

18. White, F.W.: Fluid Mechanics. 2nd ed. McGraw-Hill, Inc., New York (1986).

19. George, D. K.; Flynn, M.R.; Goodman, R.: The Impact of Boundary Layer Separation on Local Exhaust Design and Worker Exposure. Appl. Occup. Envrion. Hyg. 5:501-509 (1990).

20. Greenberg, R. W.: Medical Epidemiology. 1st. ed. Appleton \& Lange, Norwalk, CT (1993). 
Table 1. Comparison of Mean Values of Face Velocity and Cross Draft Variables for Low and High Leakage Hoods, Classified by a User Tracer Gas Test.

\begin{tabular}{|c|c|c|c|}
\hline Variable & $\begin{array}{c}\text { Low leakage } \\
\text { group } \\
(<0.25 \mathrm{ppm}) \\
\mathrm{n}=30^{*}\end{array}$ & $\begin{array}{c}\text { High leakage } \\
\text { group } \\
(>0.25 \mathrm{ppm}) \\
\mathrm{n}=14\end{array}$ & $\begin{array}{c}\text { T-test } \\
\mathrm{p}-\text { value }\end{array}$ \\
\hline Average face velocity (fpm) & 92 & 77 & 0.01 \\
\hline Spatial CV** across face (\%) & 13.4 & 14.5 & 0.36 \\
\hline Average temporal CV for face & 4.2 & 5.4 & 0.05 \\
\hline Maximum Cross Draft & 0.43 & 0.77 & 0.05 \\
\hline Minimum Face Velocity & & & \\
\hline
\end{tabular}

$*_{n}=$ sample size (number of hoods in group)

$* * \mathrm{CV}=$ coefficient of variation $=$ standard deviation $/$ mean 
Table 2. Comparison of Mean Values of Face Velocity Variables, from Historical Data, for Low and High Leakage Hoods, Classified by a Manikin Tracer Gas Test.

\begin{tabular}{|c|c|c|c|}
\hline Variable & $\begin{array}{c}\text { Low leakage } \\
\text { group } \\
(<0.25 \mathrm{ppm}) \\
\mathrm{n}=75^{*}\end{array}$ & $\begin{array}{c}\text { High leakage } \\
\text { group } \\
(>0.25 \mathrm{ppm}) \\
\mathrm{n}=13\end{array}$ & $\begin{array}{c}\mathrm{T} \text { - test } \\
\mathrm{p} \text { - value }\end{array}$ \\
\hline A verage face velocity (fpm) & 127 & 94 & $<0.001$ \\
\hline Spatial CV** across face (\%) & 12.0 & 16.8 & $<0.01$ \\
\hline
\end{tabular}

${ }^{*} \mathrm{n}=$ sample size (number of hoods in group)

${ }^{*} \mathrm{CV}=$ coefficient of variation $=$ standard deviation $/$ mean 
Table 3. Comparison of Left and Right Sash Positions for a Given Hood to Evaluate the Effect of Cross Draft Direction on Leakage.

\begin{tabular}{|c|c|c|c|c|}
\hline $\begin{array}{c}\text { Hood } \\
\text { Identification }\end{array}$ & $\begin{array}{c}\text { Sash } \\
\text { Position }\end{array}$ & $\begin{array}{c}\text { Is Cross Draft } \\
\text { Expected to } \\
\text { Augment Vortices? }\end{array}$ & $\begin{array}{l}\text { Maximum Cross } \\
\text { Draft Velocity } \\
\text { Near Edge (fpm) }\end{array}$ & $\begin{array}{c}\text { User Test Peak } \\
\text { Concentration } \\
(\mathrm{ppm})\end{array}$ \\
\hline \multirow[t]{2}{*}{ 2509AR } & Right & No & 13 & $<\mathrm{LOD}^{*}$ \\
\hline & Left & Yes & 20 & 3.40 \\
\hline \multirow[t]{2}{*}{ 2513BR } & Left & No & 43 & 1.30 \\
\hline & Right & Yes & 26 & 0.40 \\
\hline \multirow[t]{2}{*}{$2517 \mathrm{AL}$} & Left & No & 133 & 0.30 \\
\hline & Right & Yes & 82 & 1.00 \\
\hline \multirow[t]{2}{*}{ 2563BR } & Right & No & 95 & 0.30 \\
\hline & Left & Yes & 83 & 5.50 \\
\hline
\end{tabular}

${ }^{*}$ LOD $=$ limit of detection 
Table 4. Number of Hoods Passing or Failing Hood Tests, Stratified by User Tracer Gas Test Result.

\begin{tabular}{|c|c|c|c|}
\hline \multirow{2}{*}{ TEST } & RESULT & \multicolumn{2}{|c|}{ User Tracer Gas Test Result } \\
\cline { 3 - 4 } & $\begin{array}{c}\text { Pass } \\
(<0.25 \mathrm{ppm})\end{array}$ & $\begin{array}{c}\text { Fail } \\
(>0.25 \mathrm{ppm})\end{array}$ \\
\hline \multirow{2}{*}{$\begin{array}{c}\text { Smoke } \\
\text { Challenge }\end{array}$} & Pass (Good) & 23 & 7 \\
\cline { 2 - 4 } & Fail (Fair or Poor) & 7 & 7 \\
\hline \multirow{2}{*}{$\begin{array}{c}\text { Manikin Tracer } \\
\text { Gas Test }\end{array}$} & Pass (<0.25 ppm) & 21 & 5 \\
\cline { 2 - 4 } & Fail (>0.25 ppm) & 9 & 9 \\
\hline \multirow{2}{*}{$\begin{array}{c}\text { Average Face } \\
\text { Velocity }\end{array}$} & Pass (>90 fpm) & 13 & 2 \\
\cline { 2 - 4 } & Fail $(<90 \mathrm{fpm})$ & 17 & 12 \\
\hline
\end{tabular}


Table 5. Sensitivity and Specificity of Hood Tests for Predicting the User Tracer Gas Test Results.

\begin{tabular}{|c|c|c|}
\hline TEST & Sensitivity & Specificity \\
\hline Smoke Challenge & $50 \%$ & $77 \%$ \\
\hline Manikin Tracer Gas Test & $64 \%$ & $70 \%$ \\
\hline Average Face Velocity & $86 \%$ & $43 \%$ \\
\hline
\end{tabular}


Figure 1. Dimensions of Laboratory Hoods Tested.
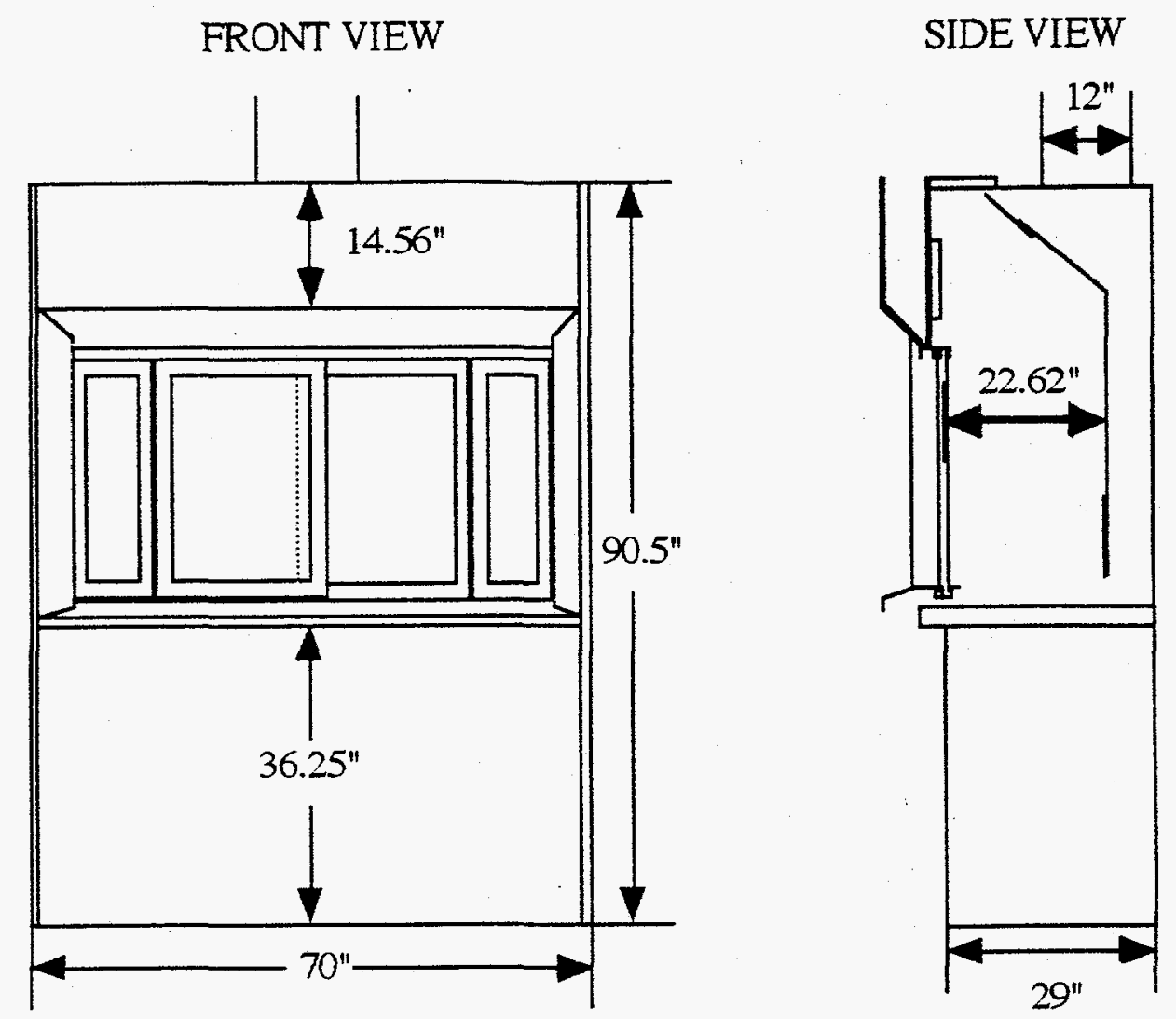

HOOD FACE

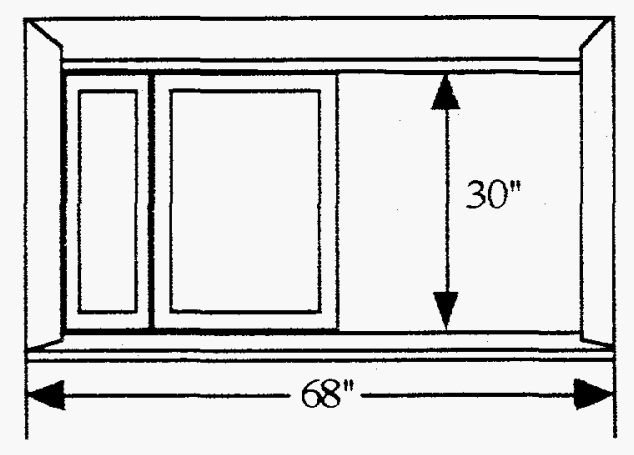

SASH DOORS
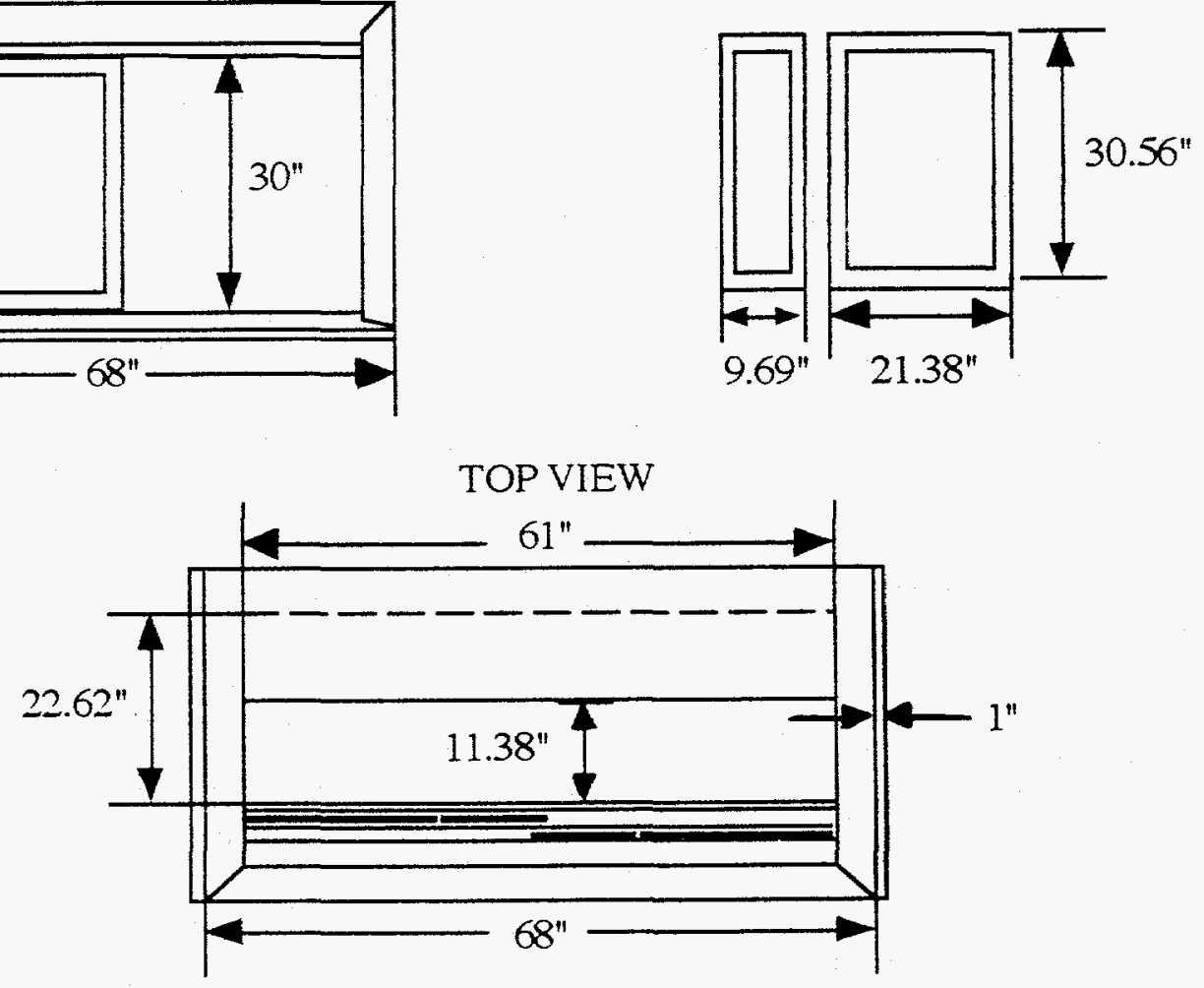
Figure 2. Sash Configurations Tested.

Right Opening, Staggered Doors

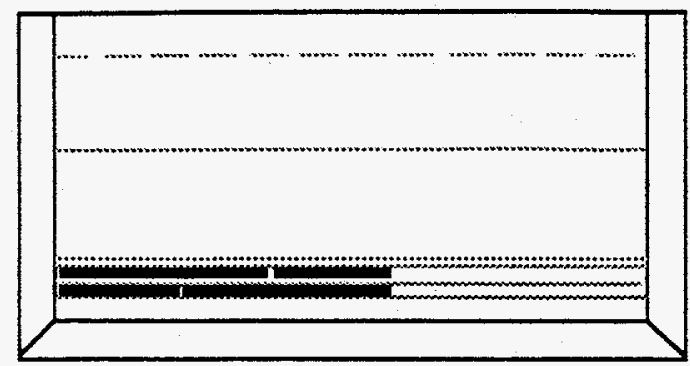

Center One-Third Opening

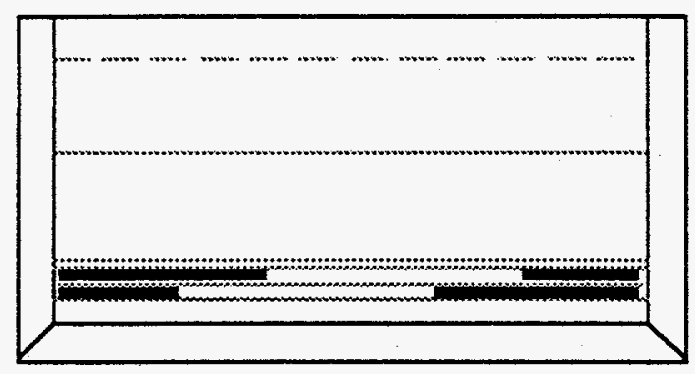

Right Center One-Third Opening

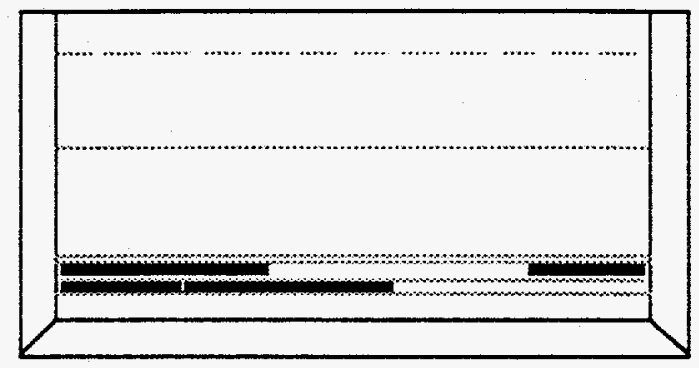

Right Center One-Half Opening

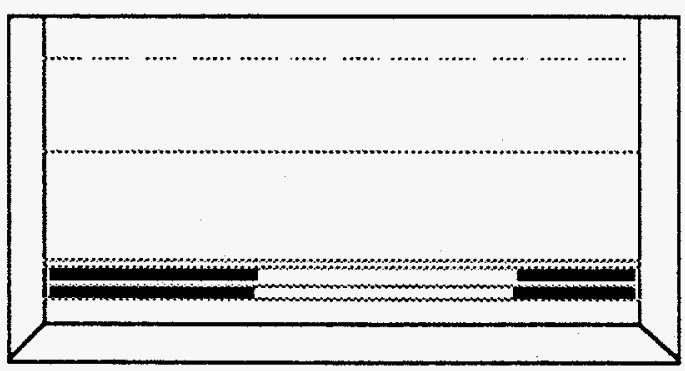

Left Opening, Stacked Doors

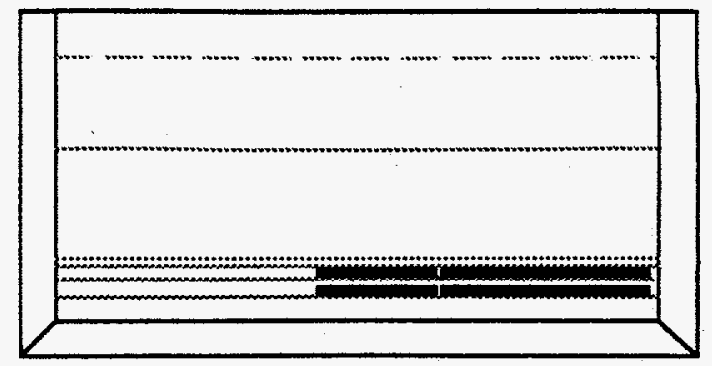

Left Center One-Third Opening

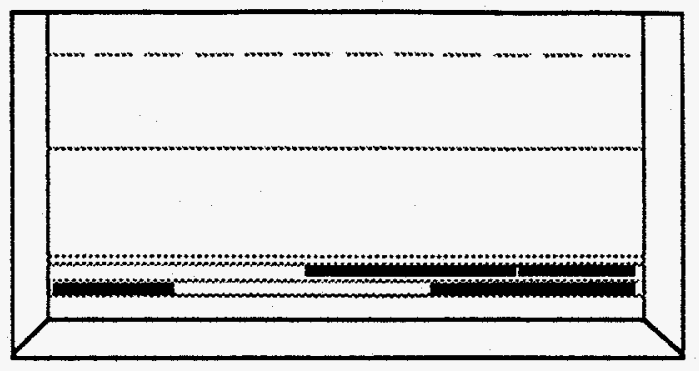

Left Center One-Half Opening

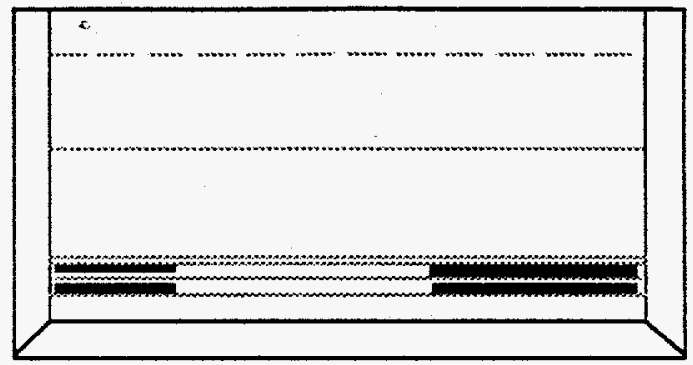

Sash Doors Indicated By:

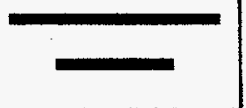


Figure 3. Typical Positions of Tested Hoods in Laboratories.

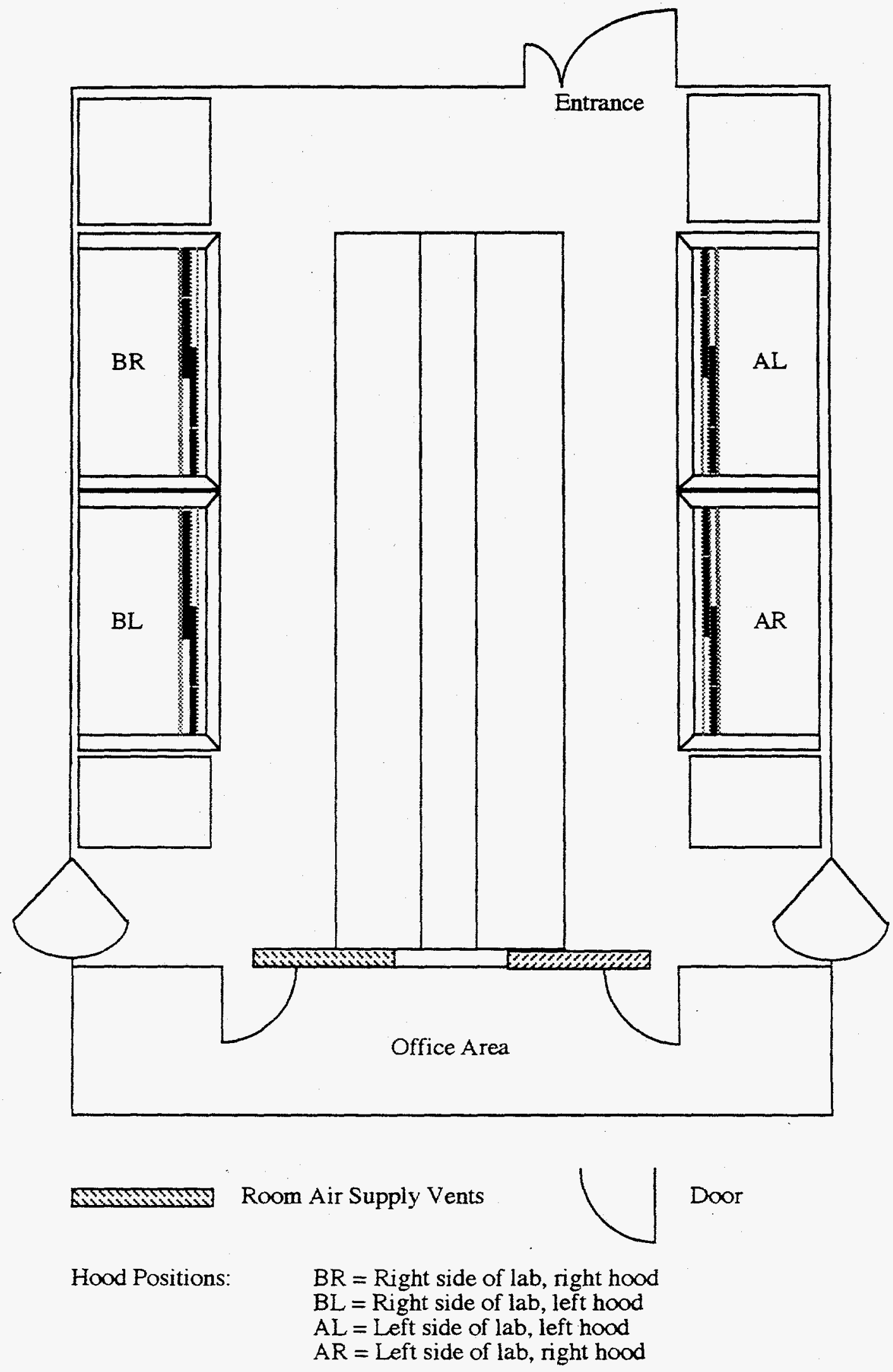


Figure 4. Top View of Vortex Formation for Air Flow into a Hood with Horizontally Sliding Sashes.

LEFT OPENING

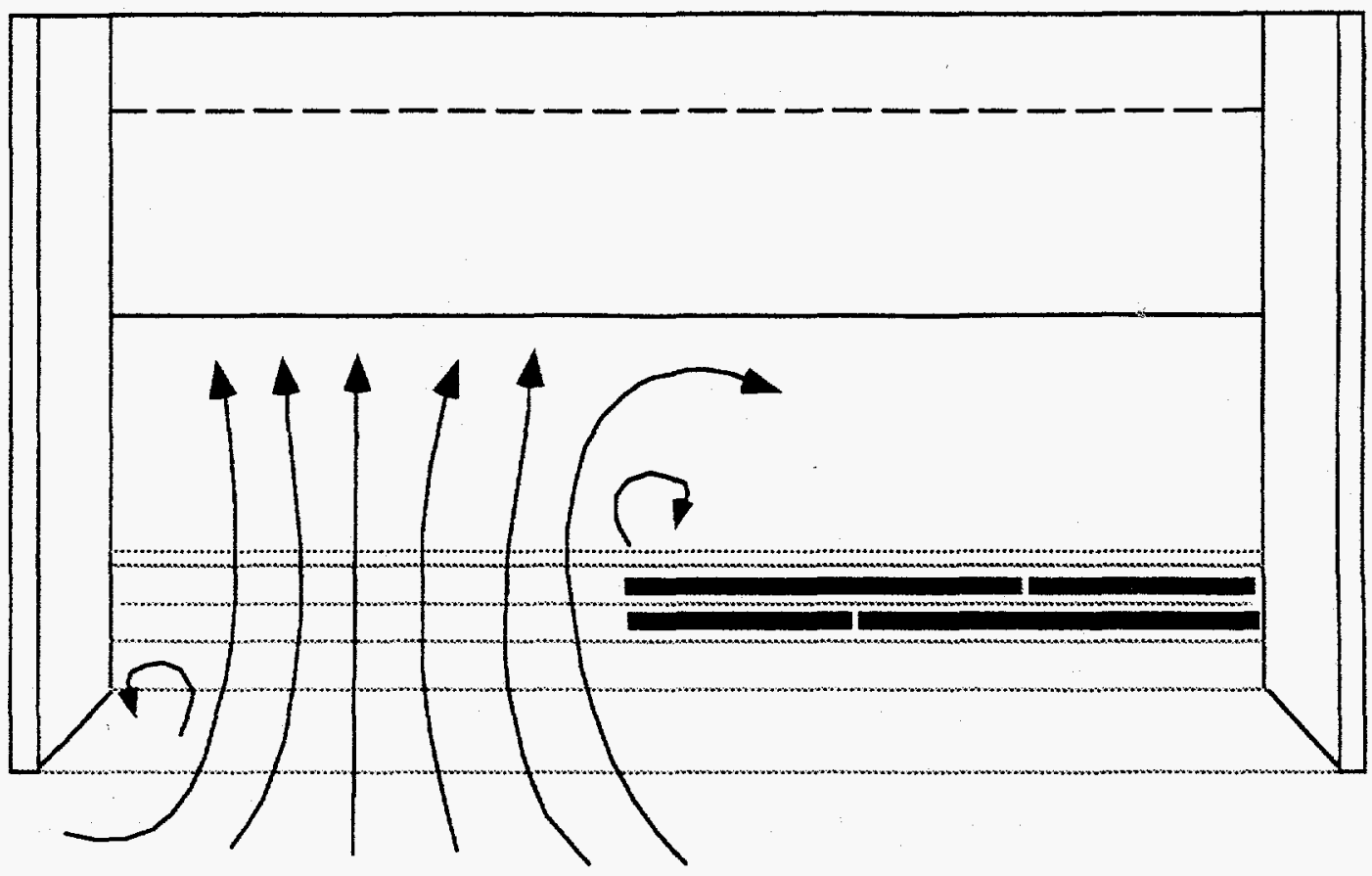

CENTER OPENING

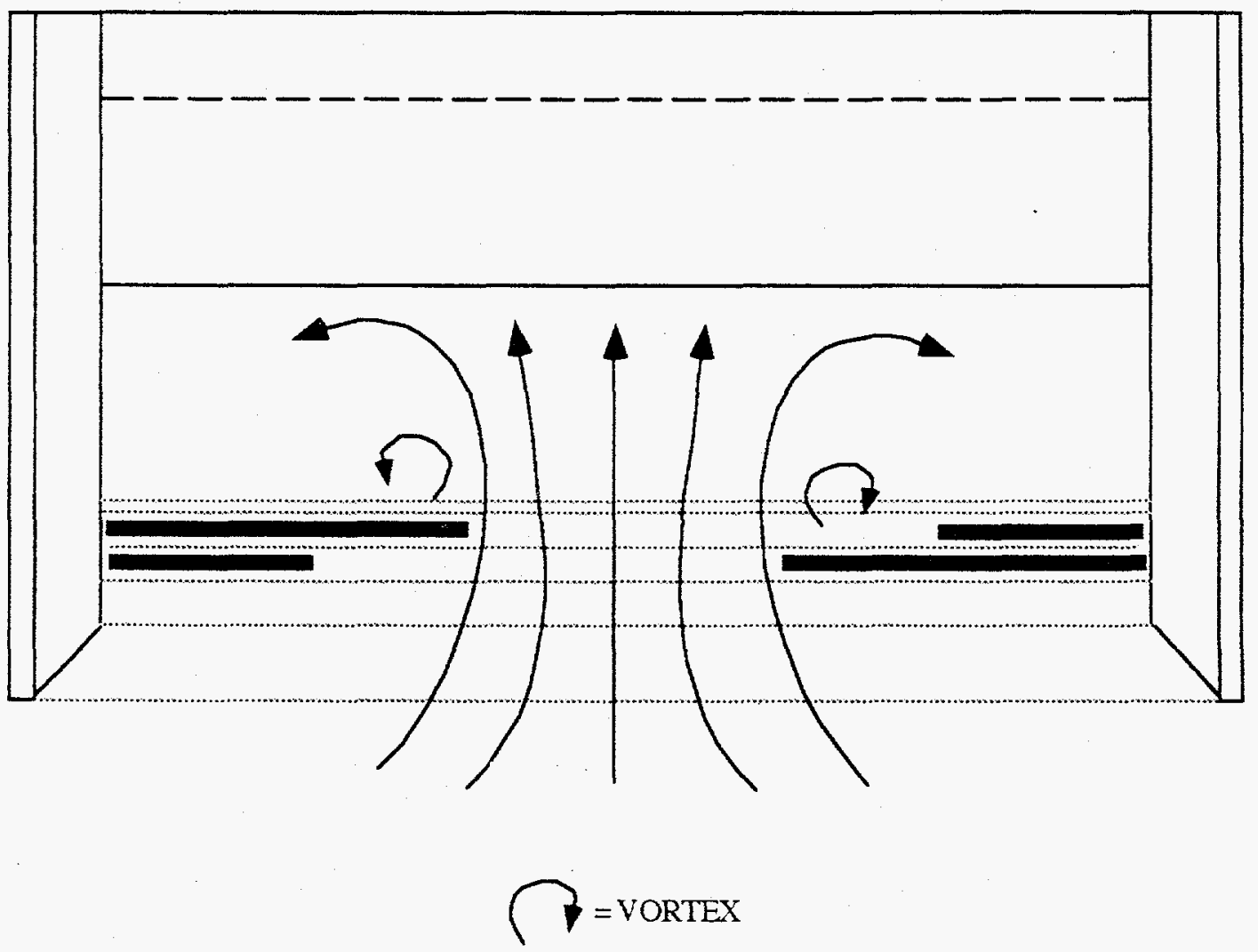


Figure 5. Side View of Vortex Formation for Air Flow into a Hood.

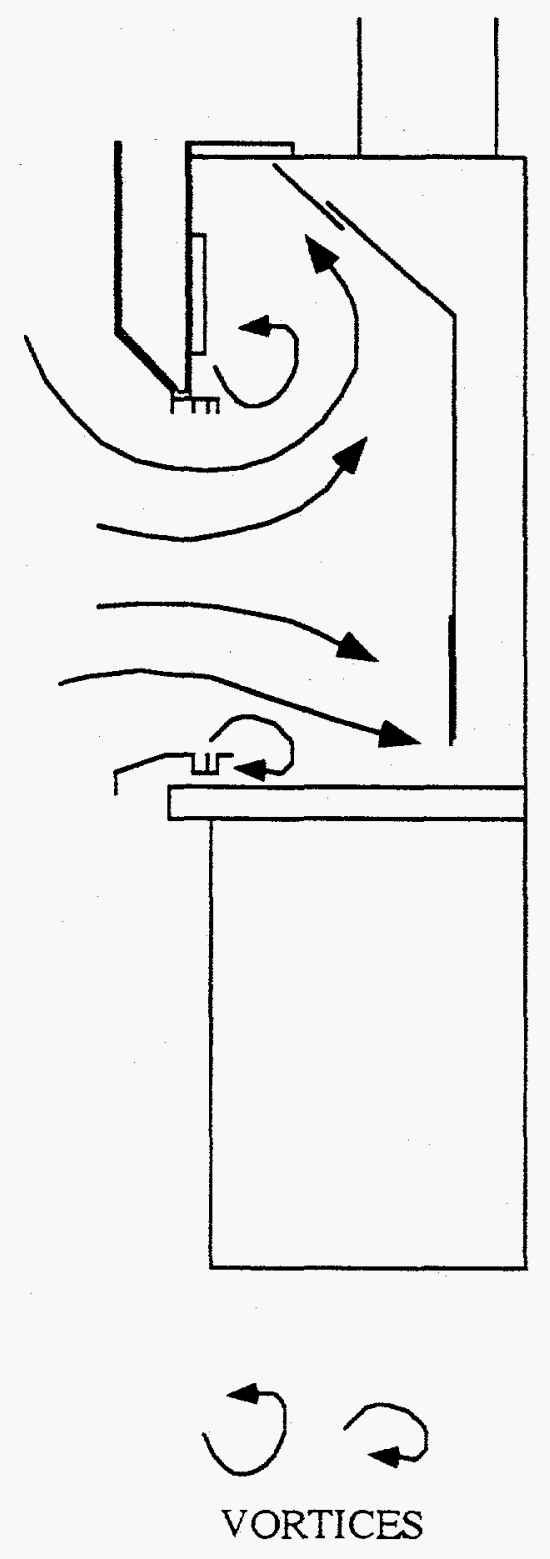


Figure 6. Location of Vortices Relative to the Wake Zone Formed Around a Person or Manikin in Front of a Hood with Horizontally Sliding Sashes.

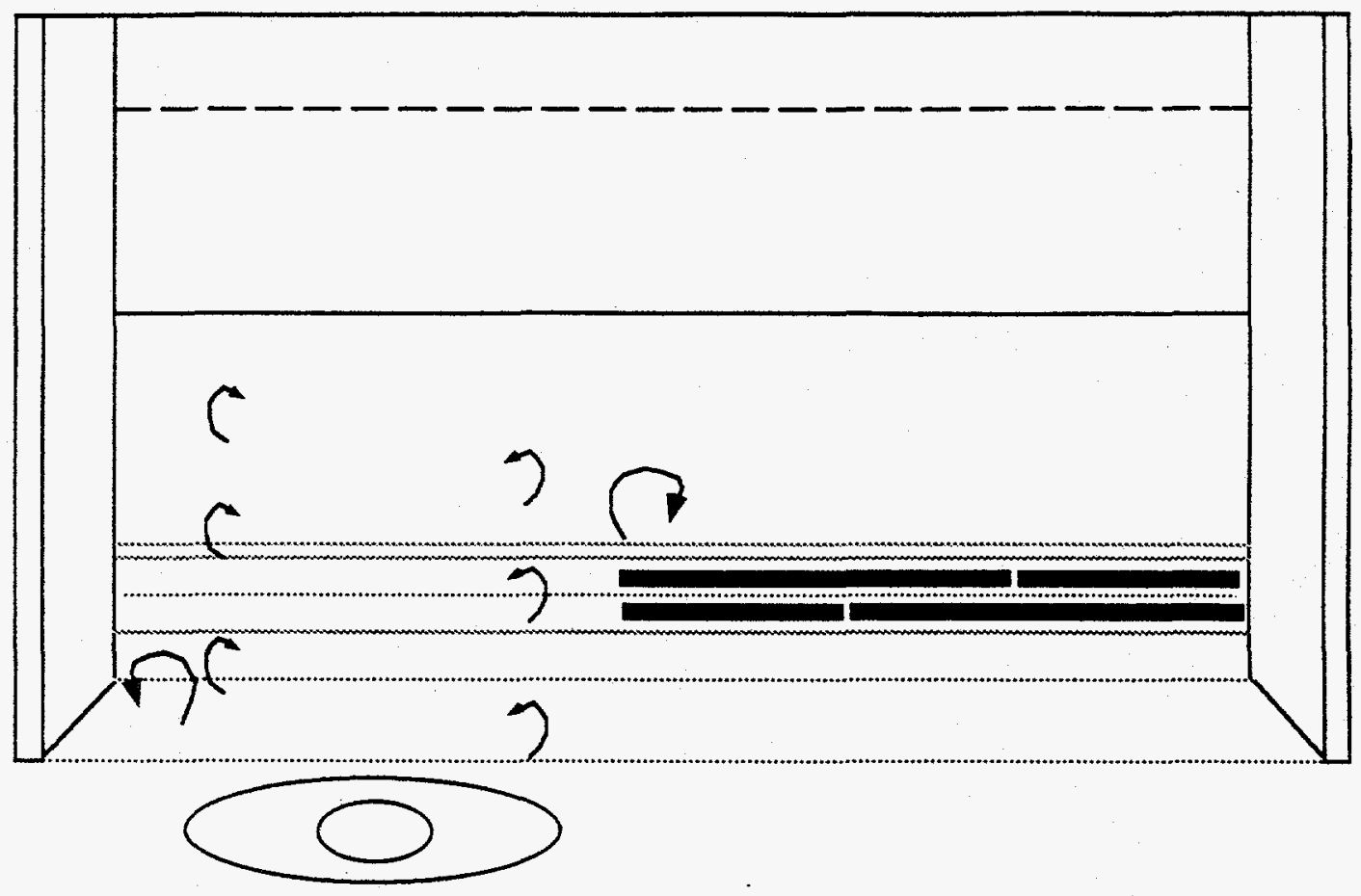

$7=$ VORTICES FORMED BY FLOW INTO HOOD

$\eta=$ VORTICES FORMED IN WAKE ZONE OF PERSON 
Figure 7. Expected Cross Draft Flow Patterns at a Hood Face in the Absence of Air Flow into the Hood.

Cross Draft Generates a Vortex in Front of Hood Face

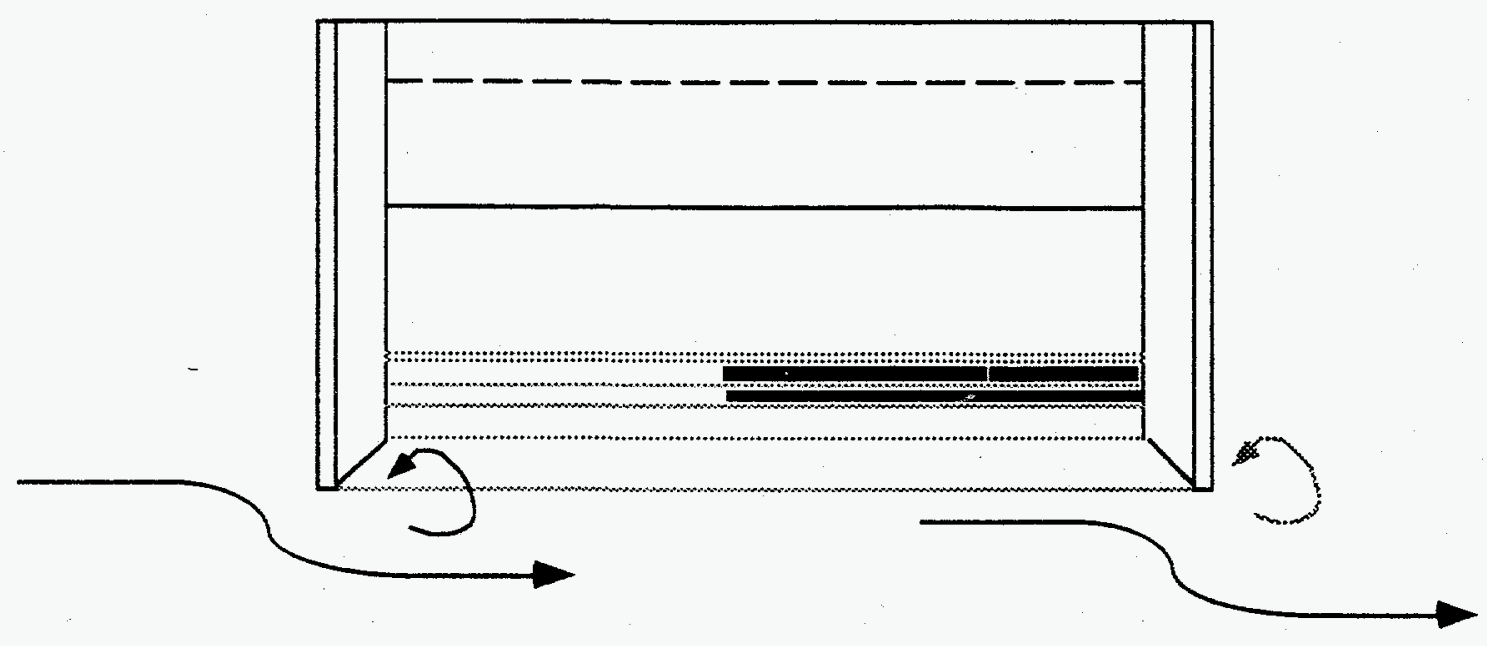

Cross Draft Generates a Vortex in Front of Sash Doors

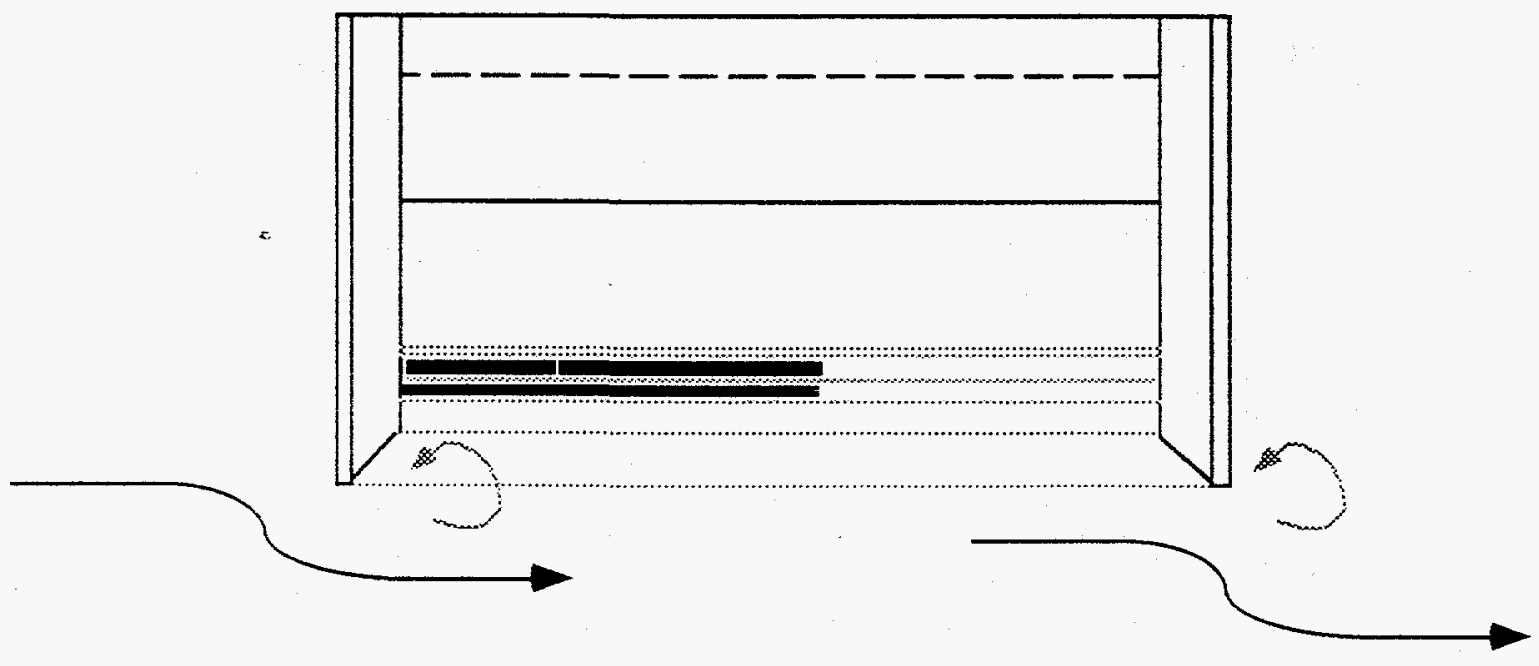

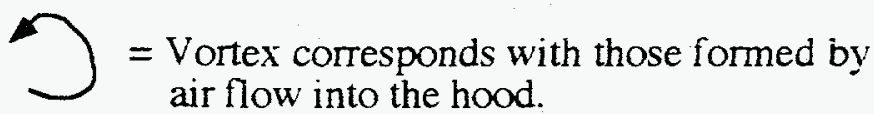

2. Vortex does not correspond with those 


\section{APPENDIX A - TEST METHODOLOGIES}

\section{Face Velocity}

Face velocity was measured at six points across the hood face with an Alnor model 8565 ThermoAnemometer (SN 003632). Information on the calibration of this instrument is contained in Appendix B. The traverse points were chosen to be at the center of six equal rectangles dividing the hood opening, approximately one square foot each. For one-half opening positions, this convention led to two horizontal rows consisting of three points. For one-third opening positions, the measurements were obtained in three horizontal rows of two points each. These locations, their spacing, and the numbering convention used to list the points are shown in Figure 8. Ten readings, spaced ten seconds apart, were taken at each point. The direction of the face velocity was observed with smoke and its approximate angle relative to the plane of the hood face was noted. The thermoanemometer probe was oriented based on the observed direction of the flow into the face.

\section{Cross Drafts}

The velocity of cross drafts proximate to the hood were also measured with the thermoanemometer. The hood doors were closed and the velocity of the air in the room was measured at six points eighteen inches from the plane of the hood face. The six points were chosen such that their height from the floor was the same as six points which would be the center of six equal rectangles across the entire hood face. The location of these readings relative to the hood face and the numbering convention used to record them are shown in Figure 9. Ten readings, spaced ten seconds apart, were taken at each position. The direction of the cross drafts was observed with smoke and recorded. The thermoanemometer probe was oriented based on the prevailing direction of the cross drafts.

\section{Exhaust Flow}

The exhaust flow of the hood was determined by measuring the flow rate of air upstream and downstream of the junction of the main exhaust duct and the hood exhaust duct. Exhaust ducts were either 12 or 14 inches in diameter. The locations and methodology for the pitot traverses followed the ACGIH convention. (13) A pitot tube and a micromanometer, a Dwyer Instruments Microtector (SN M19B), were employed for this task.

\section{Smoke Test}

A smoke test was performed on the hood face, and a rating of good, fair, or poor was assigned. A rating of good indicates that the smoke was cleared quickly and none leaked from the 
hood face. A rating of fair indicates that the smoke was not cleared quickly or slight leakage was observed. A rating of poor indicates that clearance was slow and some of the smoke leaked from the hood. Smoke was generated with tubes containing ethylenediamine and acetic acid (Mine Safety Appliances Company Ventilation Smoke Tubes).

\section{Manikin Tracer Gas Test}

Figure 10 shows the set up used for the manikin tracer gas test. During the test, $99.99 \%$ pure sulfur hexafluoride was released in the hood at 4 liters per minute from a rectangular diffuser. Concentrations of the gas in the breathing zone of a manikin were monitored continuously monitored with an Ion Track Instruments Model 120 Leakmeter electron capture detector (SN 29325) and recorded with a Metrosonics dl-712 data logger (SN 1178). The flow of tracer gas to the diffuser was monitored continuously with a calibrated rotameter. Calibration information for all of these instruments is contained in Appendix B.

The duration of the manikin tracer gas test was five minutes. The total height from the floor to the top of the manikin's head was 66 inches. The maximum width of the manikin, at the shoulders, was 16 inches. The nose of the manikin was positioned 6 inches from the face of the hood. As shown in Figure 10, the ejector was positioned 6 inches deep in the hood and 6 inches off the bottom surface of the hood.

\section{User Tracer Gas Test}

Figure 11 shows the set up for the user tracer gas test. The conditions and equipment used for the user tracer gas test were identical to the manikin test, except additional tubing was connected to the inlet of the Leakmeter to extend to the breathing zone of the human subject. Every thirty seconds for the five minute duration of the test, the subject extended both arms into the hood and pulled them back out in one motion. 
Figure 8. Position and Numbering Convention for Face Velocity Traverses. One- Half Openings

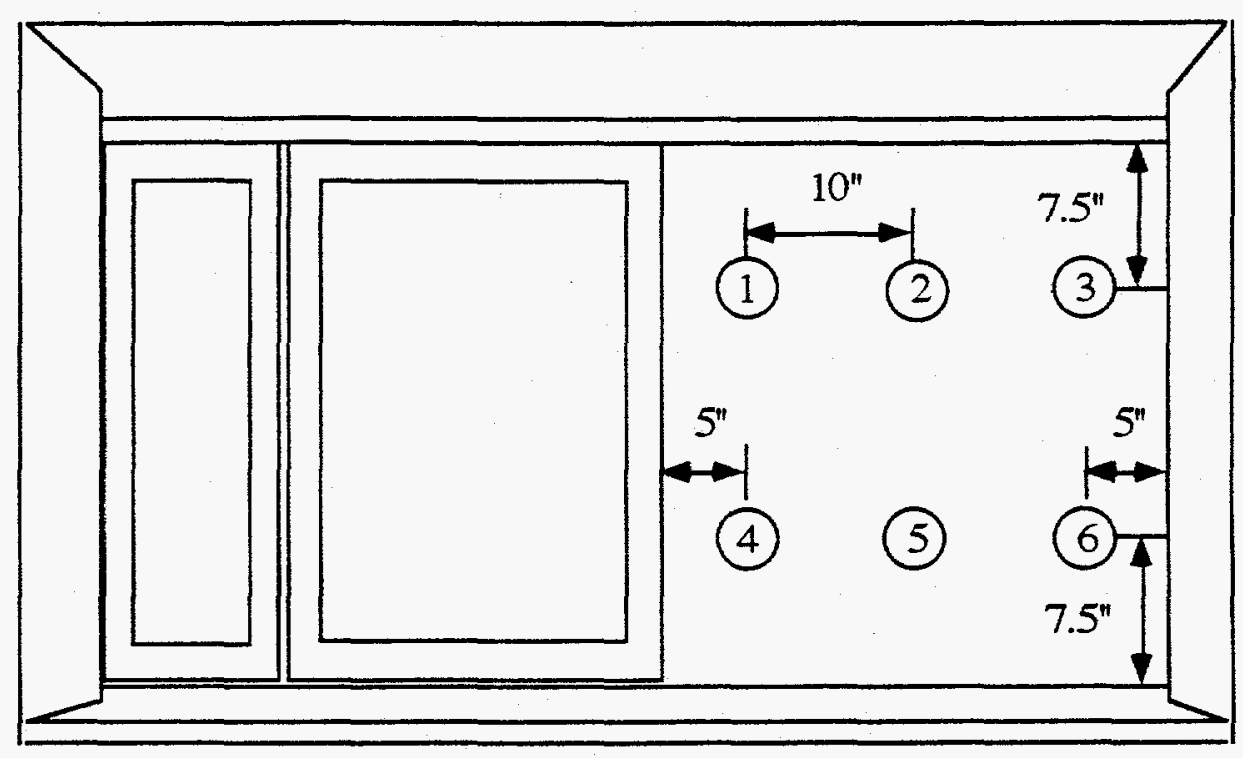

One- Third Openings

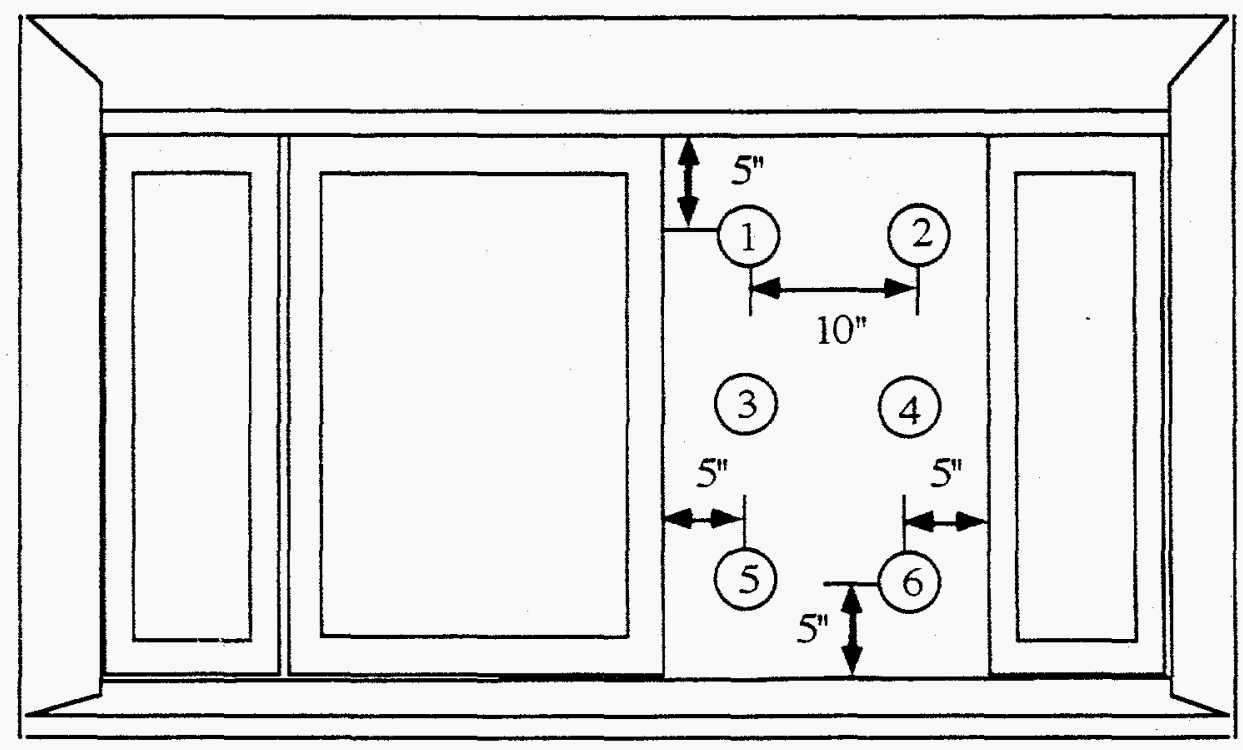


Figure 9. Position and Numbering Convention for Cross Draft Measurements. FRONT VIEW

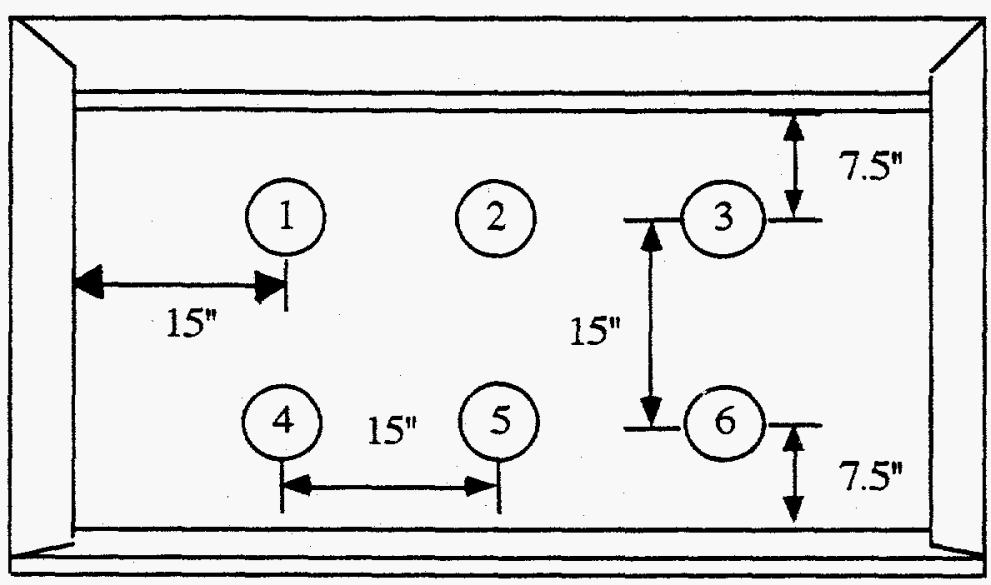

TOP VIEW

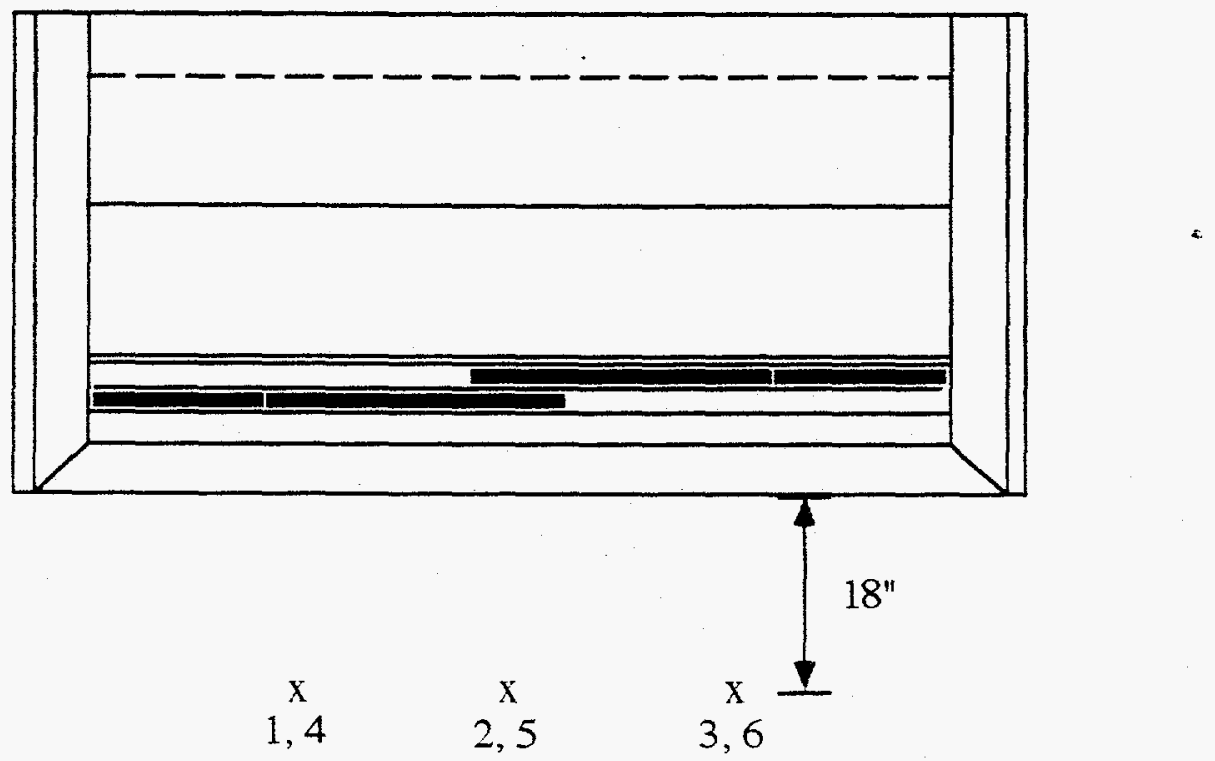


Figure 10. Setup for Manikin Tracer Gas Test.
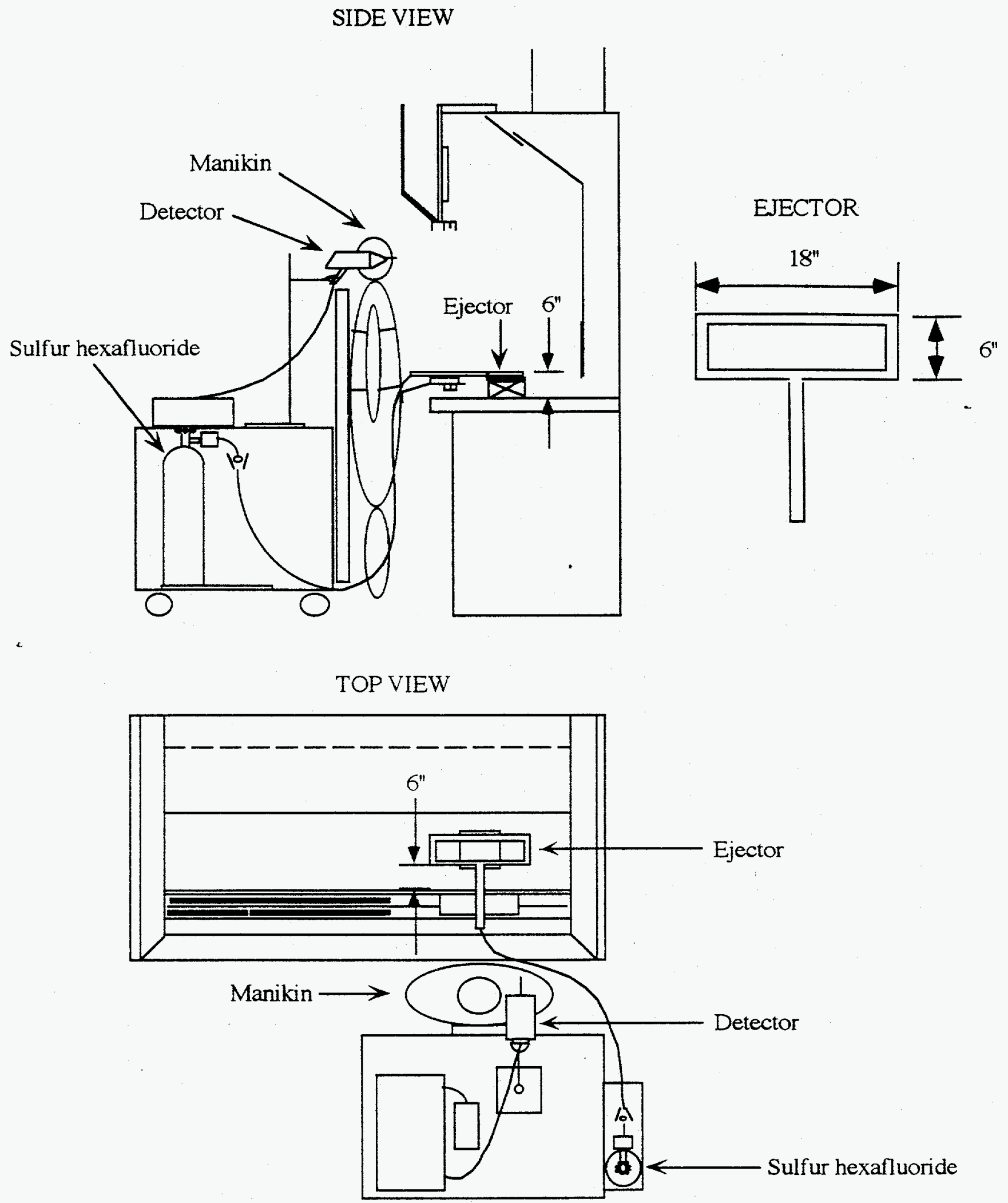
Figure 11. Setup for User Tracer Gas Test.
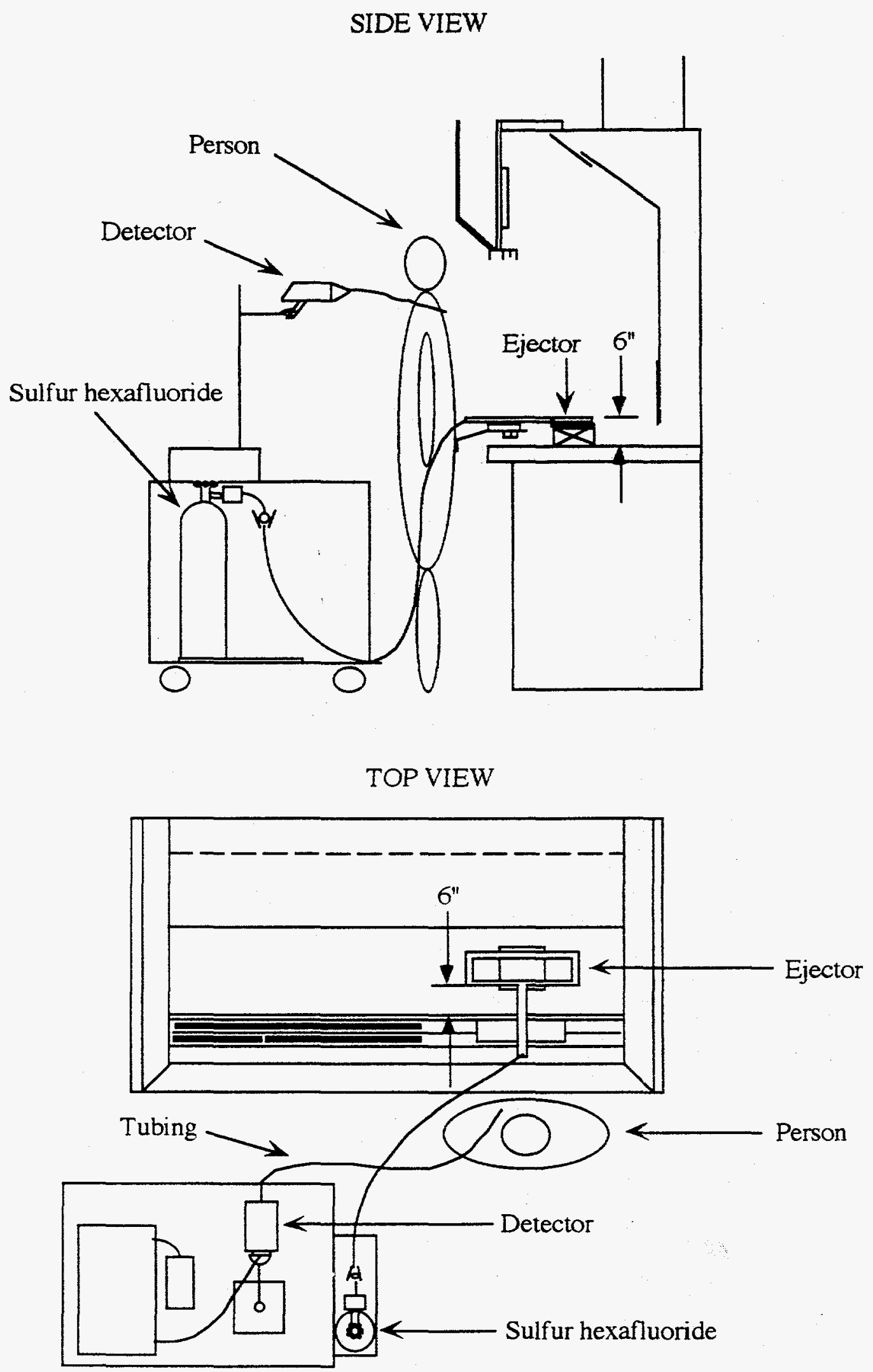


\section{APPENDIX B - INSTRUMENT CALIBRATIONS}

\section{Thermoanemometer Calibration}

An Alnor model 8565 ThermoAnemometer ( $\mathrm{SN}$ 003632) was used to measure air velocities in this study. The thermoanemometer was calibrated in a wind tunnel with a cross sectional area of 2.56 square feet. The set up used for this calibration is shown in Figure 12.

First, the air velocities in the wind tunnel were related to the static pressure in the $8 \mathrm{inch}$ duct directly behind the tunnel. This preliminary calibration was accomplished by measuring the static pressure at this point with a pitot tube and determining the flow rate of air through the system by taking a pitot traverse in a six inch duct far downstream of the wind tunnel. Static and total pressures were measured with a micromanometer, a Dwyer Instruments Microtector (SN M19B). Temperature and relative humidity were determined with a Cole-Palmer Hygrometer; atmospheric pressure was read from a Fisher Scientific Barometer. The results of the wind tunnel calibration are shown in Table 6 and Figure 13.

The thermoanemometer was then calibrated by taking the average of five static pressure measurements and five readings from the thermoanemometer. Calibrations of the instrument were completed on six separate occasions throughout the period of its use for this study. The results of the thermoanemometer calibration are shown in Table 7 and Figure 14. A least squares regression line was fit to the data and used to calculate the actual velocity for a given thermoanemometer reading.

\section{Leakmeter Calibration}

An Ion Track Instruments Model 120 Leakmeter (SN 29325) was used to detect sulfur hexafluoride during tracer gas tests of the laboratory hoods. In order to calibrate this instrument, known concentrations of sulfur hexafluoride were prepared in an SKC sampling bag.

The sampling bags were filled with pure nitrogen to avoid interference from contaminants present in room air. Figure 15 shows the set up used to fill the sampling bags. An SKC sampling pump was used to pull nitrogen from a bag containing an unknown volume through a BIOS International Dry Cal DC-1 Flow Calibrator (Dry Cal Base SN B0394, Standard Flow Cell SN S0243). The calibration bags were filled for several minutes from the exhaust of the sampling pump. The flow rate of nitrogen through the flow calibrator was checked every 15 to 30 seconds during filling so that 10 readings were obtained. The volume of nitrogen in the calibration bag was calculated by multiplying average of the 10 flow rate readings by the time of filling as indicated by a stopwatch.

Pure sulfur hexafluoride was taken from a second sampling bag with a syringe and injected into the calibration bag. $10 \mu \mathrm{L}$ and $100 \mu \mathrm{L}$ Unimetrics syringes and a $1.0 \mathrm{~mL}$ Hamilton Gastight 
syringe were used to complete this step. The concentration of sulfur hexafluoride in the calibration bag after injection is given in equation 1 .

$$
\mathrm{C}=\frac{\mathrm{V}_{\mathrm{SF}_{6}}}{\mathrm{~V}_{\mathrm{SF}_{6}}+\mathrm{V}_{\mathrm{N}_{2}}}
$$

where, $\quad \mathrm{C}=$ resulting concentration of sulfur hexafluoride in calibration bag

$\mathrm{V}_{\mathrm{SF}_{6}}=$ volume of sulfur hexafluoride injected into calibration bag

$\mathrm{V}_{\mathrm{N}_{2}}=$ volume of nitrogen in calibration bag

Low concentrations of sulfur hexafluoride, below about $1 \mathrm{ppm}$, were generally prepared in two steps. A first sampling bag was prepared with a sulfur hexafluoride concentration $\mathrm{C}_{\mathrm{i}}$. The calibration bag was then injected with a known volume from the first bag. The concentration of sulfur hexafluoride in the calibration bag is given in equation 2 .

$$
C=\frac{C_{i} V_{i}}{V_{i}+V_{N_{2}}}
$$

where, $\quad \mathrm{C}=$ concentration of sulfur hexafluoride in calibration bag

$\mathrm{C}_{\mathrm{i}}=$ concentration of sulfur hexafluoride in volume injected into calibration bag

$\mathrm{V}_{\mathrm{i}}=$ volume injected into calibration bag

$\mathrm{V}_{\mathrm{N}_{2}}=$ volume of nitrogen in calibration bag

Once a known concentration of sulfur hexafluoride was prepared, the calibration bag was connected directly to the inlet of the Leakmeter with tubing. A calibration point was set by showing the Leakmeter a $5.0 \mathrm{ppm}$ concentration of sulfur hexafluoride and inputting this concentration on the Leakmeter console. Once this calibration point is set, it is stored in the Leakmeter even after turning the instrument off. Once during the test period of this study, the instrument malfunctioned and erased the set calibration point and required resetting.

Calibrations for the response of the Leakmeter were completed on several dates over a wide range of concentrations. This calibration data are shown in Table 8. The data are arranged in order of the concentration of the calibration bag (the "Prepared Concentration").

Figure 16 shows the response of the Leakmeter as a function of sulfur hexafluoride concentrations. Shown on the figure is the least squares regression line fit to the data to allow conversion of a Leakmeter response to a sulfur hexafluoride concentration. The equation was obtained from a linear regression of the logarithms of both parameters.

In addition to the careful calibrations performed on the Leakmeter, quick calibration checks were performed on the instrument before each set of tracer gas tests on a hood on any given day. 
Two or three different calibration bags, with several different sulfur hexafluoride concentrations, were shown to the Leakmeter before each set of tests and its response recorded. Calibration bags were prepared in the same manner as the more careful tests, but were reused a number of times before preparing a new bag. The same calibration bag may have been used to run a check on the Leakmeter before tests on several different days. The calibration bag was resealed immediately after each check, but the true concentration of sulfur hexafluoride in the bag may have changed over time. The intention of the calibration checks was not to ascertain the exact response of the Leakmeter to a given concentration. Instead, the intention was to determine if the Leakmeter's calibration point was still in place and the instrument appeared to be functioning correctly prior to use. The calibration check information is given in Table 9. Figure 17 shows the response of the Leakmeter to the calibration checks.

\section{Data Logger Calibration}

A Metrosonics dl-712 Data Logger (SN 1178) was used to record the Leakmeter output during the five minute tracer gas tests. The relationship of output voltage to the data logger as a function of the Leakmeter response was established. The output voltage did not change continuously when sulfur hexafluoride concentrations were varied. Rather, the voltage changed discretely corresponding with changes in the concentration displayed by the Leakmeter.

The voltage output for a given Leakmeter display was consistent, although several linear regression lines were fit to the data because the relationship between voltage and Leakmeter response changed, in a step function manner, in different concentration ranges. Table 10 contains the data logger calibration data. Table 11 shows the equations for the relationship between output voltage and Leakmeter display. One regression equation was not best for the data because the relationship between output voltage and Leakmeter display changed abruptly, in a step function manner, at two points. The r-square values for these least squares regression lines were all greater than 0.99. Figure 18 graphically displays the relationship between output voltage and Leakmeter display. The step changes in the relationship between output voltage and Leakmeter display are not evident in the figure, but are obvious from the data in Table 10.

\section{Rotameter Calibration}

A Dwyer rotameter was used to set and monitor the flow rate of sulfur hexafluoride during the tracer gas tests. The rotameter was calibrated to $4 \mathrm{~L} / \mathrm{min}$ with all tubing and equipment used in the tests in place. A BIOS International Dry Cal DC-1 Flow Calibrator (DryCal Base SN B0394, Standard Flow Cell SN S0243) was used for the calibration. 
Table 6. Wind Tunnel Calibration Data.

\begin{tabular}{|c|c|c|c|}
\hline $\begin{array}{c}\text { Hood Static } \\
\text { Pressure ("wg) }\end{array}$ & $\begin{array}{c}\text { Square Root of } \\
\text { Hood Static Pressure }\end{array}$ & $\begin{array}{c}\text { Wind Tunnel Velocity* } \\
\text { (fpm) }\end{array}$ & $\begin{array}{c}\text { Predicted } \\
\text { Velocity** }\end{array}$ \\
\hline 0.0018 & 0.0424 & 21.6 & 19.9 \\
0.0024 & 0.0490 & 26.4 & 23.2 \\
0.0036 & 0.0600 & 28.9 & 28.7 \\
0.0116 & 0.1077 & 53.8 & 52.7 \\
0.0270 & 0.1643 & 81.9 & 81.1 \\
0.0440 & 0.2098 & 103.7 & 104.0 \\
0.0660 & 0.2569 & 128.6 & 127.7 \\
0.0910 & 0.3017 & 149.2 & 150.1 \\
0.1200 & 0.3464 & 171.9 & 172.6 \\
0.1550 & 0.3937 & 196.0 & 196.4 \\
0.1940 & 0.4405 & 219.3 & 219.9 \\
0.2340 & 0.4837 & 237.9 & 241.6 \\
0.2770 & 0.5263 & 263.3 & 263.0 \\
0.3390 & 0.5822 & 289.9 & 291.1 \\
0.3840 & 0.6197 & 314.1 & 309.9 \\
0.4460 & 0.6678 & 336.6 & 334.1 \\
0.5150 & 0.7176 & 355.4 & 359.2 \\
0.5830 & 0.7635 & 384.0 & 382.2 \\
\hline
\end{tabular}

*Determined from pitot traverse of duct downstream of wind tunnel

$* *$ Regression equation ( $\mathrm{r}$ square $=0.999$ ):

Tunnel Velocity $=-1.42+502.4458 * \mathrm{SQRT}(\mathrm{SP})$

Wind tunnel cross sectional area $=2.56$ square feet

Duct diameter at point of pitot traverse $=6$ inches 
Table 7. Thermoanemometer Calibration Data.

\begin{tabular}{|c|c|c|c|c|c|}
\hline Date & $\begin{array}{l}\text { Hood SP } \\
\text { ("wg) }\end{array}$ & SQRT (SP) & $\begin{array}{c}\text { Indicated* } \\
\text { Velocity (fpm) }\end{array}$ & $\begin{array}{l}\text { Wind Tunnel** } \\
\text { Velocity (fpm) }\end{array}$ & $\begin{array}{l}\text { Predicted*** } \\
\text { Velocity (fpm) }\end{array}$ \\
\hline$6 \longdiv { 1 2 / 9 4 }$ & 0.0037 & 0.0610 & 50 & 29.0 & 28.8 \\
\hline $6 / 12 / 94$ & 0.0075 & 0.0865 & 67 & 41.7 & 42.9 \\
\hline $6 / 12 / 94$ & 0.0123 & 0.1108 & 86 & 53.8 & 58.6 \\
\hline $6 / 12 / 94$ & 0.0178 & 0.1336 & 96 & 65.1 & 66.9 \\
\hline $6 / 12 / 94$ & 0.0248 & 0.1576 & 106 & 77.1 & 75.9 \\
\hline $6 / 12 / 94$ & 0.0339 & 0.1841 & 122 & 90.2 & 89.0 \\
\hline $6 / 12 / 94$ & 0.0436 & 0.2088 & 137 & 102.6 & 101.5 \\
\hline $6 / 12 / 94$ & 0.0642 & 0.2535 & 163 & 124.8 & 122.9 \\
\hline $6 / 12 / 94$ & 0.0880 & 0.2966 & 190 & 146.3 & 145.7 \\
\hline $6 / 12 / 94$ & 0.1192 & 0.3453 & 215 & 170.5 & 166.6 \\
\hline $6 / 12 / 94$ & 0.1530 & 0.3911 & 236 & 193.3 & 184.1 \\
\hline $6 / 12 / 94$ & 0.1797 & 0.4239 & 264 & 209.7 & 207.4 \\
\hline $6 / 12 / 94$ & 0.2332 & 0.4829 & 292 & 239.0 & 231.1 \\
\hline $6 / 18 / 94$ & 0.0050 & 0.0707 & 58 & 33.9 & 35.2 \\
\hline $6 / 18 / 94$ & 0.0088 & 0.0936 & 71 & 45.3 & 46.2 \\
\hline $6 / 18 / 94$ & 0.0146 & 0.1207 & 85 & 58.8 & 57.9 \\
\hline $6 / 18 / 94$ & 0.0197 & 0.1403 & 96 & 68.5 & 67.1 \\
\hline $6 / 18 / 94$ & 0.0280 & 0.1673 & 114 & 82.0 & 82.3 \\
\hline $6 / 18 / 94$ & 0.0362 & 0.1902 & 126 & 93.4 & 92.1 \\
\hline $6 / 18 / 94$ & 0.0465 & 0.2156 & 142 & 106.1 & 105.3 \\
\hline $6 / 18 / 94$ & 0.0566 & 0.2380 & 158 & 117.3 & 119.0 \\
\hline $6 / 18 / 94$ & 0.0681 & 0.2609 & 169 & 128.7 & 128.2 \\
\hline $6 / 18 / 94$ & 0.0803 & 0.2833 & 187 & 139.9 & 143.1 \\
\hline $6 / 18 / 94$ & 0.0940 & 0.3067 & 200 & 151.5 & 153.7 \\
\hline $6 / 18 / 94$ & 0.1084 & 0.3292 & 212 & 162.7 & 164.1 \\
\hline $6 / 18 / 94$ & 0.1235 & 0.3514 & 221 & 173.8 & 171.9 \\
\hline $6 / 18 / 94$ & 0.1420 & 0.3768 & 238 & 186.5 & 186.1 \\
\hline $6 / 18 / 94$ & 0.1590 & 0.3988 & 250 & 197.5 & 196.2 \\
\hline $6 / 18 / 94$ & 0.1780 & 0.4219 & 263 & 209.0 & 206.7 \\
\hline $6 / 18 / 94$ & 0.1960 & 0.4427 & 273 & 219.4 & 215.2 \\
\hline $6 / 18 / 94$ & 0.2392 & 0.4890 & 305 & 242.5 & 241.6 \\
\hline $6 / 18 / 94$ & 0.2840 & 0.5329 & 332 & 264.3 & 264.0 \\
\hline $6 / 18 / 94$ & 0.3356 & 0.5793 & 366 & 287.5 & 292.4 \\
\hline $6 / 18 / 94$ & 0.3917 & 0.6259 & 385 & 310.7 & 308.6 \\
\hline $6 / 18 / 94$ & 0.4552 & 0.6747 & 418 & 335.0 & 336.1 \\
\hline $7 / 4 / 94$ & 0.0056 & 0.0748 & 61 & 35.8 & 38.0 \\
\hline $7 / 4 / 94$ & 0.0150 & 0.1226 & 86 & 59.5 & 59.1 \\
\hline $7 / 4 / 94$ & 0.0289 & 0.1701 & 113 & 83.1 & 81.6 \\
\hline $7 / 4 / 94$ & 0.0467 & 0.2161 & 142 & 105.9 & 105.7 \\
\hline $7 / 4 / 94$ & 0.0668 & 0.2585 & 171 & 127.0 & 129.9 \\
\hline $7 / 4 / 94$ & 0.0942 & 0.3070 & 201 & 151.1 & 154.6 \\
\hline $7 / 4 / 94$ & 0.1251 & 0.3537 & 225 & 174.3 & 175.0 \\
\hline $7 / 4 / 94$ & 0.1550 & 0.3936 & 247 & 194.2 & 193.0 \\
\hline $7 / 4 / 94$ & 0.1941 & 0.4406 & 275 & 217.5 & 216.7 \\
\hline $7 / 4 / 94$ & 0.2881 & 0.5367 & 333 & 265.2 & 264.8 \\
\hline $7 / 4 / 94$ & 0.3964 & 0.6296 & 392 & 311.4 & 314.6 \\
\hline
\end{tabular}

(continued on following page) 


\begin{tabular}{|c|c|c|c|c|c|}
\hline Date & $\begin{array}{c}\text { Hood SP } \\
\text { ("wg) }\end{array}$ & $\begin{array}{c}\text { Indicated* } \\
\text { SQRT (SP) }\end{array}$ & $\begin{array}{c}\text { Wind Tunnel** } \\
\text { Velocity (fpm) }\end{array}$ & $\begin{array}{c}\text { Pedodicted*** } \\
\text { Velocity (fpm) }\end{array}$ & Velocity (fpm) \\
\hline $7 / 18 / 94$ & 0.0018 & 0.0420 & 31 & 19.6 & 13.0 \\
$7 / 18 / 94$ & 0.0024 & 0.0490 & 42 & 23.1 & 22.3 \\
$7 / 18 / 94$ & 0.0051 & 0.0713 & 58 & 34.3 & 35.8 \\
$7 / 18 / 94$ & 0.0162 & 0.1274 & 89 & 62.4 & 61.6 \\
$7 / 18 / 94$ & 0.0477 & 0.2184 & 144 & 108.1 & 107.2 \\
$7 / 18 / 94$ & 0.1138 & 0.3373 & 220 & 167.6 & 170.4 \\
$7 / 18 / 94$ & 0.2076 & 0.4556 & 277 & 226.9 & 218.4 \\
$7 / 18 / 94$ & 0.3274 & 0.5722 & 357 & 285.3 & 285.2 \\
$7 / 18 / 94$ & 0.4842 & 0.6958 & 422 & 347.3 & 339.6 \\
$7 / 18 / 94$ & 0.6162 & 0.7850 & 477 & 392.0 & 385.0 \\
\hline $9 / 5 / 94$ & 0.0019 & 0.0434 & 43 & 20.4 & 23.0 \\
$9 / 5 / 94$ & 0.0030 & 0.0548 & 49 & 26.1 & 28.0 \\
$9 / 5 / 94$ & 0.0041 & 0.0642 & 54 & 30.9 & 32.5 \\
$9 / 5 / 94$ & 0.0066 & 0.0810 & 65 & 39.3 & 41.0 \\
$9 / 5 / 94$ & 0.0100 & 0.1000 & 72 & 48.9 & 47.4 \\
$9 / 5 / 94$ & 0.0158 & 0.1255 & 86 & 61.7 & 59.2 \\
$9 / 5 / 94$ & 0.0226 & 0.1505 & 99 & 74.3 & 70.1 \\
$9 / 5 / 94$ & 0.0311 & 0.1764 & 114 & 87.3 & 82.3 \\
$9 / 5 / 94$ & 0.0400 & 0.1999 & 130 & 99.2 & 95.3 \\
$9 / 5 / 94$ & 0.0483 & 0.2197 & 142 & 109.1 & 105.3 \\
$9 / 5 / 94$ & 0.0730 & 0.2701 & 171 & 134.5 & 129.9 \\
$9 / 5 / 94$ & 0.1010 & 0.3179 & 200 & 158.5 & 154.4 \\
$9 / 5 / 94$ & 0.1542 & 0.3927 & 236 & 196.2 & 183.8 \\
$9 / 5 / 94$ & 0.2104 & 0.4587 & 274 & 229.4 & 215.9 \\
\hline $11 / 2 / 94$ & 0.0040 & 0.0636 & 46 & 31.3 & 25.2 \\
$11 / 2 / 94$ & 0.0068 & 0.0825 & 56 & 41.0 & 34.0 \\
$11 / 2 / 94$ & 0.0156 & 0.1249 & 85 & 62.9 & 57.7 \\
$11 / 2 / 94$ & 0.0280 & 0.1673 & 113 & 84.8 & 81.3 \\
$11 / 2 / 94$ & 0.0464 & 0.2154 & 137 & 109.5 & 101.6 \\
$11 / 2 / 94$ & 0.0672 & 0.2592 & 164 & 132.1 & 123.7 \\
$11 / 2 / 94$ & 0.1056 & 0.3250 & 208 & 166.0 & 160.4 \\
$11 / 2 / 94$ & 0.1580 & 0.3975 & 237 & 203.3 & 185.0 \\
$11 / 2 / 94$ & 0.1932 & 0.4395 & 262 & 225.0 & 206.2 \\
\hline
\end{tabular}

* Indicated velocity calculated by averaging five thermoanemometer readings

** Wind tunnel velocity calculated by averaging five hood static pressure measurements taken with pitot tube and micromanometer, converted to velocity by the equation:

Tunnel Velocity $=502.4 *$ SQRT(SP) -1.42

*** Regression equation based on $6 / 18$ data ( $r$ square $=0.997$ )

Wind tunnel velocity $=-12.92+0.835 *$ Thermo reading

Thermoanemometer reading $=15.5+1.20^{*}$ Wind tunnel velocity 
Table 8. Leakmeter Calibration Data .

\begin{tabular}{|c|c|c|c|c|c|}
\hline Date & $\begin{array}{c}\text { Prepared } \\
\text { Concentration } \\
\text { (ppm) }\end{array}$ & $\begin{array}{c}\text { Leakmeter } \\
\text { Response } \\
\text { (ppm) }\end{array}$ & Date & $\begin{array}{c}\text { Prepared } \\
\text { Concentration } \\
\text { (ppm) }\end{array}$ & $\begin{array}{c}\text { Leakmeter } \\
\text { Response } \\
\text { (ppm) }\end{array}$ \\
\hline $8 / 6 / 94$ & 0.06 & 0.0 & $7 / 25 / 94$ & 2.05 & 2.7 \\
\hline $7 / 26 / 94$ & 0.08 & 0.0 & $7 / 26 / 94$ & 2.14 & 2.4 \\
\hline $9 / 6 / 94$ & 0.10 & 0.1 & $7 / 9 / 94$ & 2.35 & 3.2 \\
\hline $7 / 26 / 94$ & 0.11 & 0.1 & $7 / 9 / 94$ & 2.43 & 2.8 \\
\hline $8 / 6 / 94$ & 0.11 & 0.0 & $7 / 26 / 94$ & 2.63 & 3.0 \\
\hline $7 / 25 / 94$ & 0.11 & 0.0 & $8 / 30 / 94$ & 2.63 & 3.0 \\
\hline $7 / 26 / 94$ & 0.13 & 0.2 & $8 / 6 / 94$ & 2.79 & 3.3 \\
\hline $7 / 26 / 94$ & 0.15 & 0.2 & $7 / 25 / 94$ & 2.82 & 3.3 \\
\hline $8 / 6 / 94$ & 0.16 & 0.1 & $8 / 8 / 94$ & 2.89 & 3.0 \\
\hline $7 / 26 / 94$ & 0.18 & 0.2 & $7 / 26 / 94$ & 3.05 & 3.7 \\
\hline $9 / 6 / 94$ & 0.21 & 0.2 & $7 / 25 / 94$ & 3.40 & 3.3 \\
\hline $7 / 26 / 94$ & 0.21 & 0.2 & $9 / 6 / 94$ & 3.97 & 3.4 \\
\hline $8 / 6 / 94$ & 0.22 & 0.1 & $7 / 26 / 94$ & 4.20 & 4.7 \\
\hline $7 / 9 / 94$ & 0.24 & 0.2 & $7 / 28 / 94$ & 4.22 & 4.5 \\
\hline $8 / 8 / 94$ & 0.26 & 0.1 & $7 / 25 / 94$ & 4.56 & 4.4 \\
\hline $7 / 26 / 94$ & 0.27 & 0.3 & $7 / 9 / 94$ & 4.88 & 5.1 \\
\hline $7 / 28 / 94$ & 0.30 & 0.4 & $7 / 9 / 94$ & 4.99 & 5.0 \\
\hline $7 / 26 / 94$ & 0.30 & 0.3 & $8 / 6 / 94$ & 5.04 & 5.0 \\
\hline $7 / 25 / 94$ & 0.33 & 0.3 & $7 / 26 / 94$ & 5.17 & 5.5 \\
\hline $8 / 8 / 94$ & 0.36 & 0.3 & $7 / 25 / 94$ & 5.53 & 4.8 \\
\hline $8 / 1 / 94$ & 0.37 & 0.4 & $9 / 6 / 94$ & 6.43 & 5.9 \\
\hline $8 / 8 / 94$ & 0.46 & 0.4 & $7 / 9 / 94$ & 7.32 & 8.4 \\
\hline $7 / 9 / 94$ & 0.48 & 0.5 & $7 / 26 / 94$ & 7.44 & 8.6 \\
\hline $9 / 6 / 94$ & 0.53 & 0.5 & $7 / 25 / 94$ & 7.79 & 7.5 \\
\hline $7 / 26 / 94$ & 0.53 & 0.8 & $8 / 6 / 94$ & 7.90 & 8.7 \\
\hline $7 / 25 / 94$ & 0.56 & 0.5 & $9 / 6 / 94$ & 8.33 & 8.7 \\
\hline $7 / 25 / 94$ & 0.67 & 0.7 & $7 / 9 / 94$ & 9.49 & 11.5 \\
\hline $8 / 8 / 94$ & 0.72 & 0.7 & $8 / 8 / 94$ & 9.53 & 12.9 \\
\hline $8 / 30 / 94$ & 0.82 & 0.9 & $7 / 26 / 94$ & 9.60 & 12.4 \\
\hline $7 / 26 / 94$ & 0.83 & 1.1 & $7 / 28 / 94$ & 10.25 & 11.1 \\
\hline $7 / 25 / 94$ & 0.99 & 0.9 & $8 / 1 / 94$ & 10.70 & 13.0 \\
\hline $8 / 6 / 94$ & 1.10 & 1.2 & $8 / 6 / 94$ & 10.82 & 14.1 \\
\hline $7 / 9 / 94$ & 1.18 & 1.4 & $7 / 25 / 94$ & 11.70 & 12.7 \\
\hline $7 / 26 / 94$ & 1.28 & 2.6 & $8 / 6 / 94$ & 12.06 & 15.4 \\
\hline $8 / 30 / 94$ & 1.65 & 1.8 & $7 / 26 / 94$ & 12.70 & 17.8 \\
\hline $7 / 26 / 94$ & 1.70 & 2.0 & $9 / 6 / 94$ & 13.29 & 17.9 \\
\hline $9 / 6 / 94$ & 1.88 & 1.9 & & & \\
\hline
\end{tabular}


Table 9. Leakmeter Calibration Check Data .

\begin{tabular}{|c|c|c|c|}
\hline $\begin{array}{l}\text { Hood } \\
\text { ID }\end{array}$ & Date & $\begin{array}{c}\text { Prepared } \\
\text { Concentration (ppm) }\end{array}$ & $\begin{array}{c}\text { Leakmeter } \\
\text { Response (ppm) }\end{array}$ \\
\hline 2509AR & $8 / 1 / 94$ & 0.4 & 0.5 \\
\hline 2509AR & $8 / 1 / 94$ & 4.5 & 2.9 \\
\hline 2509AR & $8 / 1 / 94$ & 11.1 & 10.1 \\
\hline 2511AL & $10 / 12 / 94$ & 1.9 & 1.1 \\
\hline 2511AL & $10 / 13 / 94$ & 1.9 & 1.2 \\
\hline $2511 \mathrm{AL}$ & $10 / 12 / 94$ & 5.9 & 4.0 \\
\hline 2511AL & $10 / 13 / 94$ & 5.9 & 4.1 \\
\hline $2513 \mathrm{AL}$ & $9 / 15 / 94$ & 1.9 & 1.6 \\
\hline 2513AL & $9 / 15 / 94$ & 5.9 & 4.8 \\
\hline 2513BR & $9 / 8 / 94$ & 1.9 & 1.7 \\
\hline 2513BR & $9 / 8 / 94$ & 5.9 & 5.4 \\
\hline $2515 \mathrm{AL}$ & $8 / 3 / 94$ & 0.4 & 0.4 \\
\hline 2515AL & $8 / 3 / 94$ & 10.4 & 12.3 \\
\hline 2517AL & $7 / 27 / 94$ & 0.5 & 0.4 \\
\hline 2517AL & $7 / 27 / 94$ & 5.0 & 3.9 \\
\hline 2517AL & $7 / 27 / 94$ & 10.0 & $>19.9$ \\
\hline 2517BR & $8 / 1 / 94$ & 0.4 & 0.5 \\
\hline 2517BR & $8 / 1 / 94$ & 4.5 & 2.9 \\
\hline 2517BR & $8 / 1 / 94$ & 11.1 & 10.6 \\
\hline 2555AR & $7 / 28 / 94$ & 0.3 & 0.2 \\
\hline 2555AR & $7 / 28 / 94$ & 4.1 & 3.9 \\
\hline 2555AR & $7 / 28 / 94$ & 10.1 & 10.4 \\
\hline 2555BR & $8 / 9 / 94$ & 0.7 & 0.8 \\
\hline 2555BR & $8 / 9 / 94$ & 2.9 & 2.9 \\
\hline 2555BR & $8 / 9 / 94$ & 9.6 & 11.2 \\
\hline 2557BL & $8 / 2 / 94$ & 0.4 & 0.4 \\
\hline $2557 \mathrm{BL}$ & $8 / 2 / 94$ & 10.4 & 13.7 \\
\hline 2561AR & $8 / 4 / 94$ & 0.4 & 0.4 \\
\hline 2561AR & $8 / 4 / 94$ & 10.4 & 13.3 \\
\hline $2563 \mathrm{AL}$ & $9 / 18 / 94$ & 1.9 & 1.6 \\
\hline $2563 \mathrm{AL}$ & $9 / 18 / 94$ & 5.9 & 4.6 \\
\hline 2563BR & $8 / 8 / 94$ & 0.7 & 0.7 \\
\hline 2563BR & $8 / 8 / 94$ & 2.9 & 2.8 \\
\hline 2563BR & $8 / 8 / 94$ & 9.6 & 12.0 \\
\hline 2571AL & $7 / 29 / 94$ & 0.4 & 0.5 \\
\hline $2571 \mathrm{AL}$ & $7 / 29 / 94$ & 4.5 & 4.7 \\
\hline $2571 \mathrm{AL}$ & $7 / 29 / 94$ & 11.1 & 15.5 \\
\hline $2571 B R$ & $7 / 29 / 94$ & 0.4 & 0.5 \\
\hline 2571BR & $7 / 29 / 94$ & 4.5 & 4.1 \\
\hline 2571BR & $7 / 29 / 94$ & 11.1 & 11.4 \\
\hline
\end{tabular}


Table 10. Data Logger Calibration Data.

\begin{tabular}{|c|c|c|c|}
\hline Date & $\begin{array}{l}\text { Data Logger } \\
\text { Voltage (V) }\end{array}$ & $\begin{array}{c}\text { Leakmeter } \\
\text { Reading (ppm) }\end{array}$ & $\begin{array}{c}\text { Predicted } \\
\text { Reading* (ppm) }\end{array}$ \\
\hline $6 / 10 / 94$ & 0.0040 & 0.00 & 0.00 \\
\hline $6 / 10 / 94$ & 0.0045 & 0.00 & 0.00 \\
\hline $6 / 10 / 94$ & 0.0045 & 0.00 & 0.00 \\
\hline $6 / 10 / 94$ & 0.0045 & 0.00 & 0.00 \\
\hline $6 / 22 / 94$ & 0.0055 & 0.00 & 0.00 \\
\hline $6 / 22 / 94$ & 0.0130 & 0.00 & 0.00 \\
\hline $6 / 22 / 94$ & 0.0045 & 0.00 & 0.00 \\
\hline $6 / 22 / 94$ & 0.0055 & 0.00 & 0.00 \\
\hline $6 / 22 / 94$ & 0.0050 & 0.00 & 0.00 \\
\hline $6 / 23 / 94$ & 0.0040 & 0.00 & 0.00 \\
\hline $6 / 23 / 94$ & 0.0190 & 0.00 & 0.00 \\
\hline $6 / 24 / 94$ & 0.0060 & 0.00 & 0.00 \\
\hline $6 / 24 / 94$ & 0.0055 & 0.00 & 0.00 \\
\hline $6 / 10 / 94$ & 0.0145 & 0.10 & 0.10 \\
\hline $6 / 10 / 94$ & 0.0145 & 0.10 & 0.10 \\
\hline $6 / 22 / 94$ & 0.0145 & 0.10 & 0.10 \\
\hline $6 / 22 / 94$ & 0.0150 & 0.10 & 0.11 \\
\hline $6 / 10 / 94$ & 0.0245 & 0.20 & 0.20 \\
\hline $6 / 22 / 94$ & 0.0345 & 0.30 & 0.30 \\
\hline $6 / 10 / 94$ & 0.0545 & 0.40 & 0.40 \\
\hline $6 / 24 / 94$ & 0.0555 & 0.40 & 0.41 \\
\hline $6 / 22 / 94$ & 0.0640 & 0.50 & 0.50 \\
\hline $6 / 10 / 94$ & 0.0740 & 0.60 & 0.60 \\
\hline $6 / 22 / 94$ & 0.0745 & 0.60 & 0.60 \\
\hline $6 / 23 / 94$ & 0.0750 & 0.60 & 0.61 \\
\hline $6 / 23 / 94$ & 0.0850 & 0.70 & 0.71 \\
\hline $6 / 22 / 94$ & 0.1135 & 0.90 & 0.90 \\
\hline $6 / 23 / 94$ & 0.1145 & 0.90 & 0.90 \\
\hline $6 / 23 / 94$ & 0.1140 & 0.90 & 0.90 \\
\hline $6 / 23 / 94$ & 0.1145 & 0.90 & 0.90 \\
\hline $6: 23 / 94$ & 0.1220 & 1.00 & 0.96 \\
\hline $6 / 23 / 94$ & 0.1245 & 1.00 & 0.98 \\
\hline $6 / 23 / 94$ & 0.1540 & 1.20 & 1.21 \\
\hline $6 / 23 / 94$ & 0.1535 & 1.20 & 1.21 \\
\hline $624 / 94$ & 0.1715 & 1.35 & 1.35 \\
\hline $6 / 23 / 94$ & 0.1735 & 1.40 & 1.37 \\
\hline $6: 23 / 94$ & 0.1935 & 1.50 & 1.52 \\
\hline $6 / 10 / 94$ & 0.2130 & 1.70 & 1.68 \\
\hline $6 / 23 / 94$ & 0.2330 & 1.80 & 1.83 \\
\hline $6 / 23 / 94$ & 0.2430 & 1.90 & 1.91 \\
\hline $6 / 24 / 94$ & 0.2430 & 1.90 & 1.91 \\
\hline $6: 22 / 94$ & 0.2530 & 2.00 & 1.99 \\
\hline $6 / 23 / 94$ & 0.2515 & 2.00 & 1.98 \\
\hline $6 / 23 / 94$ & 0.2535 & 2.00 & 1.99 \\
\hline $6 / 23 / 94$ & 0.2630 & 2.10 & 2.07 \\
\hline $6 / 23 / 94$ & 0.3090 & 2.40 & 2.43 \\
\hline $6 / 23 / 94$ & 0.3230 & 2.50 & 2.54 \\
\hline $6 / 24: 94$ & 0.3330 & 2.60 & 2.62 \\
\hline
\end{tabular}

*Regression equations given in Table 11 


\begin{tabular}{|c|c|c|c|}
\hline Date & $\begin{array}{l}\text { Data Logger } \\
\text { Voltage }(V)\end{array}$ & $\begin{array}{c}\text { Leakmeter } \\
\text { Reading (ppm) }\end{array}$ & $\begin{array}{c}\text { Predicted } \\
\text { Reading* (ppm) }\end{array}$ \\
\hline $6 / 10 / 94$ & 0.3525 & 2.80 & 2.77 \\
\hline $6 / 23 / 94$ & 0.4920 & 3.90 & 3.86 \\
\hline $6 / 23 / 94$ & 0.5200 & 4.10 & 4.08 \\
\hline $6 / 23 / 94$ & 0.5220 & 4.10 & 4.10 \\
\hline $6 / 22 / 94$ & 0.5285 & 4.20 & 4.15 \\
\hline $6 / 10 / 94$ & 0.6360 & 5.00 & 4.99 \\
\hline $6 / 23 / 94$ & 0.6420 & 5.00 & 5.04 \\
\hline $6 / 23 / 94$ & 0.6720 & 5.30 & 5.27 \\
\hline $6 / 23 / 94$ & 0.6860 & 5.40 & 5.38 \\
\hline $6 / 23 / 94$ & 0.6920 & 5.40 & 5.43 \\
\hline $6 / 23 / 94$ & 0.7000 & 5.50 & 5.49 \\
\hline $6 / 23 / 94$ & 0.7115 & 5.60 & 5.58 \\
\hline $6 / 23 / 94$ & 0.7315 & 5.70 & 5.74 \\
\hline $6 / 24 / 94$ & 0.7315 & 5.70 & 5.74 \\
\hline $6 / 23 / 94$ & 0.7415 & 5.80 & 5.82 \\
\hline $6 / 24 / 94$ & 0.8010 & 6.30 & 6.28 \\
\hline $6 / 23 / 94$ & 0.8710 & 6.80 & 6.83 \\
\hline $6 / 10 / 94$ & 0.8915 & 7.00 & 6.99 \\
\hline $6 / 23 / 94$ & 0.9405 & 7.40 & 7.38 \\
\hline $6 / 23 / 94$ & 1.1000 & 8.60 & 8.63 \\
\hline $6 / 23 / 94$ & 1.1200 & 8.80 & 8.79 \\
\hline $6 / 23 / 94$ & 1.4855 & 11.70 & 11.65 \\
\hline $6 / 23 / 94$ & 1.5610 & 12.20 & 12.24 \\
\hline $6 / 23 / 94$ & 1.5585 & 12.20 & 12.22 \\
\hline $6 / 23 / 94$ & 1.7180 & 13.50 & 13.47 \\
\hline $6 / 22 / 94$ & 1.7395 & 13.60 & 13.64 \\
\hline $6 / 23 / 94$ & 2.1340 & 16.80 & 16.73 \\
\hline $6 / 23 / 94$ & 2.1460 & 16.80 & 16.83 \\
\hline $6 / 23 / 94$ & 2.1765 & 17.00 & 17.07 \\
\hline $6 / 23 / 94$ & 2.1655 & 17.00 & 16.98 \\
\hline $6 / 23 / 94$ & 2.2205 & 17.45 & 17.41 \\
\hline $6 / 23 / 94$ & 2.2655 & 17.75 & 17.76 \\
\hline $6 / 23 / 94$ & 2.3825 & 18.70 & 18.68 \\
\hline $6 / 23 / 94$ & 2.3850 & 18.70 & 18.70 \\
\hline $6 / 23 / 94$ & 2.4495 & 19.20 & 19.21 \\
\hline $6 / 10 / 94$ & 2.5440 & $>19.9$ & \\
\hline $6 / 22 / 94$ & 2.5435 & $>19.9$ & \\
\hline $6 / 22 / 94$ & 2.5440 & $>19.9$ & \\
\hline $6 / 22 / 94$ & 2.5435 & $>19.9$ & \\
\hline $6 / 23 / 94$ & 2.5440 & $>19.9$ & \\
\hline $6 / 23 / 94$ & 2.5440 & $>19.9$ & \\
\hline
\end{tabular}

*Regression equations given in Table 11 
Table 11. Least Squares Regression Equations to Calculate Leakmeter Response Given Data Logger Voltage Output .

\begin{tabular}{|c|c|c|}
\hline $\begin{array}{c}\text { Data Logger } \\
\text { Response (Volts) }\end{array}$ & $\begin{array}{c}\text { Leakmeter } \\
\text { Response (ppm)* }\end{array}$ & r-square \\
\hline$<0.01$ & $<0.01$ & 0.9995 \\
\hline 0.01 to 0.05 & $10 \mathrm{X}-0.045$ & 0.998 \\
\hline 0.05 to 0.1 & $10 \mathrm{X}-0.145$ & 0.99998 \\
\hline 0.1 to 2.54 & $7.838 \mathrm{X}+0.0065$ & \\
\hline$>2.54$ & $>19.9$ & \\
\hline
\end{tabular}

${ }^{*} \bar{X}=$ Data logger voltage. 
Figure 12. Thermoanemometer Calibration Set Up.

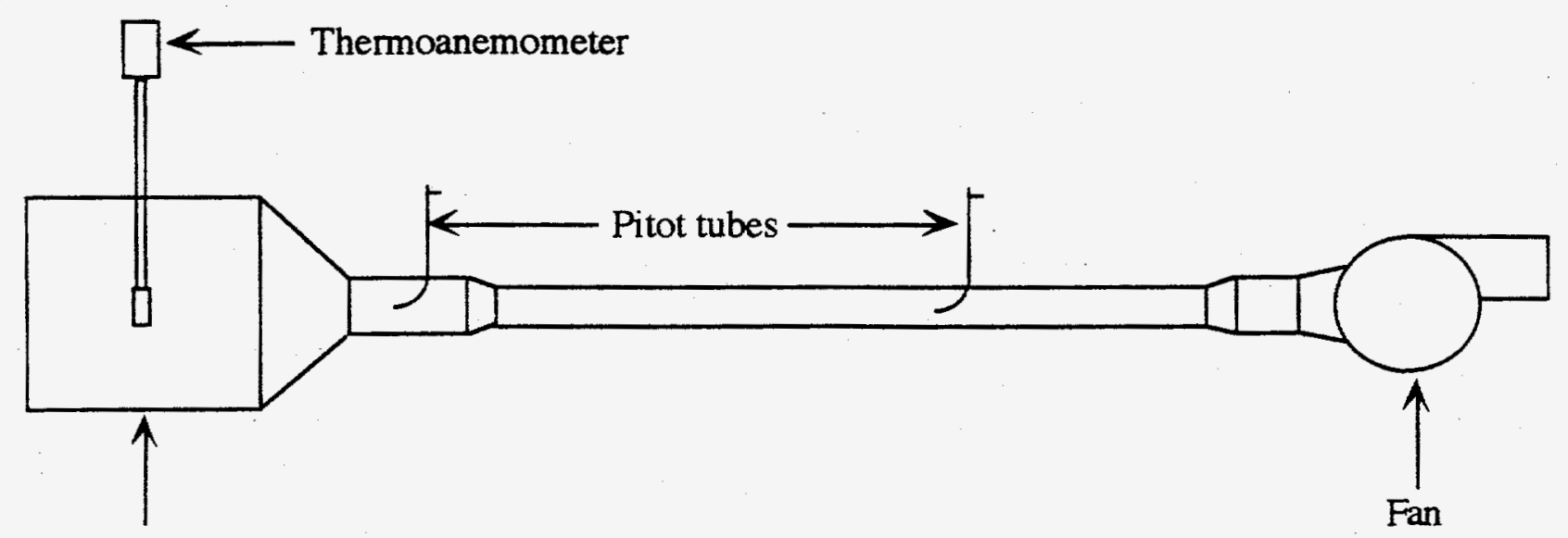

Wind Tunnel 
Figure 13. Calibration of Wind Tunnel Velocity to Hood Static Pressure.

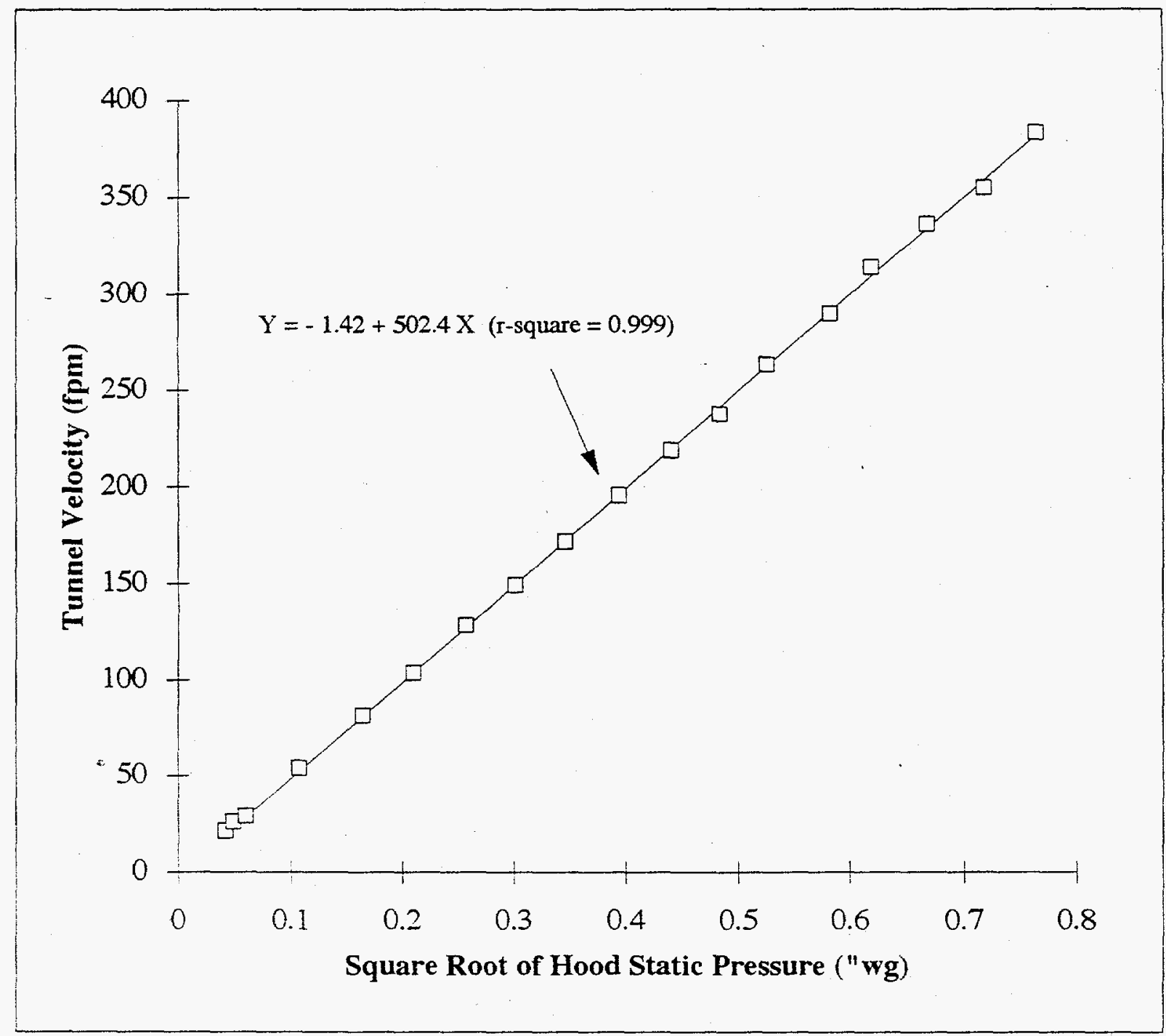


Figure 14. Thermoanemometer Reading as a Function of Wind Tunnel Velocity.

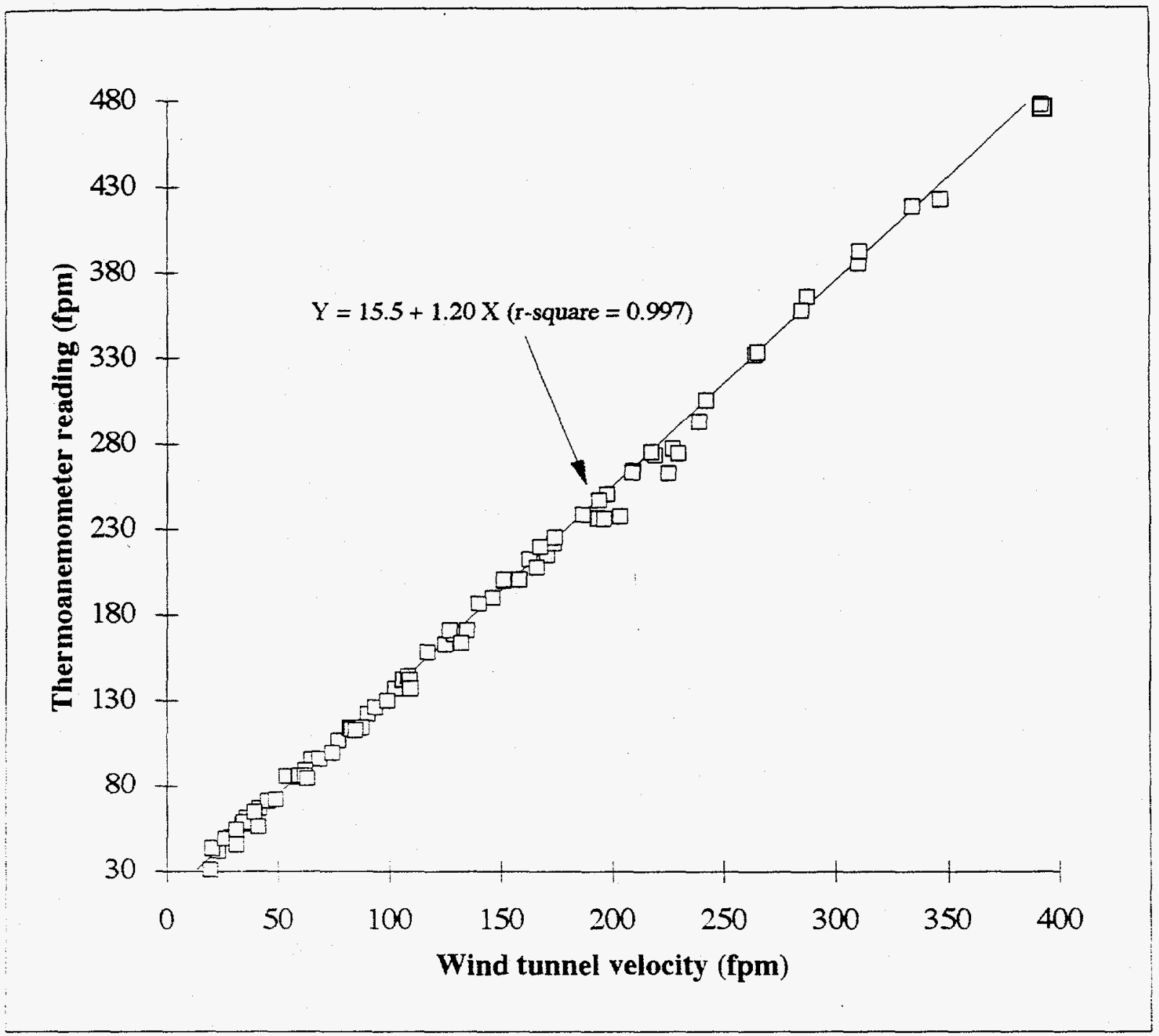


Figure 15. Set Up to Fill Calibration Bag for Leakmeter Calibration.

$\begin{array}{cccc}\begin{array}{l}\text { Nitrogen } \\ \text { filled bag }\end{array} & \text { Flow } & \text { Sampling } & \text { Calibration } \\ \text { pump } & \text { bag }\end{array}$

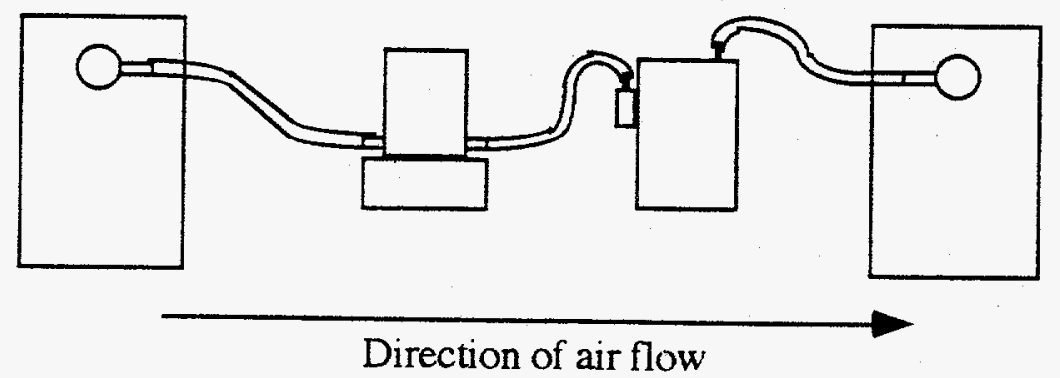


Figure 16. Leakmeter Response as a Function of Sulfur Hexafluoride Concentration.

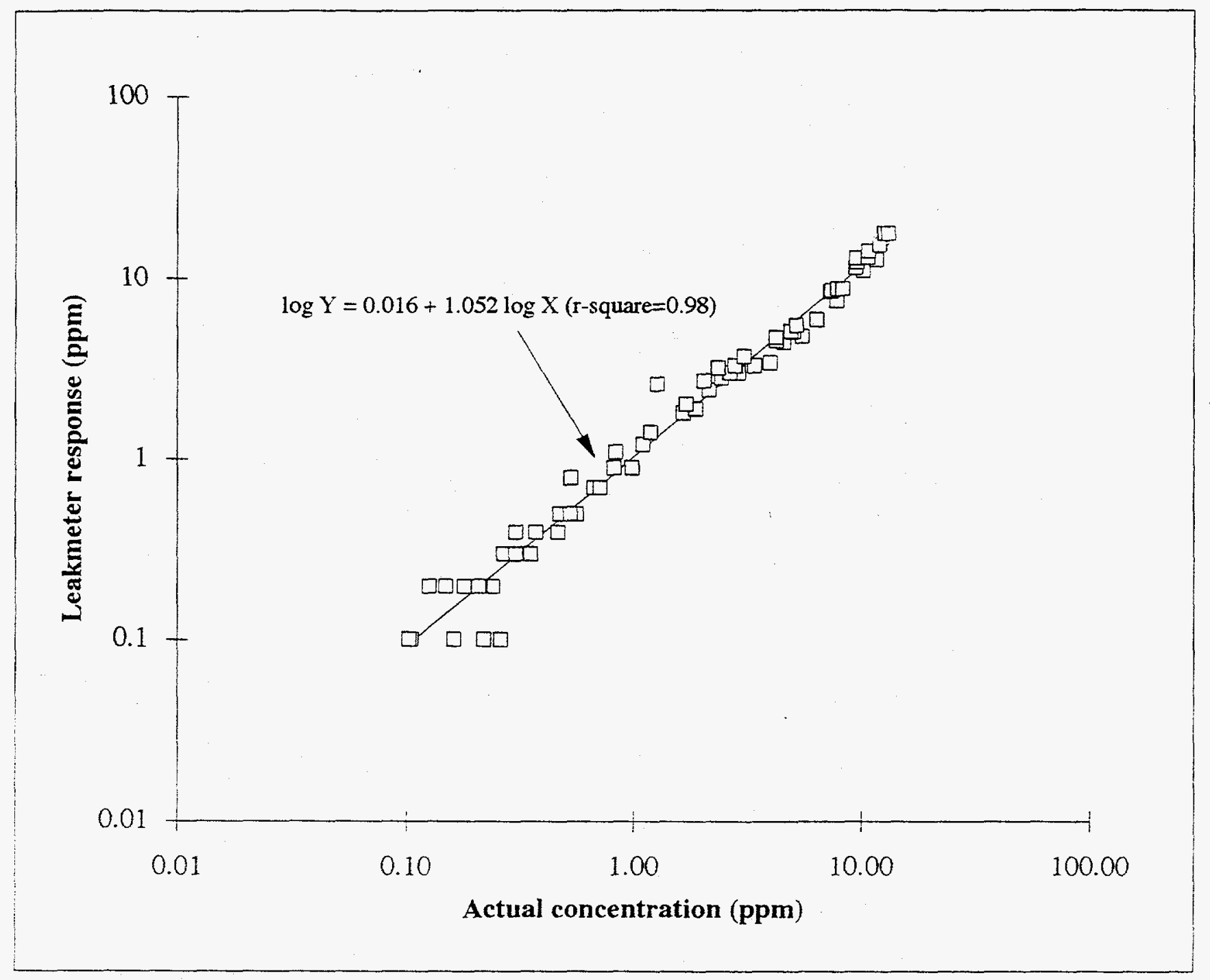


Figure 17. Leakmeter Response During Calibration Checks Prior to Tracer Gas Tests.

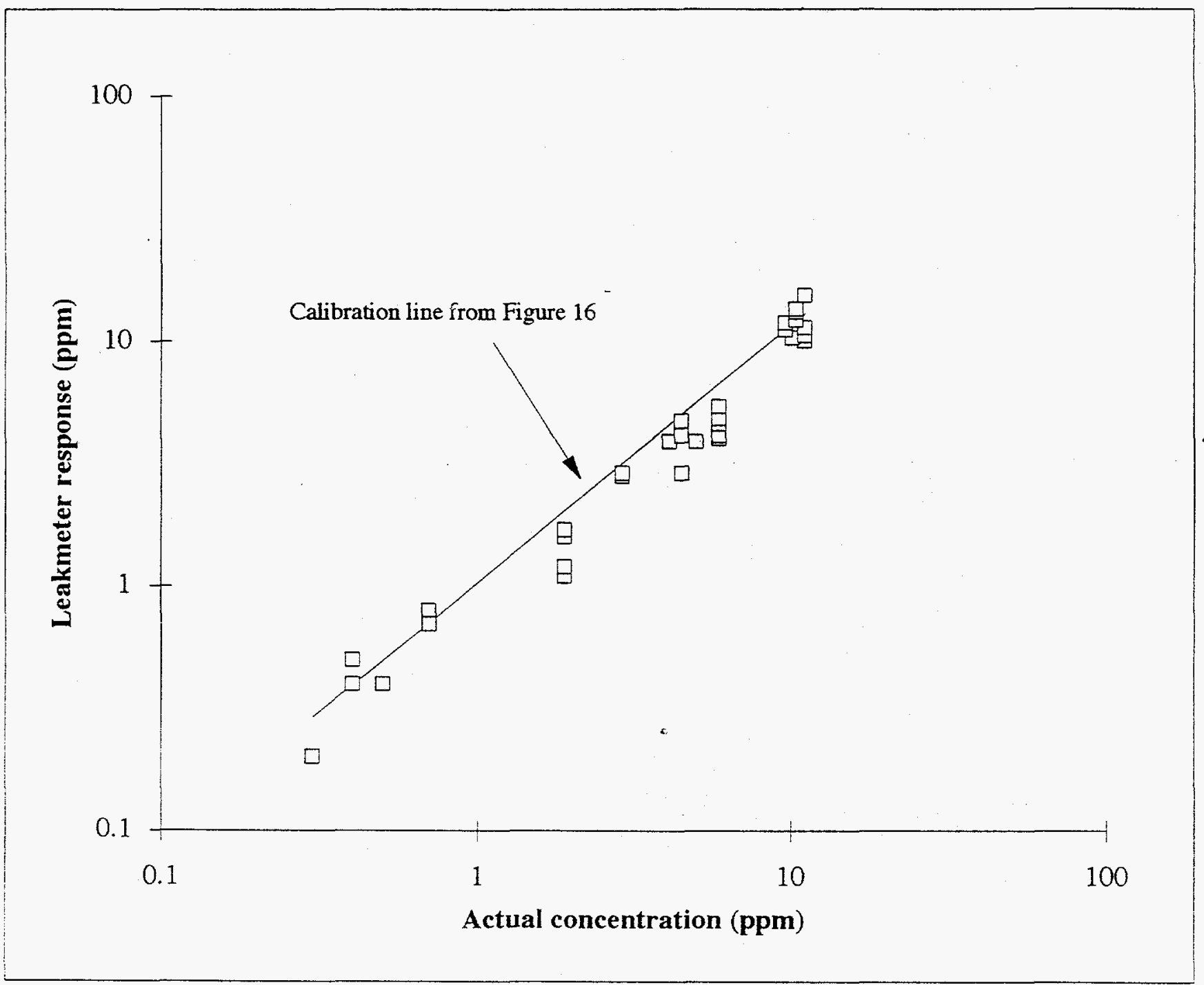


Figure 18. Output Voltage to Data Logger as a Function of Leakmeter Display.

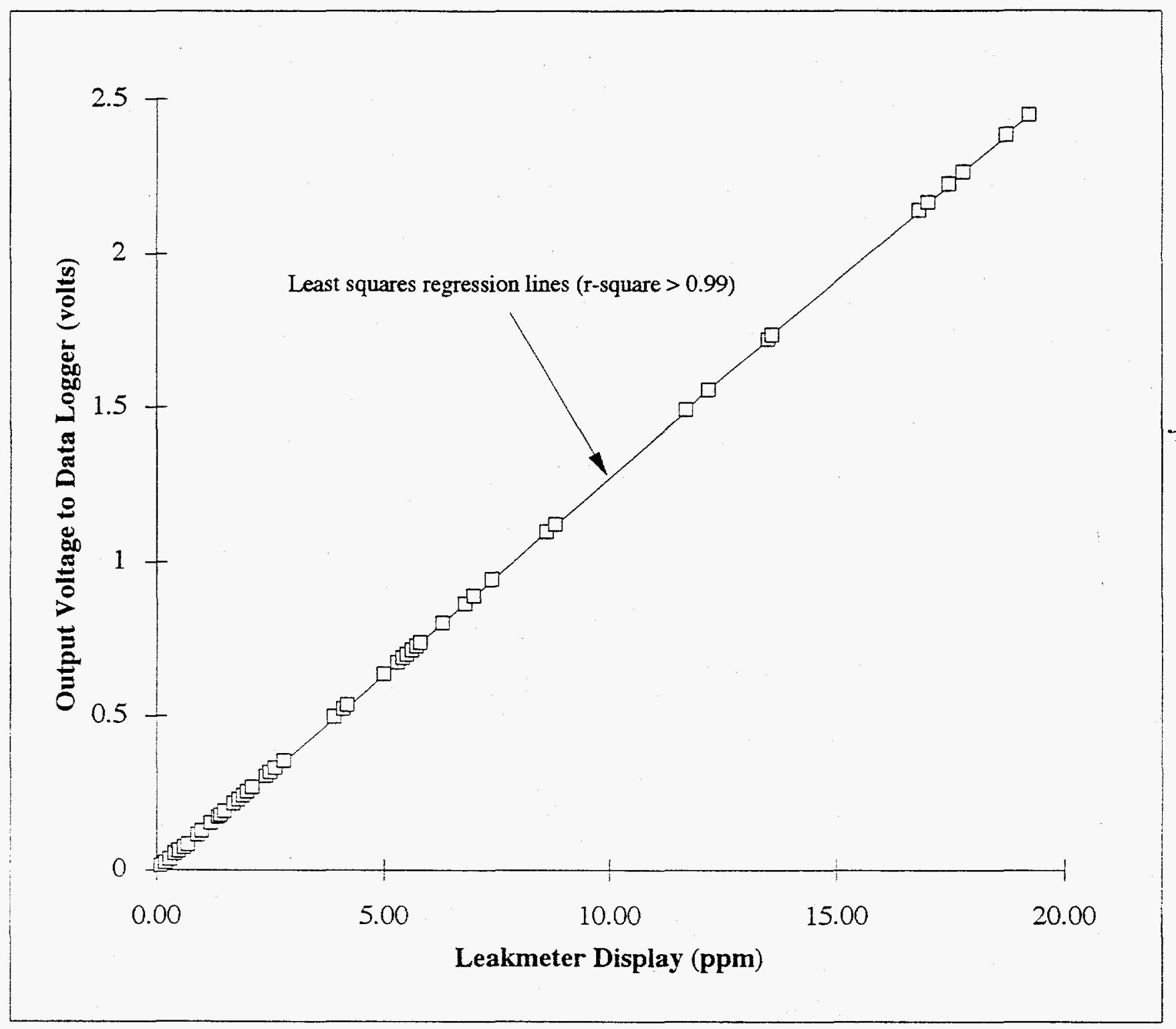




\section{APPENDIX C - RAW DATA}

Table 12. Test Data Collected June through October 1994.

\begin{tabular}{|c|c|c|c|c|c|c|c|c|c|c|c|}
\hline Hood ID & \begin{tabular}{|c|} 
Sash \\
Position
\end{tabular} & $\begin{array}{l}\text { Rel. to } \\
\text { supply }\end{array}$ & $\begin{array}{c}\text { Area } \\
\text { (sq. ft) }\end{array}$ & $\begin{array}{c}\text { Smoke } \\
\text { Test }\end{array}$ & $\begin{array}{l}\text { Smoke } \\
\text { Rank }\end{array}$ & $\begin{array}{c}Q \\
(\mathrm{cfm})\end{array}$ & $\mathrm{Q} / \mathrm{A}$ & AFV & $\mathrm{MxFV}$ & $\mathrm{MnFV}$ & $\mathrm{MnEV}$ \\
\hline 2509AR & Left & Far & 6.250 & Good & 1 & 491 & 79 & 69 & 84 & 61 & 65 \\
\hline 2509AR & $\mathrm{Cl} / 3$ & Center & 3.802 & Good & 1 & 488 & 128 & 106 & 118 & 96 & $\mathrm{n} / \mathrm{a}^{*}$ \\
\hline 2509AR & Right & Near & 6.250 & Good & 1 & 472 & 76 & 68 & 89 & 52 & 58 \\
\hline $2511 \mathrm{AL}$ & Left & Far & 6.224 & Fair & 2 & 451 & 72 & 70 & 89 & 42 & 42 \\
\hline $2511 \mathrm{AL}$ & $\mathrm{RC} 1 / 3$ & Near & 4.167 & Good & 1 & 451 & 108 & 103 & 122 & 74 & $n / a$ \\
\hline 2511AL & Right & Near & 6.198 & Fair & 2 & 451 & 73 & 78 & 112 & 56 & 46 \\
\hline $2513 \mathrm{AL}$ & Left & Far & 6.250 & Good & 1 & 611 & 98 & 85 & 95 & 76 & 76 \\
\hline $2513 \mathrm{AL}$ & $\mathrm{LC} 1 / 3$ & Far & 4.208 & Good & 1 & 611 & 145 & 125 & 133 & 119 & $\mathrm{n} / \mathrm{a}$ \\
\hline $2513 \mathrm{BR}$ & Left & Near & 6.250 & Good & 1 & 610 & 98 & 83 & 101 & 66 & 74 \\
\hline $2513 B R$ & $\mathrm{RC} 1 / 3$ & Far & 4.167 & Good & 1 & 610 & 146 & 119 & 130 & 99 & $\mathrm{n} / \mathbf{a}$ \\
\hline 2513BR & Right & $\mathrm{Far}$ & 6.250 & Good & 1 & 610 & 98 & 85 & 100 & 69 & 85 \\
\hline $2515 \mathrm{AL}$ & Left & $\overline{F a r}$ & 6.224 & Fair & 2 & 588 & 94 & 97 & 123 & 74 & $\overline{66}$ \\
\hline 2515AL & $\mathrm{LCl} / 3$ & Far & 4.167 & Good & 1 & 597 & 143 & 139 & 159 & 122 & $n / a$ \\
\hline $2515 \mathrm{AL}$ & Right & Near & 6.224 & Good & 1 & 635 & 102 & 92 & 99 & 85 & 69 \\
\hline $2517 \mathrm{AL}$ & Left & Far & 6.302 & Fair & 2 & 467 & 74 & 63 & 72 & 40 & 40 \\
\hline $2517 \mathrm{AL}$ & $\mathrm{LC} 1 / 3$ & Far & 4.254 & Good & 1 & 464 & 109 & 97 & 113 & 80 & $\mathrm{n} / \mathbf{a}$ \\
\hline $2517 \mathrm{AL}$ & Right & Near & 6.302 & Fair & 2 & 489 & 78 & 66 & 74 & 59 & 59 \\
\hline $2517 \mathrm{BR}$ & Left & Near & 6.224 & Fair & 2 & 651 & 105 & 82 & 107 & 59 & 59 \\
\hline $2517 \mathrm{BR}$ & $\mathrm{RC} 1 / 3$ & Far & 4.193 & Good & 1 & 621 & 148 & 116 & 121 & 109 & $n / a$ \\
\hline $2517 \mathrm{BR}$ & Right & Far & 6.224 & Fair & 2 & 634 & 102 & 83 & 87 & 80 & 80 \\
\hline $2555 \mathrm{AR}$ & Left & $\mathrm{Far}$ & 6.198 & Good & 1 & 436 & 70 & 78 & 98 & 57 & 57 \\
\hline $2555 \mathrm{AR}$ & $\mathrm{C} 1 / 3$ & Center & 3.646 & Good & 1 & 450 & 123 & 129 & 134 & 119 & $\mathrm{n} / \mathrm{a}$ \\
\hline 2555AR & Right & Near & 6.224 & Fair & 2 & 444 & 71 & 79 & 89 & 69 & 69 \\
\hline $2555 \mathrm{BR}$ & Left & Near & 6.250 & Good & 1 & 488 & 78 & 81 & 107 & 63 & 63 \\
\hline $2555 \mathrm{BR}$ & $\mathrm{RC} 1 / 2$ & Far & 6.250 & Good & 1 & 488 & 78 & 83 & 91 & 62 & $\mathrm{n} / \mathrm{a}$ \\
\hline 2555BR & Right & Far & 6.250 & Fair & 2 & 488 & 78 & 80 & 90 & 74 & 76 \\
\hline $2557 \mathrm{BL}$ & Left & Near & 6.198 & Good & 1 & 571 & 92 & 79 & 91 & 71 & 72 \\
\hline $2557 \mathrm{BL}$ & $\mathrm{RC} 1 / 2$ & Far & 6.198 & Good & 1 & 562 & 91 & 83 & 89 & 77 & $\mathrm{n} / \mathrm{a}$ \\
\hline $2557 \mathrm{BL}$ & Right & Far & 6.250 & Good & 1 & 581 & 93 & 80 & 98 & 75 & 75 \\
\hline $2561 \mathrm{AR}$ & Left & Far & 6.015 & Fair & 2 & 508 & 84 & 70 & 80 & 62 & 67 \\
\hline 2561AR & $\mathrm{C} 1 / 3$ & Center & 3.802 & Good & 1 & 503 & 132 & 103 & 112 & 97 & $\mathrm{n} / \mathbf{a}$ \\
\hline $2561 \mathrm{AR}$ & Right & Near & 5.990 & Fair & 2 & 506 & 84 & 68 & 87 & 56 & 55 \\
\hline $2563 \mathrm{AL}$ & Left & Far & 6.250 & Fair & 2 & 524 & 84 & 69 & 90 & 46 & 64 \\
\hline $2563 \mathrm{AL}$ & $\mathrm{RCl} / 3$ & Near & 4.219 & Good & 1 & 523 & 124 & 110 & 127 & 93 & $\mathrm{n} / \mathrm{a}$ \\
\hline $2563 \mathrm{AL}$ & Right & Near & 6.250 & Good & 1 & 540 & 86 & 81 & 113 & 55 & 55 \\
\hline $2563 B R$ & Left & Near & 6.172 & Poor & 2 & 306 & 50 & 41 & 62 & 22 & 22 \\
\hline $2563 \mathrm{BR}$ & $\mathrm{LC} 1 / 3$ & Near & 4.219 & Good & 1 & 305 & 72 & 64 & 75 & 51 & $n / a$ \\
\hline $2563 \mathrm{BR}$ & Right & Far & 6.224 & Fair & 2 & 302 & 49 & 54 & 68 & 30 & 30 \\
\hline $2571 \mathrm{AL}$ & Left & $\overline{\text { Far }}$ & 6.250 & Good & 1 & 629 & 101 & 92 & 105 & 80 & 80 \\
\hline $2571 \mathrm{AL}$ & $\mathrm{RCl} / 3$ & Near & 4.219 & Good & 1 & 624 & 148 & 128 & 135 & 123 & $\mathrm{n} / \mathrm{a}$ \\
\hline 2571AL & Right & Near & 6.250 & Good & 1 & 652 & 104 & 92 & 102 & 85 & 85 \\
\hline $2571 \mathrm{BR}$ & Left & Near & 6.302 & Good & $\overline{1}$ & 621 & 99 & 88 & 101 & 73 & 89 \\
\hline $2571 \mathrm{BR}$ & $\mathrm{LC} 1 / 2$ & Near & 6.276 & Good & 1 & 570 & 91 & 87 & 99 & 78 & $\mathrm{n} / \mathrm{a}$ \\
\hline $2571 \mathrm{BR}$ & Right & $\mathrm{Far}$ & 6.250 & Good & 1 & 579 & 93 & 84 & 108 & 66 & 71 \\
\hline
\end{tabular}

* $\mathrm{n} / \mathrm{a}=$ not applicable. Since MnEV refers to the minimum velocity along the beveled edge of the hood, it could not be calculated for center sash positions. 


\begin{tabular}{|c|c|c|c|c|c|c|c|c|c|}
\hline Hood ID & $\begin{array}{c}\text { Sash } \\
\text { Position }\end{array}$ & FSCV & FMxTCV & FATCV & $\begin{array}{c}C D \\
\text { Direct }\end{array}$ & $A C D$ & $\begin{array}{l}\mathrm{ACD} \\
\mathrm{AFV}\end{array}$ & $\begin{array}{l}\mathrm{ACD} / \\
\mathrm{M} \times \mathrm{FV}\end{array}$ & $\begin{array}{l}\text { ACD/ } \\
\mathrm{MnFV}\end{array}$ \\
\hline 2509AR & Left & 6.9 & 6.6 & 3.4 & 1 & 10 & 0.14 & 0.12 & 0.16 \\
\hline 2509AR & $\mathrm{Cl} / 3$ & 3.8 & 4.7 & 2.2 & $\mathrm{n} / \mathrm{a}^{*}$ & 8 & 0.07 & 0.06 & 0.08 \\
\hline 2509AR & Right & 11.9 & 13.5 & 5.0 & 0 & 8 & 0.12 & 0.09 & 0.15 \\
\hline $2511 \mathrm{AL}$ & Left & 24.3 & 27.7 & 10.0 & 1 & 49 & 0.70 & 0.55 & 1.17 \\
\hline 2511AL & $\mathrm{RC} 1 / 3$ & 20.1 & 5.7 & 3.5 & $\mathrm{n} / \mathrm{a}$ & 37 & 0.35 & 0.30 & 0.49 \\
\hline 2511AL & Right & 34.9 & 10.6 & 5.3 & 0 & 32 & 0.40 & 0.28 & 0.56 \\
\hline $2513 \mathrm{AL}$ & Left & 7.2 & 6.3 & 4.4 & 1 & 33 & 0.39 & 0.35 & 0.43 \\
\hline $2513 \mathrm{AL}$ & $\mathrm{LC} 1 / 3$ & 4.4 & 4.0 & 2.7 & $\mathrm{n} / \mathbf{a}$ & 26 & 0.21 & 0.20 & 0.22 \\
\hline 2513BR & Left & 15.5 & 7.7 & 5.3 & 0 & 31 & 0.37 & 0.31 & 0.47 \\
\hline $2513 \mathrm{BR}$ & $\mathrm{RC} 1 / 3$ & 10.7 & 3.3 & 2.6 & $\mathrm{n} / \mathrm{a}$ & 28 & 0.24 & 0.22 & 0.28 \\
\hline 2513BR & Right & 14.0 & 5.3 & 4.4 & 1 & 14 & 0.16 & 0.14 & 0.20 \\
\hline $2515 \mathrm{AI}$ & Left & 17.9 & 8.4 & 5.6 & 0 & 28 & 0.29 & 0.23 & 0.38 \\
\hline $2515 \mathrm{AL}$ & $\mathrm{LC} 1 / 3$ & 9.8 & 9.9 & 4.0 & $\mathrm{n} / \mathrm{a}$ & 31 & 0.22 & 0.19 & 0.25 \\
\hline 2515AL & Right & 6.9 & 12.3 & 6.1 & 1 & 42 & 0.46 & 0.42 & 0.49 \\
\hline $2517 \mathrm{AL}$ & Left & 20.6 & 19.8 & 10.5 & 0 & 73 & 1.15 & 1.01 & 1.81 \\
\hline $2517 \mathrm{AL}$ & $\mathrm{LC} 1 / 3$ & 12.9 & 4.6 & 3.5 & $n / a$ & 48 & 0.49 & 0.42 & 0.60 \\
\hline $2517 \mathrm{AL}$ & Right & 10.1 & 10.6 & 7.0 & 1 & 49 & 0.73 & 0.66 & 0.82 \\
\hline 2517BR & Left & 23.8 & 15.8 & 5.3 & 0 & 13 & 0.16 & 0.12 & 0.22 \\
\hline 2517BR & $\mathrm{RC} 1 / 3$ & 4.2 & 2.9 & 2.1 & $\mathrm{n} / \mathrm{a}$ & 13 & 0.11 & 0.10 & 0.11 \\
\hline 2517BR & Right & 3.1 & 8.5 & 3.9 & 1 & 19 & 0.22 & 0.21 & 0.23 \\
\hline $2555 \mathrm{AR}$ & Left & 20.8 & 5.5 & 3.4 & 0 & 30 & 0.38 & 0.30 & 0.52 \\
\hline 2555AR & $\mathrm{Cl} / 3$ & 4.2 & 3.3 & 2.1 & $\mathrm{n} / \mathrm{a}$ & 23 & 0.17 & 0.17 & 0.19 \\
\hline 2555AR & Right & 8.5 & 7.2 & 4.7 & 1 & 19 & 0.24 & 0.21 & 0.28 \\
\hline 2555BR & Left & 21.9 & 11.6 & 6.3 & 1 & 22 & 0.27 & 0.20 & 0.34 \\
\hline $2555 \mathrm{BR}$ & $\mathrm{RC} 1 / 2$ & 13.3 & 8.1 & 6.0 & $\mathrm{n} / \mathrm{a}$ & 23 & 0.28 & 0.25 & 0.37 \\
\hline $2555 \mathrm{BR}$ & Right & 7.6 & 13.5 & 5.8 & 0 & 22 & 0.28 & 0.24 & 0.30 \\
\hline $2557 \mathrm{BL}$ & Left & 10.0 & 4.7 & 3.4 & 1 & 20 & 0.25 & 0.22 & 0.28 \\
\hline $2557 \mathrm{BL}$ & $\mathrm{RC} 1 / 2$ & 5.2 & 9.9 & 4.5 & $\mathrm{n} / \mathrm{a}$ & 24 & 0.28 & 0.26 & 0.31 \\
\hline $2557 \mathrm{BL}$ & Right & 11.4 & 6.7 & 3.3 & 0 & 13 & 0.16 & 0.13 & 0.17 \\
\hline 2561AR & Left & 8.8 & 8.5 & 3.9 & 0 & 6 & 0.08 & 0.07 & 0.09 \\
\hline 2561AR & $\mathrm{C} 1 / 3$ & 5.2 & 3.7 & 2.7 & $\mathrm{n} / \mathrm{a}$ & 7 & 0.07 & 0.06 & 0.07 \\
\hline $2561 \mathrm{AR}$ & Right & 19.7 & 4.2 & 3.0 & 1 & 6 & 0.09 & 0.07 & 0.11 \\
\hline $2563 \mathrm{AL}$ & Left & 21.0 & 11.8 & 6.6 & 1 & 24 & 0.35 & 0.27 & 0.52 \\
\hline $2563 \mathrm{AL}$ & $\mathrm{RC} 1 / 3$ & 14.2 & 6.7 & 3.2 & $\mathrm{n} / \mathrm{a}$ & 15 & 0.13 & 0.11 & 0.16 \\
\hline $2563 \mathrm{AL}$ & Right & 31.8 & 3.5 & 2.8 & 0 & 10 & 0.12 & 0.08 & 0.17 \\
\hline $2563 \mathrm{BR}$ & Left & 41.7 & 18.4 & 9.6 & 1 & 36 & 0.88 & 0.58 & 1.64 \\
\hline $2563 \mathrm{BR}$ & $\mathrm{LCl} / 3$ & 16.9 & 7.4 & 5.5 & $\mathrm{n} / \mathrm{a}$ & 43 & 0.67 & 0.57 & 0.84 \\
\hline $2563 \mathrm{BR}$ & Right & 28.2 & 17.8 & 10.8 & 0 & 54 & 0.99 & 0.79 & 1.78 \\
\hline $2571 \mathrm{AL}$ & Left & 10.4 & 9.8 & 4.7 & 0 & 6 & 0.06 & 0.05 & 0.07 \\
\hline $2571 \mathrm{AL}$ & $\mathrm{RC} 1 / 3$ & 3.8 & 3.7 & 2.4 & $\mathrm{n} / \mathrm{a}$ & 16 & 0.13 & 0.12 & 0.13 \\
\hline $2571 \mathrm{AL}$ & Right & 6.2 & 4.0 & 2.8 & 1 & 18 & 0.19 & 0.17 & 0.21 \\
\hline 2571BR & Left & 8.5 & 3.9 & 2.7 & 1 & 4 & 0.05 & 0.04 & 0.05 \\
\hline $2571 \mathrm{BR}$ & $\mathrm{LC} 1 / 2$ & 6.8 & 2.9 & 2.0 & $\mathrm{n} / \mathrm{a}$ & 6 & 0.07 & 0.06 & 0.08 \\
\hline $2571 B R$ & Right & 16.0 & 6.6 & 3.0 & 0 & 7 & 0.08 & 0.06 & 0.10 \\
\hline
\end{tabular}

${ }^{*} \mathrm{n} / \mathrm{a}=$ not applicable. A value for CD Direct could not be assigned to center sash positions. See Appendix $D$ for a definition of the variable. 


\begin{tabular}{|c|c|c|c|c|c|c|c|c|c|c|}
\hline Hood ID & $\begin{array}{c}\text { Sash } \\
\text { Position }\end{array}$ & $M \times C D$ & $\begin{array}{c}\mathrm{M} \times \mathrm{CD} / \\
\mathrm{AFV}\end{array}$ & $\begin{array}{l}\text { MxCD } / \\
\text { MxFV }\end{array}$ & $\begin{array}{l}\mathrm{MxCD} / \\
\mathrm{MnFV}\end{array}$ & Peak-M & CL-M & Peak-U & CLUU & $\begin{array}{l}\text { StgC } \\
(\mathrm{kHz})\end{array}$ \\
\hline 2509AR & Left & 20 & 0.29 & 0.24 & 0.33 & 0.07 & 3.6 & 3.40 & 1.9 & 9 \\
\hline 2509AR & $\mathrm{Cl} / 3$ & 13 & 0.12 & 0.11 & 0.14 & 0.07 & 3.6 & 0.07 & 3.6 & 9 \\
\hline 2509AR & Right & 13 & 0.19 & 0.15 & 0.25 & 0.07 & 3.6 & 0.07 & 3.6 & 9 \\
\hline $2511 \mathrm{AL}$ & Left & 57 & 0.81 & 0.64 & 1.36 & 0.10 & 3.5 & 0.10 & 3.5 & 8 \\
\hline $2511 \mathrm{AL}$ & $\mathrm{RC} 1 / 3$ & 49 & 0.48 & 0.40 & 0.66 & 0.07 & 3.6 & 0.07 & 3.6 & 8 \\
\hline $2511 \mathrm{AL}$ & Right & 43 & 0.55 & 0.38 & 0.77 & 0.20 & 3.2 & 0.07 & 3.6 & 8 \\
\hline $2513 \mathrm{AL}$ & Left & 44 & 0.52 & 0.46 & 0.58 & 0.10 & 3.4 & 0.07 & 3.5 & 8 \\
\hline $2513 \mathrm{AL}$ & $\mathrm{LC} 1 / 3$ & 42 & 0.34 & 0.32 & 0.35 & 0.20 & 3.1 & 0.07 & 3.5 & 8 \\
\hline $2513 \mathrm{BR}$ & Left & 43 & 0.52 & 0.43 & 0.65 & 0.40 & 2.8 & 1.30 & 2.2 & 10 \\
\hline 2513BR & $\mathrm{RCl} / 3$ & 45 & 0.38 & 0.35 & 0.45 & 0.30 & 2.9 & 0.07 & 3.5 & 10 \\
\hline $2513 \mathrm{BR}$ & Right & 26 & 0.31 & 0.26 & 0.38 & 0.30 & 2.9 & 0.40 & 2.8 & 10 \\
\hline $2515 \mathrm{AL}$ & Left & 51 & 0.53 & 0.41 & 0.69 & 0.07 & 3.5 & 0.20 & 3.1 & 9 \\
\hline 2515AL & $\mathrm{LC} 1 / 3$ & 53 & 0.38 & 0.33 & 0.43 & 0.07 & 3.5 & 0.07 & 3.5 & 9 \\
\hline $2515 \mathrm{AL}$ & Right & 64 & 0.70 & 0.65 & 0.75 & 0.07 & 3.5 & 0.10 & 3.3 & 9 \\
\hline $2517 \mathrm{AL}$ & Left & 133 & 2.11 & 1.85 & 3.33 & 0.07 & 3.6 & 0.30 & 3.0 & 9 \\
\hline $2517 \mathrm{AL}$ & $\mathrm{LC} 1 / 3$ & 93 & 0.96 & 0.82 & 1.16 & 0.07 & 3.6 & 0.10 & 3.5 & 9 \\
\hline $2517 \mathrm{AL}$ & Right & 82 & 1.24 & 1.11 & 1.39 & 1.20 & 2.4 & 1.00 & 2.5 & 9 \\
\hline $2517 \mathrm{BR}$ & Left & 20 & 0.24 & 0.19 & 0.34 & 0.40 & 2.7 & 0.30 & 2.9 & 9 \\
\hline $2517 \mathrm{BR}$ & $\mathrm{RCl} 1 / 3$ & 20 & 0.17 & 0.17 & 0.18 & 0.30 & 2.9 & 0.30 & 2.9 & 9 \\
\hline $2517 \mathrm{BR}$ & Right & 25 & 0.30 & 0.29 & 0.31 & 0.30 & 2.9 & 0.30 & 2.9 & 9 \\
\hline $2555 \mathrm{AR}$ & Left & 66 & 0.85 & 0.67 & 1.16 & 0.70 & 2.7 & 0.20 & 3.2 & 9 \\
\hline 2555AR & $\mathrm{C} 1 / 3$ & 38 & 0.29 & 0.28 & 0.32 & 0.30 & 3.0 & 0.20 & 3.2 & 9 \\
\hline 2555AR & Right & 41 & 0.52 & 0.46 & 0.59 & 0.50 & 2.8 & 0.20 & 3.2 & 9 \\
\hline $2555 \mathrm{BR}$ & Left & 45 & 0.56 & 0.42 & 0.71 & 0.10 & 3.5 & 0.20 & 3.2 & 8 \\
\hline 2555BR & $\mathrm{RC} 1 / 2$ & 42 & 0.51 & 0.46 & 0.68 & 0.30 & 3.0 & 0.10 & 3.5 & 8 \\
\hline $2555 \mathrm{BR}$ & Right & 30 & 0.38 & 0.33 & 0.41 & 0.20 & 3.2 & 0.10 & 3.5 & 8 \\
\hline $2557 \mathrm{BL}$ & Left & 36 & 0.46 & 0.40 & $\overline{0.51}$ & 0.40 & 2.8 & 0.07 & 3.5 & 8 \\
\hline $2557 \mathrm{BL}$ & $\mathrm{RC} 1 / 2$ & 37 & 0.45 & 0.42 & 0.48 & 0.10 & 3.4 & 0.07 & 3.6 & 8 \\
\hline $2557 \mathrm{BL}$ & Right & 26 & 0.33 & 0.27 & 0.35 & 0.07 & 3.5 & 0.10 & 3.4 & 8 \\
\hline $2561 \mathrm{AR}$ & Left & 10 & 0.14 & 0.13 & 0.16 & 0.30 & 3.0 & 0.40 & 2.8 & 8 \\
\hline $2561 \mathrm{AR}$ & $\mathrm{C} 1 / 3$ & 21 & 0.20 & 0.19 & 0.22 & 0.30 & 3.0 & 0.20 & 3.1 & 8 \\
\hline $2561 \mathrm{AR}$ & Right & 18 & 0.26 & 0.21 & 0.32 & 0.60 & 2.7 & 0.07 & 3.6 & 8 \\
\hline $2563 \mathrm{AL}$ & Left & 37 & 0.54 & 0.41 & 0.80 & 0.07 & 3.6 & 0.07 & 3.6 & 10 \\
\hline $2563 \mathrm{AL}$ & $\mathrm{RC} 1 / 3$ & 22 & 0.20 & 0.17 & 0.24 & 0.07 & 3.6 & 0.07 & 3.6 & 10 \\
\hline $2563 \mathrm{AL}$ & Right & 20 & 0.25 & 0.18 & 0.36 & 0.07 & 3.6 & 0.07 & 3.6 & 10 \\
\hline $2563 \mathrm{BR}$ & Left & 83 & 2.02 & 1.34 & 3.77 & 14.50 & 1.5 & 5.50 & 1.9 & 7 \\
\hline $2563 \mathrm{BR}$ & $\mathrm{LC} 1 / 3$ & 77 & 1.20 & 1.03 & 1.51 & 0.07 & 3.8 & 0.07 & 3.8 & 7 \\
\hline $2563 \mathrm{BR}$ & Right & 95 & 1.76 & 1.40 & 3.17 & 0.20 & 3.4 & 0.30 & 3.2 & 7 \\
\hline $2571 \mathrm{AL}$ & Left & 10 & 0.11 & 0.10 & 0.13 & 0.50 & 2.6 & 0.40 & 2.7 & 7 \\
\hline $2571 \mathrm{AL}$ & $\mathrm{RC} 1 / 3$ & 54 & 0.42 & 0.40 & 0.44 & 0.70 & 2.5 & 0.20 & 3.0 & 8 \\
\hline $2571 \mathrm{AL}$ & Right & 33 & 0.36 & 0.32 & 0.39 & 0.10 & 3.3 & 0.10 & 3.3 & 9 \\
\hline $2571 \mathrm{BR}$ & Left & 7 & 0.08 & 0.07 & 0.10 & 0.07 & 3.5 & 0.40 & 2.8 & 9 \\
\hline $2571 \mathrm{BR}$ & $\mathrm{LCI} / 2$ & 11 & 0.13 & 0.11 & 0.14 & 0.10 & 3.4 & 0.30 & 2.9 & 9 \\
\hline $2571 \mathrm{BR}$ & Right & 16 & 0.19 & 0.15 & 0.24 & 0.07 & 3.5 & 0.10 & 3.4 & 9 \\
\hline
\end{tabular}


Table 13. Historical Data Collected May 13, 1992 Through July 17, 1992 by Contamination Control Technologies, Inc.

\begin{tabular}{|c|c|c|c|c|c|c|c|c|c|c|}
\hline Hood ID & $\begin{array}{l}\text { Sash } \\
\text { Pos. }\end{array}$ & $\begin{array}{c}\text { Area } \\
\text { (sq. ft) }\end{array}$ & Smoke & $\begin{array}{l}\text { Smoke } \\
\text { Rank }\end{array}$ & AFV & $\mathrm{MxFV}$ & $\mathrm{MnFV}$ & FSCV & Peak-M & CL-M \\
\hline $1507 \mathrm{~A}$ & $\mathrm{Cl} / 2$ & 6.61 & Fair & 2 & 141 & 168 & 120 & 10.0 & 0.09 & 1.1 \\
\hline $1507 \mathrm{~B}$ & & 6.61 & Fair & 2 & 136 & 165 & 108 & 12.4 & 0.09 & 1.1 \\
\hline $1509 \mathrm{AL}$ & Left & 6.61 & Fair & 2 & 120 & 138 & 105 & 10.5 & 0.02 & 0.5 \\
\hline 1509AR & Left & 6.61 & Poor & 3 & 101 & 120 & 83 & 13.4 & 0.02 & 0.6 \\
\hline $1509 \mathrm{BL}$ & Left & 6.61 & Poor & 3 & 90 & 118 & 50 & 24.3 & 0.02 & 0.7 \\
\hline 1509BR & Right & 6.61 & Fair & 2 & 129 & 165 & 89 & 19.8 & 0.09 & 1.2 \\
\hline $1511 \mathrm{~A}$ & Left & 6.61 & Fair & 2 & 138 & 165 & 102 & 15.9 & 0.02 & 0.5 \\
\hline $1511 \mathrm{~B}$ & Left & 6.61 & Good & 1 & 156 & 185 & 130 & 14.6 & 0.02 & 0.4 \\
\hline 1517AR & $\mathrm{C} 1 / 2$ & 6.56 & Poor & 3 & 93 & 122 & 79 & 14.1 & 0.10 & 1.4 \\
\hline 1519AR & & 3.90 & Fair & 2 & 97 & 115 & 84 & 13.2 & 0.02 & 0.9 \\
\hline $1519 \mathrm{~B}$ & $\mathrm{LC} 1 / 3$ & 4.00 & Fair & 2 & 208 & 230 & 180 & 9.7 & 0.02 & 0.5 \\
\hline $1521 \mathrm{~A}$ & $\mathrm{C} 1 / 3$ & 4.10 & Fair & 2 & 185 & 200 & 170 & 6.8 & 0.02 & 0.6 \\
\hline $1521 \mathrm{~B}$ & $\mathrm{C} 1 / 3$ & 3.90 & Fair & 2 & 156 & 180 & 140 & 8.9 & 0.02 & 0.7 \\
\hline $1523 \mathrm{~A}$ & $\mathrm{Cl} / 3$ & 3.90 & Poor & 3 & 120 & 140 & 110 & 8.9 & 0.02 & 0.8 \\
\hline $1525 \mathrm{~A}$ & Right & 8.80 & Fair & 2 & 134 & 182 & 105 & 20.0 & 0.09 & 1.0 \\
\hline $1525 \mathrm{~B}$ & Left & 6.40 & Fair & 2 & 144 & 177 & 123 & 12.1 & 0.10 & 1.2 \\
\hline $1561 \mathrm{AR}$ & Left & 6.70 & Fair & 2 & 132 & 145 & 118 & 7.7 & 0.02 & 0.5 \\
\hline $1561 \mathrm{BL}$ & Right & 6.70 & Fair & 2 & 150 & 200 & 120 & 15.9 & 0.02 & 0.4 \\
\hline $1563 \mathrm{AR}$ & Right & 6.70 & Fair & 2 & 134 & 160 & 105 & 14.0 & 0.02 & 0.5 \\
\hline $1563 \mathrm{BL}$ & & 6.70 & Fair & 2 & 148 & 189 & 103 & 22.1 & 0.09 & 1.1 \\
\hline $1565 \mathrm{AR}$ & & 6.70 & Poor & 3 & 75 & 104 & 46 & 27.1 & 0.25 & 1.8 \\
\hline $1565 \mathrm{BL}$ & Right & 6.70 & Poor & 3 & 40 & 50 & 24 & 18.1 & 5.07 & 3.4 \\
\hline $1571 \mathrm{AR}$ & Right & 6.70 & Fair & 2 & 71 & 87 & 50 & 17.5 & 0.09 & 1.4 \\
\hline $1571 \mathrm{BL}$ & Right & 6.70 & Poor & 3 & 101 & 112 & 90 & 7.8 & 0.25 & 1.7 \\
\hline 1573AR & Left & 6.70 & Faịr & 2 & 100 & 135 & 80 & 17.2 & 0.48 & 2.0 \\
\hline $1573 \mathrm{BL}$ & Left & 6.70 & Fair & 2 & 101 & 123 & 82 & 11.9 & 0.02 & 0.6 \\
\hline $1575 \mathrm{AR}$ & Left & 6.40 & Fair & 2 & 145 & 166 & 104 & 12.1 & 0.02 & 0.5 \\
\hline $1575 \mathrm{BL}$ & $\mathrm{L} 1 / 3$ & 4.10 & Fair & 2 & 135 & 146 & 122 & 5.8 & 0.10 & 1.4 \\
\hline $1577 \mathrm{AR}$ & Left & 6.40 & Fair & 2 & 78 & 105 & 40 & 27.8 & 0.02 & 0.7 \\
\hline $1577 \mathrm{BL}$ & Right & 6.70 & Fail & 3 & 83 & 94 & 46 & 17.3 & 0.17 & 1.6 \\
\hline $1579 \mathrm{BL}$ & Right & 6.40 & Poor & 3 & 74 & 94 & 63 & 14.2 & 1.18 & 2.5 \\
\hline 1711 & $\mathrm{~L} 1 / 3$ & 4.10 & Good & 1 & 233 & 250 & 210 & 6.8 & 0.02 & 0.5 \\
\hline 1732 & $\mathrm{~L} 1 / 3$ & 4.40 & Good & 1 & 172 & 200 & 155 & 9.3 & 0.02 & 0.6 \\
\hline $2509 \mathrm{AL}$ & Right & 6.77 & Good & 1 & 109 & 150 & 66 & 24.5 & 0.02 & 0.6 \\
\hline $2509 \mathrm{AR}$ & Right & 6.77 & Fair & 2 & 97 & 130 & 74 & 19.0 & 0.02 & 0.6 \\
\hline $2509 \mathrm{BL}$ & $\mathrm{RCl} / 3$ & 4.57 & Fair & 2 & 97 & 105 & 90 & 5.2 & 0.02 & 0.8 \\
\hline $2509 \mathrm{BR}$ & Right & 6.77 & Good & 1 & 99 & 112 & 86 & 8.9 & 0.02 & 0.6 \\
\hline $2511 \mathrm{AL}$ & $\mathrm{RCl} / 2$ & 6.71 & Good & 1 & 98 & 125 & 78 & 18.8 & 0.02 & 0.6 \\
\hline $2511 \mathrm{AR}$ & Left & 6.71 & Good & 1 & 95 & 112 & 84 & 9.8 & 0.02 & 0.6 \\
\hline $25 \mathrm{I} 1 \mathrm{BL}$ & $\operatorname{LCi} / 2$ & 6.67 & Good & 1 & 107 & 122 & 87 & 11.7 & 0.007 & 0.1 \\
\hline $2511 \mathrm{BR}$ & & 6.66 & Fair & 2 & 128 & 145 & 115 & 9.5 & 0.02 & 0.5 \\
\hline $2513 \mathrm{AL}$ & Right & 6.77 & Good & 1 & 129 & 175 & 105 & 17.9 & 0.02 & 0.5 \\
\hline $2513 \mathrm{AR}$ & $\mathrm{C} 1 / 3$ & 4.06 & Good & 1 & 135 & 155 & 120 & 8.8 & 0.02 & 0.7 \\
\hline $2513 \mathrm{BL}$ & $\mathrm{LC} 1 / 3$ & 4.57 & Good & 1 & 109 & 120 & 96 & 8.4 & 0.02 & .0 .7 \\
\hline
\end{tabular}




\begin{tabular}{|c|c|c|c|c|c|c|c|c|c|c|}
\hline Hood ID & $\begin{array}{l}\text { Sash } \\
\text { Pos. }\end{array}$ & $\begin{array}{c}\text { Area } \\
\text { (sq. ft) }\end{array}$ & Smoke & $\begin{array}{l}\text { Smoke } \\
\text { Rank }\end{array}$ & AFV & $\mathrm{MxFV}$ & $\mathrm{MnFV}$ & FSCV & Peak-M & CL-M \\
\hline $2513 \mathrm{BR}$ & $\mathrm{Cl} / 3$ & 4.12 & Fair & 2 & 144 & 150 & 129 & 5.6 & 0.02 & 0.7 \\
\hline $2515 \mathrm{AL}$ & $\mathrm{Cl} / 3$ & 4.51 & Fair & 2 & 156 & 180 & 137 & 10.2 & 0.01 & 0.3 \\
\hline 2515AR & $\mathrm{RC} 1 / 3$ & 4.51 & Fair & 2 & 132 & 145 & 115 & 8.3 & 0.02 & 0.7 \\
\hline 2515BL & $L 1 / 3$ & 4.51 & Fair & 2 & 116 & 127 & 105 & 6.6 & 0.02 & 0.7 \\
\hline 2515BR & & 4.51 & Fair & 2 & 127 & 142 & 115 & 7.4 & 0.02 & 0.7 \\
\hline $2517 \mathrm{AL}$ & $\mathrm{R} 1 / 3$ & 4.56 & Fair & 2 & 120 & 127 & 112 & 4.9 & 0.02 & 0.7 \\
\hline 2517BR & $\mathrm{LCl} / 3$ & 4.44 & Fair & 2 & 150 & 180 & 112 & 13.1 & 0.02 & 0.6 \\
\hline $2519 \mathrm{AL}$ & Left & 6.30 & Fair & 2 & 137 & 145 & 129 & 4.5 & 0.02 & 0.5 \\
\hline 2519BR & $\mathrm{LC} 1 / 3$ & 4.00 & Poor & 3 & 120 & 145 & 100 & 13.5 & 0.02 & 0.8 \\
\hline $2523 \mathrm{AL}$ & $\mathrm{LCl} / 2$ & 6.10 & Good & 1 & 93 & 105 & 75 & 10.3 & 0.09 & 1.3 \\
\hline $2523 \mathrm{BR}$ & $\mathrm{LC} 1 / 2$ & 6.60 & Good & 1 & 109 & 130 & 92 & 9.7 & 0.17 & 1.5 \\
\hline $2525 \mathrm{AL}$ & Right & 6.30 & Fair & 2 & 120 & 140 & 86 & 14.7 & 1.80 & 2.5 \\
\hline $2525 \mathrm{BR}$ & $\mathrm{LC} 1 / 2$ & 6.70 & Fair & 2 & 90 & 100 & 80 & 7.9 & 0.63 & 2.2 \\
\hline $2527 \mathrm{~B}$ & Right & 6.30 & Poor & 3 & 139 & 155 & 112 & 10.6 & 0.02 & 0.5 \\
\hline $2529 \mathrm{~B}$ & Right & 6.40 & Good & 1 & 174 & 205 & 150 & 10.8 & 0.02 & 0.4 \\
\hline $2539 B$ & $\mathrm{C} 1 / 3$ & 4,00 & Fair & 2 & 233 & 243 & 220 & 4.2 & 0.02 & 0.5 \\
\hline $2555 \mathrm{AL}$ & Right & 6.67 & Fair & 2 & 127 & 148 & 105 & 13.4 & 0.10 & 1.2 \\
\hline $2555 \mathrm{AR}$ & Right & 6.67 & Fair & 2 & 94 & 103 & 88 & 6.0 & 0.02 & 0.6 \\
\hline $2555 \mathrm{BL}$ & Left & 6.70 & Fair & 2 & 93 & 105 & 75 & 9.9 & 0.10 & 1.4 \\
\hline $2555 \mathrm{BR}$ & Left & 6.70 & Fair & 2 & 115 & 125 & 96 & 7.8 & 0.02 & 0.6 \\
\hline $2557 \mathrm{AL}$ & Left & 6.67 & Poor & 3 & 112 & 125 & 99 & 7.8 & 0.02 & 0.6 \\
\hline 2557AR & $\mathrm{LCl} / 2$ & 6.67 & Good & 1 & 96 & 104 & 88 & 5.5 & 0.02 & 0.6 \\
\hline $2557 \mathrm{BL}$ & Right & 6.67 & Fair & 2 & 105 & 135 & 81 & 21.3 & 0.02 & 0.6 \\
\hline $2557 \mathrm{BR}$ & $\mathrm{LCl} / 2$ & 6.67 & Good & 1 & 124 & .140 & 113 & 7.1 & 0.17 & 1.5 \\
\hline $2559 \mathrm{AL}$ & $\mathrm{LCl} / 2$ & 6.61 & Good & 1 & 128 & 155 & 110 & 14.2 & 0.02 & 0.5 \\
\hline 2559AR & Right & 6.67 & Fair & 2 & 109 & 150 & 79 & 25.1 & 5.45 & 3.0 \\
\hline $2559 \mathrm{BL}$ & Right & 6.61 & Fair & 2 & 94 & 120 & 50 & 28.5 & 0.63 & 2.2 \\
\hline $2559 \mathrm{BR}$ & Right & 6.67 & Fair & 2 & 128 & 155 & 110 & 10.8 & 0.10 & 1.2 \\
\hline $2561 \mathrm{AL}$ & $\mathrm{LC} 1 / 2$ & 6.67 & Fair & 2 & 129 & 175 & 95 & 23.5 & 0.02 & 0.5 \\
\hline 2561AR & $\mathrm{RCl} / 3$ & 4.11 & Fair & 2 & 139 & 150 & 130 & 5.8 & 0.02 & 0.7 \\
\hline $2561 \mathrm{BL}$ & $\mathrm{LC} 1 / 3$ & 4.50 & Fair & 2 & 140 & 172 & 115 & 14.9 & 0.02 & 0.6 \\
\hline $2561 \mathrm{BR}$ & LC13 3 & 4.44 & Good & 1 & 169 & 185 & 150 & 7.1 & 0.02 & 0.6 \\
\hline $2563 \mathrm{AL}$ & Right & 6.66 & Fair & 2 & 102 & 138 & 72 & 24.4 & 0.02 & 0.6 \\
\hline $2563 \mathrm{BR}$ & Right & $6.6 ?$ & Fair & 2 & 79 & 105 & 55 & 21.5 & 2.97 & 2.9 \\
\hline $2563 \mathrm{BR}$ & $\mathrm{C} 1 / 3$ & 4.11 & Fair & 2 & 94 & 103 & 72 & 12.9 & 0.02 & 0.9 \\
\hline $2565 \mathrm{~A}$ & $\mathrm{Cl} / 3$ & 4.10 & Fair & 2 & 163 & 175 & 140 & 8.0 & 2.74 & 2.8 \\
\hline $2569 \mathrm{AL}$ & $\mathrm{LCl} / 3$ & 4.00 & Good & 1 & 135 & 150 & 122 & 7.6 & 0.02 & 0.7 \\
\hline $2569 \mathrm{BR}$ & $\mathrm{LC} 1 / 2$ & 6.67 & Good & 1 & 124 & 140 & 110 & 8.3 & 0.02 & 0.5 \\
\hline $2571 \mathrm{AL}$ & $\mathrm{RC} 1: 2$ & 6.67 & Fair & 2 & 77 & 93 & 59 & 14.1 & 6.39 & 3.2 \\
\hline $2571 \mathrm{BR}$ & LCl/2 & 6.67 & Fair & 2 & 121 & 145 & 107 & 11.2 & 0.02 & 0.5 \\
\hline $2573 \mathrm{AL}$ & $\mathrm{RCl} / 3$ & 4.50 & Fair & 2 & 136 & 151 & 120 & 10.1 & 0.02 & 0.7 \\
\hline $2573 \mathrm{BR}$ & $\mathrm{RC} 1 / 3$ & 4.44 & Fair & 2 & 113 & 135 & 92 & 10.9 & 0.09 & 1.4 \\
\hline $2573 \mathrm{BR}$ & $\mathrm{RCi} / 3$ & 4.44 & Fair & 2 & 113 & 135 & 92 & 10.9 & 0.09 & 1.4 \\
\hline $2573 \mathrm{BR}$ & Left & 6.56 & Poor & 3 & 89 & 105 & 72 & 13.6 & 4.13 & 3.0 \\
\hline
\end{tabular}




\section{APPENDIX D - VARIABLE DEFINITIONS}

The face velocity and cross draft variables potentially important for predicting hood containment are listed and defined below. The variables are divided into four groups, based on their statistical correlation with one another. Many of the variables considered were merely ratios of other variables. These are listed only by the abbreviations of their constituent variables. The units used for each variable, where appropriate, are indicated at the end of the definition. Feet per minute is abbreviated fpm.

\section{Group 1}

- Average face velocity (AFV) - the arithmetic average of the measurements taken at the six face velocity traverse points. (fpm)

- Maximum face velocity (MxFV) - the maximum average velocity at any of the six face velocity traverse points. (fpm)

- Minimum face velocity (MnFV)- the minimum average velocity at any of the six face velocity traverse points. (fpm)

- Predicted average face velocity $(\mathrm{Q} / \mathrm{A})$ - the average face velocity predicted by dividing the total exhaust flow as measured with a pitot traverse by the cross sectional area of the hood face.

- Minimum edge velocity (MnEV) - The minimum average velocity at either of the two traverse points along the beveled edge of a hood opening. (fpm)

\section{Group 2}

- Face velocity spatial coefficient of variation (FSCV) - the coefficient of variation (standard deviation divided by the mean) of the average velocities at the six face velocity traverse points. (\%)

\section{Group 3}

- Face velocity average temporal coefficient of variation (FATCV) - the average value of the six coefficient of variations (standard deviation divided by the mean) calculated from the ten readings taken at each face velocity traverse point. (\%) - Face velocity maximum temporal coefficient of variation (FMxTCV) - the maximum value of the six coefficient of variations (standard deviation divided by the mean) calculated from the ten readings taken at each face velocity traverse point. $(\%)$ 


\section{Group 4}

- Average cross draft (ACD) - the arithmetic average of the cross draft measurements taken at two points proximate to each hood opening. (fpm)

- Maximum cross draft (MxCD) - the maximum average cross draft velocity at either of teh two measurement locations proximate to a hood opening. (fpm)

The remaining cross draft variables considered with Group 4 were ratios of cross draft and face velocity variables:

- $\mathrm{ACD} / \mathrm{AFV}$

- $\mathrm{ACD} / \mathrm{MxFV}$

- $\mathrm{ACD} / \mathrm{MnFV}$

- MxCD/AFV

- $\mathrm{MxCD} / \mathrm{MxFV}$

- $\mathrm{MxCD} / \mathrm{MnFV}$

The abbreviations of other variables recorded or used in some manner in the text or the appendices of this report are listed below, with units where appropriate. Cubic feet per minute is abbreviated cfm; parts per million is abbreviated ppm.

- Exhaust flow rate (Q) - the total flow rate of air exhausting from the hood. (cfm)

- Smoke rank - the results of the smoke test were quantified, with good being assigned a value of 1 , fair assigned 2, and poor assigned 3.

- Cross draft direction (CD Direct) - a variable used to indicate the prevailing direction of cross drafts relative to a hood face. A value of 0 indicates that the cross drafts were moving in a direction such that they would not be expected to augment the vortex along the beveled edge of a hood opening. A value of 1 indicates that the cross drafts were moving in a direction such that they wouldbe expected to augment the vortices along the beveled edge of a hood opening.

- Peak breathing zone concentration, manikin test (Peak-M) - the maximum concentration of sulfur hexafluoride detected in the breathing zone of a manikin outside of the hood during a five minute challenge of 4 liters per minute inside the hood. (ppm)

- Peak breathing zone concentration, user test (Peak-U) - the maximum concentration of sulfur hexafluoride detected in the breathing zone of a human user outside of the hood during a five minute challenge of 4 liters per minute inside the hood. (ppm) 
- Containment level, manikin test or user test (CL-M or CL-U) - a variable used to normalize the leakage concentration to the exhaust flow rate of the hood and to transform the concentration to a log scale. The equation to calculate containment level, CL is:

$$
\mathrm{CL}=\log \left(\frac{\mathrm{G} / \mathrm{Q}}{\mathrm{Co}}\right)
$$

where $\mathrm{G}$ is the generation rate of the tracer gas, $\mathrm{Q}$ is the exhaust flow rate, and Co is the peak concentration of tracer gas detected in the manikin or user's breathing zone.

- Standing current (StgC) - a parameter which indicates the status of the electron capture detector used to quantify the concentration of sulfur hexafluoride leaking from a hood. A standing current below $20 \mathrm{kHz}$ is deemed acceptable by the instrument manufacturer. $(\mathrm{kHz})$ 


\section{APPENDIX E - STATISTICAL TEST RESULTS}

Table 14. Test Data T-test Results for the Comparison of Mean Values of All Considered Variables for High and Low Leakage Groups as Determined by a User Tracer Gas Test.

\begin{tabular}{|c|c|c|c|c|c|c|c|}
\hline $\begin{array}{c}\text { User Test } \\
\text { Result (ppm) }\end{array}$ & $\mathrm{n}$ & $\begin{array}{c}\text { Smoke } \\
\text { Rank }\end{array}$ & $\mathrm{Q} / \mathrm{A}$ & AFV & MxFV & MnFV & FSCV \\
\hline$<0.25$ & 30 & 1.23 & 100 & 92 & 107 & 77 & 13.4 \\
$>0.25$ & 14 & 1.50 & 89 & 77 & 90 & 63 & 14.5 \\
\hline & $\mathrm{Sp}^{\prime 2}$ & 0.21 & 630 & 390 & 349 & 515 & 82 \\
& $\mathrm{~T}$ & -1.79 & 1.29 & 2.28 & 2.85 & 1.87 & -0.36 \\
& $\mathrm{p}$ & 0.04 & 0.10 & 0.01 & 0.003 & 0.03 & 0.36
\end{tabular}

\begin{tabular}{|c|c|c|c|c|c|c|c|}
\hline $\begin{array}{c}\text { User Test } \\
\text { Result }(\mathrm{ppm})\end{array}$ & $\mathrm{n}$ & FMxTCV & FATCV & ACD & ACD/AFV & ACD/MxFV & ACD/MnFV \\
\hline$<0.25$ & 30 & 7.8 & 4.2 & 23.7 & 0.27 & 0.23 & 0.34 \\
$>0.25$ & 14 & 9.9 & 5.4 & 23.9 & 0.37 & 0.31 & 0.56 \\
\hline & $\mathrm{Sp}^{\wedge} 2$ & 27 & 5 & 246 & 0.07 & 0.04 & 0.18 \\
& $\mathrm{~T}$ & -1.25 & -1.66 & -0.02 & -1.23 & -1.14 & -1.56 \\
& $\mathrm{p}$ & 0.11 & 0.05 & 0.49 & 0.11 & 0.13 & 0.06
\end{tabular}

\begin{tabular}{|c|c|c|c|c|c|c|c|}
\hline $\begin{array}{c}\text { User Test } \\
\text { Result (ppm) }\end{array}$ & $\mathrm{n}$ & $\mathrm{MxCD}$ & $\mathrm{MxCD} / \mathrm{AFV}$ & $\mathrm{MxCD} / \mathrm{MxFV}$ & MxCD/MnFV & Mkn Conc & Mkn CL \\
\hline$<0.25$ & 30 & 29.7 & 0.34 & 0.29 & 0.43 & 0.20 & 3.28 \\
$>0.25$ & 14 & 31.3 & 0.51 & 0.41 & 0.77 & 1.22 & 2.94 \\
\hline & $\mathrm{Sp} / 2$ & 466 & 0.14 & 0.09 & 0.38 & 3.55 & 0.2 \\
& $\mathrm{~T}$ & -0.22 & -1.39 & -1.29 & -1.73 & -1.66 & 2.42 \\
& $\mathrm{p}$ & 0.41 & 0.09 & 0.10 & 0.05 & 0.05 & 0.01 \\
\hline
\end{tabular}

$\mathrm{n}=$ number of hoods in User Test Result category.

$\mathrm{Sp}^{\wedge} 2=$ pooled sample variance $=\frac{\left(\mathrm{n}_{1}-1\right) \mathrm{S}_{1}^{2}+\left(\mathrm{n}_{2}-1\right) \mathrm{S}_{2}^{2}}{\mathrm{n}_{1}+\mathrm{n}_{2}-2}$

$\mathrm{n}_{1}=$ number of hoods in low leakage group (user test concentration $<0.25 \mathrm{ppm}$ )

$S_{1}^{2}=$ variance of given variable for hoods in low leakage group

$\mathrm{n}_{2}=$ number of hoods in high leakage group (user test concentration $>0.25 \mathrm{ppm}$ )

$s_{1}^{2}=$ variance of given variable for hoods in high leakage group

$T=$ two-sample $t$ test statistic $=\frac{\left(\bar{Y}_{1}-\bar{Y}_{2}\right) / \sqrt{1 / n_{1}+1 / n_{2}}}{S_{p}}$

$\bar{Y}_{1}=$ mean value, as given in table, for a given variable in low leakage group

$\bar{Y}_{2}=$ mean value, as given in table, for a given variable in high leakage group

$\mathrm{p}=$ critical value for the one tailed $\mathrm{t}$ test for the difference in means between the two groups 
Table 15. Historical Data T-test Results for the Comparison of Mean Values of All Considered Variables for High and Low Leakage Groups as Determined by a Manikin Tracer Gas Test.

\begin{tabular}{|c|c|c|c|c|c|c|}
\hline $\begin{array}{c}\text { Manikin Test } \\
\text { Result (ppm) }\end{array}$ & $\mathbf{n}$ & $\begin{array}{c}\text { Smoke } \\
\text { Rank }\end{array}$ & AFV & MxFV & MnFV & FSCV \\
\hline$<0.25$ & 75 & 1.84 & 127 & 149 & 106 & 12.0 \\
$>0.25$ & 13 & 2.38 & 93 & 114 & 71 & 16.8 \\
\hline & $\mathrm{Sp}^{\wedge 2}$ & 0.36 & 969 & 1139 & 1003 & 33.3 \\
& $\mathrm{~T}$ & 3.04 & -3.61 & -3.40 & -3.71 & 2.77 \\
& $\mathrm{p}$ & 0.002 & 0.0003 & 0.0005 & 0.0002 & 0.003 \\
\hline
\end{tabular}

$\mathrm{n}=$ number of hoods in Manikin Test Result category.

$\mathrm{Sp}^{\wedge} 2=$ pooled sample variance $=\frac{\left(\mathrm{n}_{1}-1\right) \mathrm{S}_{1}^{2}+\left(\mathrm{n}_{2}-1\right) \mathrm{S}_{2}^{2}}{\mathrm{n}_{1}+\mathrm{n}_{2}-2}$

$\mathrm{n}_{1}=$ number of hoods in low leakage group (user test concentration $<0.25 \mathrm{ppm}$ )

$S_{1}^{2}=$ variance of given variable for hoods in low leakage group

$\mathrm{n}_{2}=$ number of hoods in high leakage group (user test concentration $>0.25 \mathrm{ppm}$ )

$s_{1}^{2}=$ variance of given variable for hoods in high leakage group

$\mathrm{T}=$ two-sample $\mathrm{t}$ test statistic $=\frac{\left(\overline{\mathrm{Y}}_{1}-\overline{\mathrm{Y}}_{2}\right) / \sqrt{1 / \mathrm{n}_{1}+1 / \mathrm{n}_{2}}}{\mathrm{~S}_{\mathrm{p}}}$

$\bar{Y}_{1}=$ mean value, as given in table, for a given variable in low leakage group

$\bar{Y}_{2}=$ mean value, as given in table, for a given variable in high leakage group

$\mathrm{p}=$ critical value for the one tailed $\mathrm{t}$ test for the difference in means between the two groups 